\title{
Magnetic materials for magnetoelectric coupling: an
}

\section{unexpected journey}

\author{
Ana Catarina Lima ${ }^{1,2}$, Nelson Pereira ${ }^{1,3}$, Pedro Martins ${ }^{1,4}$, and Senentxu \\ Lanceros-Mendez ${ }^{5,6, *}$
}

${ }^{1}$ Centro/Departamento de Física, Universidade do Minho, 4710-057 Braga, Portugal

${ }^{2}$ INL- International Iberian Nanotechnology Laboratory, 4715-330 Braga, Portugal

${ }^{3}$ Algoritmi Center, Minho University, 4800-058 Guimarães, Portugal

${ }^{4}$ IB-S Institute of Science and Innovation for Sustainability, Universidade do Minho, 4710-057, Braga, Portugal

5 BCMaterials, Basque Center for Materials, Applications and Nanostructures, UPV/EHU Science Park, 48940 Leioa, Spain

${ }^{6}$ IKERBASQUE, Basque Foundation for Science, 48013 Bilbao, Spain

"We are like islands in the sea, separate on the surface but connected in the deep." William James (1842 - 1910)

\begin{abstract}
Magnetic materials for magnetoelectric coupling are reported. After an introduction of magnetoelectric effect and materials, an historical on the main developments in this field are presented. Then, the main concepts related to multiferroic and magnetoelectric materials are introduced, together with the description of the main types of
\end{abstract}


magnetoelectric materials and structures. Finally, the magnetic materials used the development of magnetoelectric composites are presented and discussed, highlighting their main physico-chemical characteristics and processing methods. In this way, a complete account on concepts, materials and methods is presented in this strongly evolving research field, with strong application potential in the areas of sensors and actuators, among others.

Keywords: magnetoelectrics; magnetostriction; piezoelectric; multiferroic; ferroelectric

\section{Introduction}

Web navigators of the modern times rely on magnetic devices to move around and explore the Internet, but their ancestors were actually navigating and exploring unknown seas with magnetite compass needles, hundreds of years ago. Therefore, the impact of magnetic materials on science and technology is a phenomenon that expands from ancient to modern times.

In our days, magnetic materials are essential in a wide variety of systems and devices used in power generation and transmission, electronics, data storage, medical devices, magnetic therapy and drug delivery, sensors and scientific equipment, among others (Dias and Paulo Silva Cunha, 2018). It is challenging to imagine a world without magnetic materials, and day after day, they are becoming more important in the development of modern societies (Dutta Pramanik et al., 2018).

Magnetic materials are also important due to the need of efficient generation/use of electricity that demand high-performance magnetic materials and optimized designs (Figure 1). 


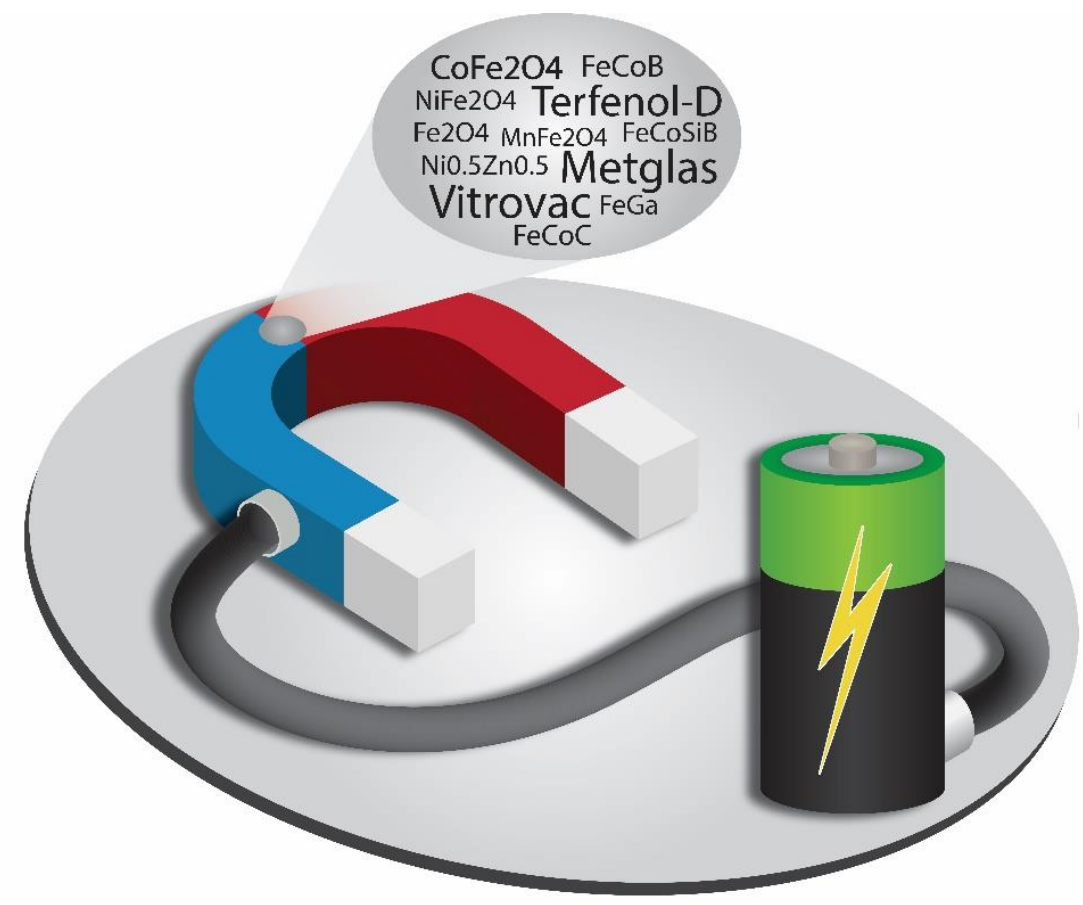

Figure 1. Schematic representation of the relation between magnetic properties of materials and their electric response, an ongoing journey that will be discussed in this work.

Further, electric vehicles will rely on efficient motors using advanced magnetic materials. The telecommunications industry is always striving for faster data transmission and miniaturization of devices, both of which require the development of improved magnetic materials (Matizamhuka, 2018, Rawlings, 2009).

Conventionally, only those materials that exhibit ferromagnetic or ferrimagnetic properties are traditionally identified as "magnetic". There are just nine elements considered ferromagnets, all metals, of which three (Fe, $\mathrm{Co}, \mathrm{Ni})$ are iron group metals and the other six (Gd, Tb, Dy, Ho, Er, Tm) are rare-earth metals (RE). The transition metals $\mathrm{Fe}$ and $\mathrm{Co}$ are the basic elements for the preparation of alloys and compounds with large Curie temperature $\left(\mathrm{T}_{\mathrm{C}}\right)$ and a large spontaneous magnetization $\left(\mathrm{M}_{\mathrm{s}}\right)$. Some of the intermetallic compounds with rare-earth metals are characterized by a very high value of magnetocrystalline anisotropy and magnetostriction (Satishchandra B. Ogale et al., 2013). The primary criterion allowing the classification of magnetic materials is 
coercivity $\left(\mathrm{H}_{\mathrm{c}}\right)$, which is a measure of the stability of the remanent state. Soft magnetic materials are characterized by low values of coercivity $\left(\mathrm{H}_{\mathrm{c}}<15 \mathrm{Oe}\right)$, while the coercivity of hard magnetic materials (usually permanent magnets) is higher than 125 Oe. Lastly, semi-hard magnetic materials (mostly for storage) show coercivities in between these two values (Sgobba, 2011).

The earliest observations of magnetism and reports of magnetic materials can be traced back to the Greek philosopher Thales, in the 6th Century B.C. However, it was not until 1600 that the modern understanding of magnetism began. Table I summarizes the main achievements in this area, over time (Sgobba, 2011).

Table I. Summary of the key achievements of magnetism over time.

\begin{tabular}{l|l}
\hline \hline $\mathbf{1 6 0 0}$ & $\begin{array}{l}\text { Dr. William Gilbert published the first systematic experiments on magnetism in "De } \\
\text { Magnete". }\end{array}$ \\
\hline $\mathbf{1 8 1 9}$ & $\begin{array}{l}\text { Oerstead accidentally made the relationship between magnetism and electricity, discovering } \\
\text { that a current carrying wire deflected a compass needle. }\end{array}$ \\
\hline $\mathbf{1 8 2 5}$ & Sturgeon invented the electromagnet. \\
\hline $\mathbf{1 8 9 0}$ & Warburg reported the first hysteresis loop for iron. \\
\hline $\mathbf{1 9 0 5}$ & The Curie Law was proposed. \\
\hline $\mathbf{1 9 0 6}$ & Weiss proposed ferromagnetic theory. \\
\hline $\mathbf{1 9 2 0}$ & $\begin{array}{l}\text { The physics of magnetism was developed with theories involving electron spins and exchange } \\
\text { interactions; the introduction of quantum mechanics to the field. }\end{array}$ \\
\hline
\end{tabular}

Since the 1930s, AlNiCo magnets have been commonly used, initially in military and later in civilian applications including electronics, automotive and aircraft sensor applications. The improvement of AlNiCo magnets represented the beginning of a new way of thinking about magnetic materials where composite materials with multiple phases lead to superior materials characteristics than those of the individual components 
(Lewis and Jiménez-Villacorta, 2013). AlNiCo magnets are alloys mainly based on nickel, cobalt, and iron with smaller amounts of aluminum, copper, and titanium (usual composition in weight percentages (wt.\%): Fe-35; Co-35; Ni-15; Al-7; Cu-4; Ti-4) (Rawlings, 2009). They possess a fine microstructure consisting of micron- or submicronscale ferromagnetic particles dispersed in a weak magnetic matrix. In 1952, Phillips Company (Eindhoven, Netherlands) declared the successful commercialization of the first ceramic magnets (Went et al., 1952). These complex oxides were based on the prototypical composition $\mathrm{MFe}_{12} \mathrm{O}_{16}$ where $\mathrm{M}$ represents the divalent metals $\mathrm{Ba}, \mathrm{Sr}$, or $\mathrm{Pb}$. The most popular of these ceramic magnets is barium ferrite or barium hexaferrite $\left(\mathrm{BaFe}_{12} \mathrm{O}_{19}\right)$ (Lewis and Jiménez-Villacorta, 2013). These magnets had commercial significance due to their low cost and chemical inertness, as well as for their easy processing. They are classified as ferrimagnetics (populations of atoms with opposing magnetic moments, as in antiferromagnetism; however, the opposing moments are unequal and a spontaneous magnetization remain), being the magnetic coupling dependent on the specific crystallographic position of Fe ions. However, the major drawback of these magnets is the decrease in magnetization values with increasing temperature, brittle behavior, and low magnetization values at room temperature (Lewis and Jiménez-Villacorta, 2013).

In the mid-1960s, under the direction of Dr. Karl J. Strnat at the US Air Force Materials Laboratory, large magnetic energy products were reported in intermetallic compounds based on samarium-cobalt typically $5.1 \mathrm{MGOe}\left(40.6 \mathrm{~kJ} / \mathrm{m}^{3}\right)$ and later optimized to $18 \mathrm{MGOe}\left(143.2 \mathrm{~kJ} / \mathrm{m}^{3}\right.$ ) (Went et al., 1952). Such energy product is an index expressing the performance of a permanent magnet that yardsticks the maximum amount of magnetic flux taken out from the magnet per unit of volume. The SmCo magnets were later commercialized with typical energy products in the range 22-32 GMOe (175- 
$255 \mathrm{~kJ} / \mathrm{m}^{3}$ ) depending on the composition, combined with an attractive Curie temperature ( $1023 \mathrm{~K})$ making them suitable for high-temperature applications (Zhou et al., 2000). The progress on permanent magnetic materials proceeds in a series of steps. Each material is developed and improved before being complemented or replaced by a new one. This trend is shown in Figure 2 which shows the evolution of permanent magnet materials throughout the 20th century. The figure also illustrates the advance in maximum energy product $(\mathrm{BH})_{\text {MAX }}$ of the materials, which is used as a figure of merit, as it is a measure of the ability of magnets to do work per unit volume of material (Niarchos et al., 2015).

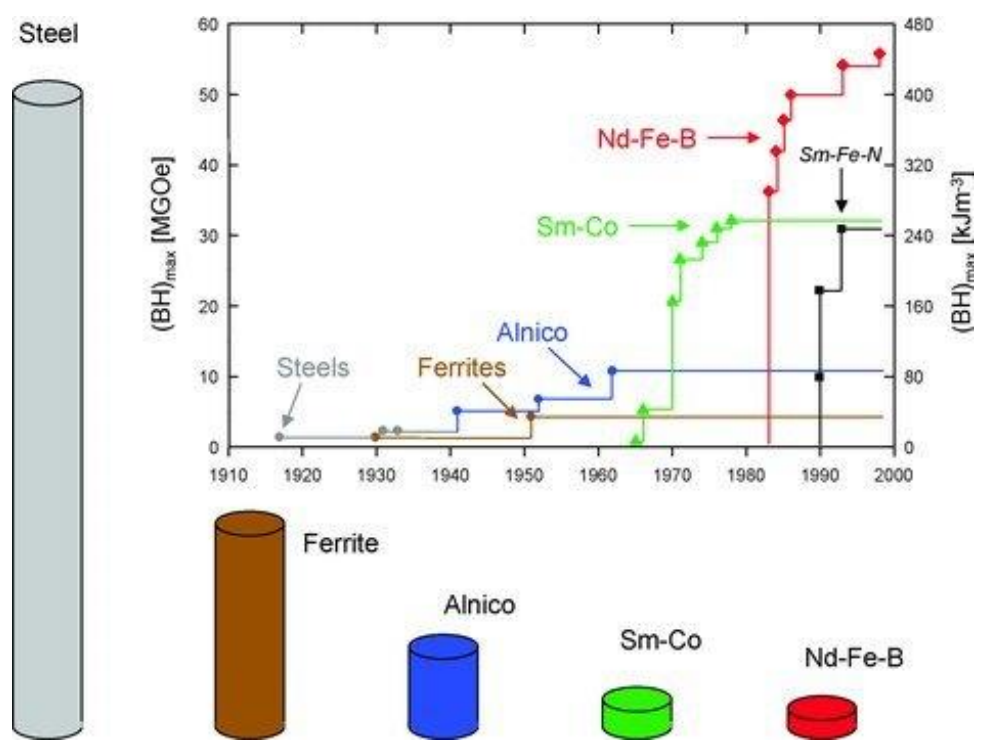

Figure 2. The development of permanent magnets in the 20th Century. $(\mathrm{BH})_{\max }$ has been improved exponentially. The cylindrical scale showes the relative magnet volume for the same magnet energy. Reproduced with permission from (Gutfleisch et al., 2011)

Essentially, in the last 50 years the major advances in magnetic materials have been appearing at an accelerating pace. Permanent magnets have developed from AlNiCo's with $(\mathrm{BH})_{\max } \approx 8 \mathrm{MGOe}$ and $\mathrm{H}_{\mathrm{c}} \approx 800$ Oe to the more recently discoveries of NdFe-B supermagnets with $\mathrm{H}_{\mathrm{c}} \approx 15 \mathrm{kOe}$ and $(\mathrm{BH})_{\max }$ up to $\approx 54 \mathrm{MGOe}$. Soft magnetic materials have progressed from bulk electrical steels to amorphous Metglas (Fe-Si-B) and 
to the most recent nanocrystalline alloys $(\mathrm{Fe}-\mathrm{Zr}-\mathrm{Cu}-\mathrm{B})$ with much lower core losses and coercivities down to mOe. Particulate media for magnetic storage has progressed from $\mathrm{CrO}_{2}$ and $\gamma-\mathrm{F}_{2} \mathrm{O}_{3}$ particles with $\mathrm{H}_{\mathrm{c}} \approx 300 \mathrm{Oe}$ to particles with much higher coercivities such as Co-doped $\mathrm{F}_{2} \mathrm{O}_{3}\left(\mathrm{H}_{\mathrm{c}} \approx 700 \mathrm{Oe}\right)$, metallic $\mathrm{Fe}\left(\mathrm{H}_{\mathrm{c}} \approx 2000 \mathrm{Oe}\right)$ and barium ferrite particles $\left(\mathrm{H}_{\mathrm{c}} \approx 2000-30000 e\right)$ (Jaćimović et al., 2017) .

Nowadays, the selection of a permanent magnetic material for a given application is mainly based on a balanced consideration of price and specific performance (Cui et al., 2018). The design goal for lightweight devices and smaller sizes has enabled NdFeB to be the magnet of choice for higher-end applications. It is noteworthy to mention, that the fastest growing market for permanent magnetic materials is the one of energy-related applications (Jaćimović et al., 2017).

Magnetic materials, whose magnetic properties can be changed with the application of a magnetic field, can also display magnetic properties coupled to the electrical ones: the so-called magnetoelectric (ME) materials.

Magnetoelectricity is a product property and needs biphasic surrounding to exhibit its complex behavior (Palneedi et al., 2015). The primary requisite for the observance of this effect is the coexistence and coupling of magnetic and electric dipoles. Materials exhibiting the ME effect can be classified into two classes: single-phase and composites. Single-phase ME materials show an ordered structure and demand the presence of a ferroelectric/ferrielectric/antiferroelectric state. These materials should show two transitions: one from a ferroelectric to a paraelectric state and the other from a ferromagnetic/ferrimagnetic/antiferromagnetic to a paramagnetic state (Figure 3) (Ortega et al., 2015). 


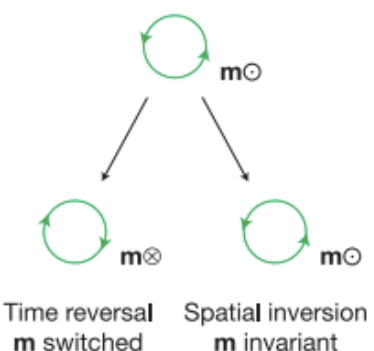

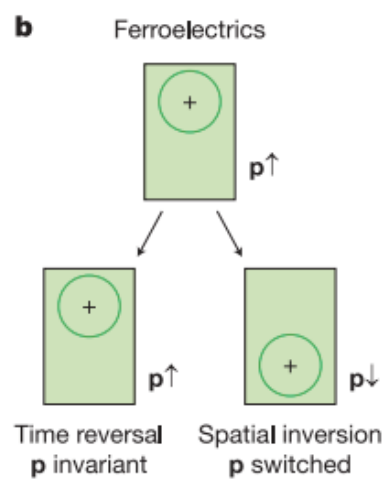

p invariant p switched

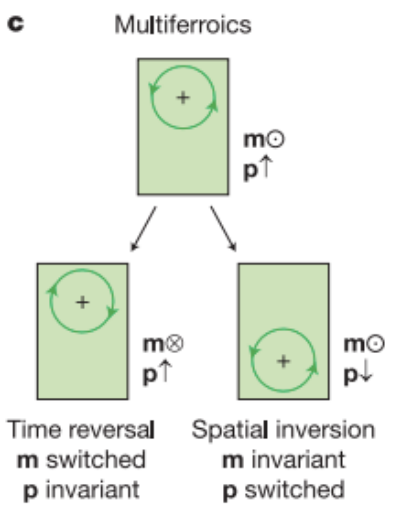

Figure 3. a) Ferromagnets. The local magnetic moment $m$ may be represented classically by a charge that dynamically traces an orbit, as indicated by the arrowheads. A spatial inversion produces no change, but time reversal switches the orbit and thus m. b), Ferroelectrics. The local dipole moment $\mathrm{p}$ may be represented by a positive point charge that lies asymmetrically within a crystallographic unit cell that has no net charge. There is no net time dependence, but spatial inversion reverses p.c) Multiferroics that are both ferromagnetic and ferroelectric possess neither symmetry. Reproduced with permission from (Eerenstein et al., 2006).

The ME effect arises due to the local interaction between the ordered magnetic and ferroelectric sublattices. The conditions for the occurrence of ferroelectricity and magnetic order in the same material, often accompanied by ferroelasticity, implies:

(a) the presence of adequate structural building blocks allowing ferroelectric-type ionic movements;

(b) magnetic-interaction pathways, usually of the superexchange type;

(c) the fulfillment of symmetry conditions (Schmid, 1994).

One simple inference from this is that it is possible to synthesize the ferroelectric ferromagnets by replacing diamagnetic ions by paramagnetic ones on the B-site of oxyoctahedral ferroelectric perovskites. Smolensky and Ioffe (Smolensky and Ioffe, 1958) in 1958 synthesized the antiferromagnetic ferroelectric perovskite ceramic $\mathrm{Pb}\left(\mathrm{Fe}_{1 / 2} \mathrm{Nb}_{1 / 2}\right) \mathrm{O}_{3}(\mathrm{PFN})$. Later single crystals of PFN were grown and the presence of a 
weak spontaneous moment in the ferroelectric phase below 9K was confirmed (Astrov, 1960). The ME effect has been reported in materials with the perovskite structure, rareearth magnets, pseudo-ilmenites, $\mathrm{BaMeF}_{4}(\mathrm{Me}=\mathrm{Mn}, \mathrm{Fe}, \mathrm{Co}, \mathrm{Ni}), \mathrm{Cr}_{2} \mathrm{BeO}_{4}$ and inverted spinels (Smolensky and Chupi, 1982). Those single-phase materials have the drawbacks of low ME response at very low temperatures, hindering their use in room-temperature technological applications.

In composite materials, the ME effect is realized by using the concept of product properties introduced by Van Suchtelen (Suchtelen, 1972). A suitable combination of two phases can yield the desirable property such as a combination of piezomagnetic and piezoelectric phases or a combination of magnetostrictive and piezoelectric phases.

The ME effect can also be realized by coupling the thermal interaction in pyroelectric-pyromagnetic composites. Most ferromagnetic materials show the magnetostrictive effect, however, piezomagnetic effect in these materials has not been observed. This means that the strain caused by a magnetic field in these materials is not linearly proportional to the field strength but is related to the square of the magnetic field strength. This makes the product property, the ME effect in the piezoelectricmagnetostrictive composites, a non-linear effect unlike the single phase materials where the magnetoelectric effect is a linear effect over a wide range of the values of the magnetic or electric field (Zygmunt Surowiak and Bochenek, 2008). Moreover, the ME effect in these composites shows a hysteretic behavior. This makes the applications of such composites difficult in linear devices. Linearity in such composites is achieved by applying a bias magnetic field across them so that the magnetoelectric effect over a short range around this bias can be approximated as a linear effect. The hysteretic nature of this effect can be made use of in memory devices, for which there is no necessity of a bias magnetic field (Fuentes-Cobas et al., 2015). 
Thus, it is worth to conclude that the context of increasing interconnectivity promoted by the Internet of Things (IoT) and industry 4.0 paradigms, advanced solutions and devices demand for magneto-electro active materials, as optimized performances, low power consumption and new integrated applications can be achieved with ME materials. ME systems that convert magnetic energy into electrical output (or vice-versa) (Figure 4) can improve integration and efficiency (Aceto et al., 2020). Additionally, information and communication technologies are connected to a cloud that allows ME smart products with embedded sensors, actuators, processing units, connected via internet enabling functionalities for monitoring, control, real time optimization and autonomy (Dalenogare et al., 2018, Beier et al., 2020).

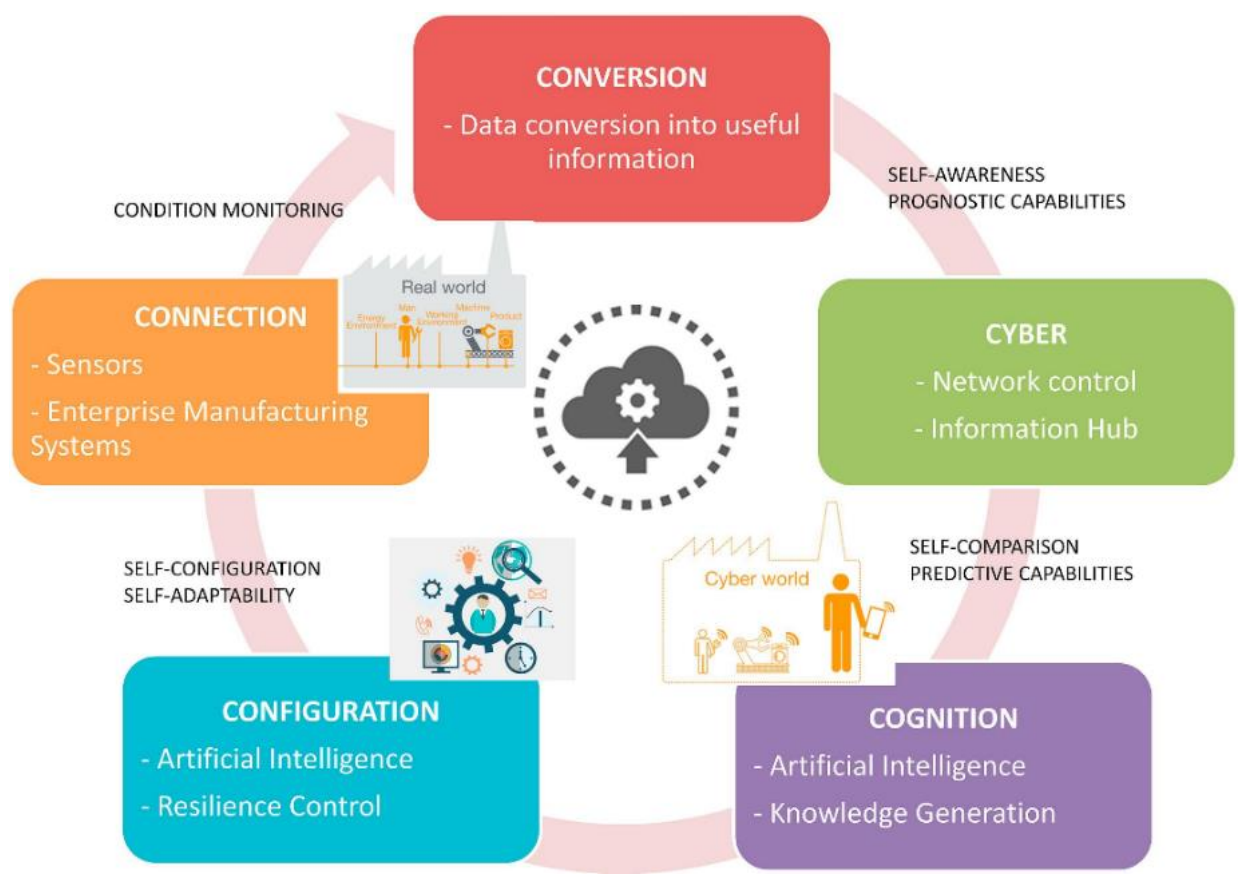

Figure 4. Model for Industry 4.0. Reproduced with permission from (Longo et al., 2017).

\section{History of multiferroic and magnetoelectric materials}


Multiferroics are described as materials that combine at least two of the primary ferroic order parameters simultaneously in a single-phase. The established primary ferroics are ferromagnets (materials with a spontaneous magnetization that is switchable by an applied magnetic field), ferroelectrics (materials with a spontaneous electric polarization that is switchable by an applied electric field), and ferroelastics (materials with a spontaneous deformation that is switchable by an applied stress) (Wang et al., 2009, Nan et al., 2008). The interaction between different ferroic orders can produce effects such as the magnetoelectric (ME) one, represented in Figure 5. Such ME response is observed by the an electric polarization variation when applying an external magnetic field, or an induced magnetization variation under an external electric field (Nan et al., 2008, Martins et al., 2015).

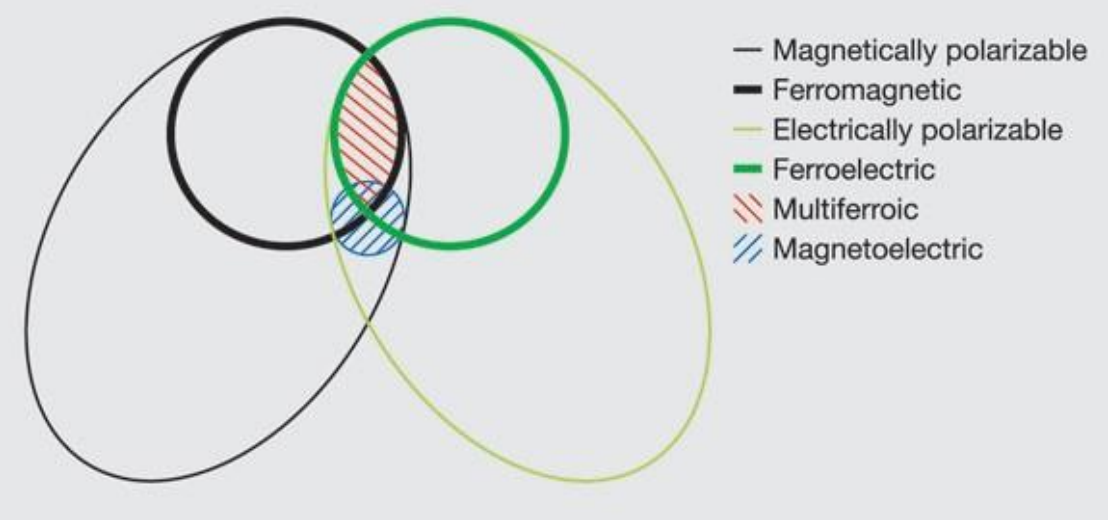

Figure 5. Relation between ferroic, multiferroic and magnetoelectric materials. Reproduced with permission from (Eerenstein et al., 2006).

The initial studies considering the ME effect by Rontgen in 1888 (Röntgen, 1888) and Pierre Curie in 1894 (Curie, 1894), stated that a moving dielectric became magnetized when placed in a magnetic field and the possibility of intrinsic ME behavior of crystals on the basis of symmetry considerations, respectively. With this studies and considerations, the ME concept began to get increasing attention by the scientific 
community (Lorenz, 2013). A variety of promising technological applications include energy transformation, signal generation and processing, information storage, and so on. Nevertheless, the main driving force for multiferroic research in the past decade was mainly triggered by increasing scientific knowledge than by the potential applicability (Nan et al., 2008).

The term "magnetoelectric" was introduced by Debye in 1926, after the first unsuccessful attempts to experimentally verify the ME effect. The first specific written mention of the ME effect occurred in 1958 in the classic book Electrodynamics of Continuous Media by Landau and Lifshitz (Landau and Lifshitz 1960) which affirmed, "Let us point out two more phenomena, which, in principle, could exist. One is piezomagnetism. The other is a linear coupling between magnetic and electric fields in a media, which would cause, for example, a magnetization proportional to an electric field." The authors continue, "We will not discuss these phenomena in more detail because it seems that till present, presumably, they have not been observed in any substance." (Landau and Lifshitz 1960) Soon after this rather unpromising statement, in 1959, Dzyaloshinkii reported two valid evidences of the ME effect: i) that an electric field induced magnetization on $\mathrm{Cr}_{2} \mathrm{O}_{3}$ and, ii) that a magnetic field induced polarization in the same $\mathrm{Cr}_{2} \mathrm{O}_{3}$ (Dzyaloshinskii, 1960, Wang et al., 2009). After such first evidences of the ME effect in $\mathrm{Cr}_{2} \mathrm{O}_{3}$ happening in 1960, the activity in relation with the ME effect declined from some years due to the low ME coupling magnitude that was not enough to allow the ME phase control in devices with magnetic control of an electrical polarization, and viceversa (Fiebig, 2005).

The low number of materials displaying ME behavior also did not help the proposed applications requiring specific physical properties and stability. In particular, the Curie temperature $\left(\mathrm{T}_{\mathrm{c}}\right)$ was below room temperature (close to $0 \mathrm{~K}$ ), and their discrete 
compositions with limited possibilities for tuning the ME response were some of the Achilles heels in this area. Additionally, and in more objective terms there were no available standardized techniques for the detailed/reproducible study of the ME behavior (Fiebig, 2005).

In the 1970s it was produced the first ME composite material by merging ferroelectric piezoelectric $\mathrm{BaTiO}_{3}$ and ferromagnetic piezomagnetic $\mathrm{CoFe}_{2} \mathrm{O}_{4}$ (Suchtelen, 1972), and single-phase $\mathrm{BiFeO}_{3}$ thin films were discovered with large room temperature ferroelectric polarization in coexistence with magnetization (Skinner, 1970).

Despite these developments on composites that allowed ME coupling to happen at room-temperature, the ME response never was above the $\approx 100 \mathrm{mV} . \mathrm{cm}^{-1} . \mathrm{Oe}^{-1}$ value, mainly due to inconsistencies in chemical reactions during the sintering process, low resistivity of the magnetostrictive phase and induced eddy currents in the conducting phase by the applied AC voltage (Fiebig, 2005). Additionally, dispersion issues in nanocomposites in order to suppress percolation, mechanical defects limiting the mechanical coupling and difficulties on aligning the electric dipoles were concerns that persisted to be solved (Fiebig, 2005).

Finally, in 1990s the ME effect was improved with the introduction of new ME interactions and degrees of freedom in designing ME compounds, innovative experimental techniques and optimized theoretical tools (Silva et al., 2013). The studies with tuning new parameters, such as stoichiometry and the microstructure of MEs, produced large ME response, orders of magnitude higher than in single-phase materials at room temperature (Fiebig, 2005).

In 2000, in a seminal paper entitled "Why are there so few magnetic ferroelectrics?", Hill analyzed the intrinsic challenges for accommodating magnetism and ferroelectricity 
in single-phase perovskite oxides (Hill, 2000), shedding a pessimistic prediction of this discipline.

The long incubation period was finally over because of two surprising breakthroughs, both occurring in 2003. The first one was the discovery of room temperature large ferroelectric polarization in coexistence with notable magnetization in $\mathrm{BiFeO}_{3}$ thin films (Wang et al., 2003), which stimulated numerous subsequent investigations on $\mathrm{BiFeO}_{3}$ bulks, films, and heterostructures. Although the reported strong magnetization was later found to be non-intrinsic (Eerenstein et al., 2006), it was the first time to get a singlephase magnetoelectric compound offering excellent multiferroic performance with potential room temperature applications. It should be noted that this progress was made possible not only by the developments in materials theory from which the authors understood where to start looking for new multiferroics, but also by important improvements in materials synthesis methods. Figure 6a) shows a polycrystal grown from a $\mathrm{B}_{2} \mathrm{O}_{3} / \mathrm{Bi}_{2} \mathrm{O}_{3} / \mathrm{Fe}_{2} \mathrm{O}_{3}$ flux in the 1980s by the Schmid group (Tabares-Muñoz 1986). It is an extraordinarily beautiful sample with its exquisite fern-like texture due to crystallographic twinning. However, it is not a good sample for measuring ferroelectric behavior because the twins clamp the ferroelectric domains, preventing them from switching, and the fern dendrites are conductive. In addition, $\mathrm{BiFeO}_{3}$ is a wide-bandgap insulator, which should be colorless, so the black colour indicates the presence of impurities. These could be $\mathrm{Fe}_{3} \mathrm{O}_{4}$, which is a decomposition product, or other competing phases.

In contrast, Ramesh's 21 st century $\mathrm{BiFeO}_{3}$ films were, basically, perfect. Figure 6b) shows a high-angle annular dark-field image of such a film, grown using pulsed laser deposition, with the large white spots indicating columns of $\mathrm{Bi}$ ions and the small white 
dots showing the Fe ions. Such improvements in growth methods were required in order for multiferroics to become a viable research and application field (Spaldin, 2017).

(A)
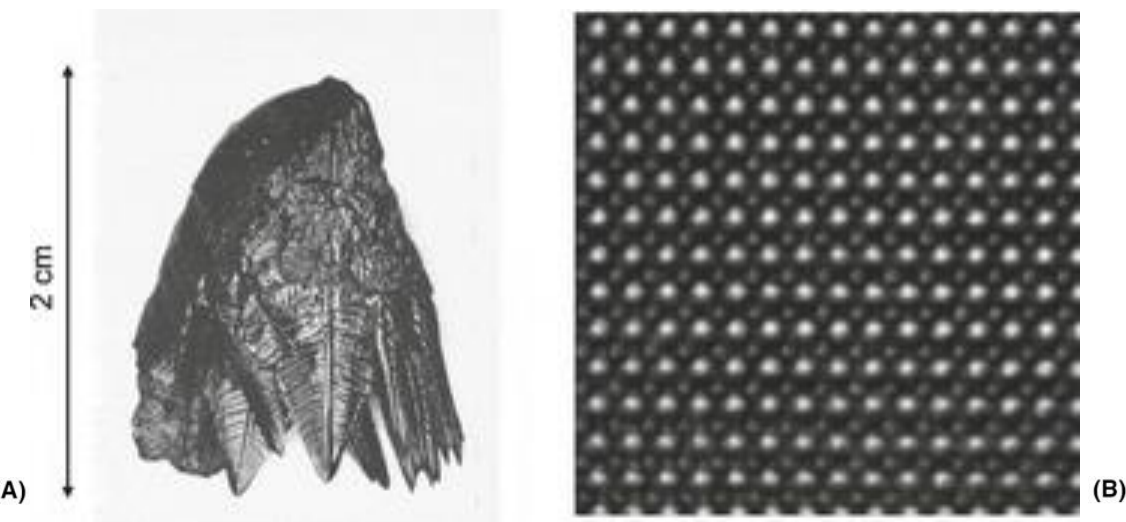

Figure 6. a) A "fern-like" crystal of bismuth ferrite containing many twin boundaries and defects. The length of the crystal is $\approx 2 \mathrm{~cm}$. b) High-resolution transmission electron microscope image of a BiFO. Reproduced with permission from (Spaldin, 2017).

Different from thin film $\mathrm{BiFeO}_{3}$, bulk $\mathrm{BiFeO}_{3}$ (in both ceramic and single crystal forms) has been for a long time much less interesting due to the notorious leakage caused by non-stoichiometry of species and high density of defects. Substantial efforts have been devoted to synthesis strategies which can produce stoichiometric and defect-free samples, including the rapid liquid phase sintering (Zhang et al., 2005). This concern has not been fixed until the successful synthesis of high-quality single crystals (Choi et al., 2009), and measurements did confirm the large spontaneous polarization: along the [001]-direction and along the [111]-axis or its equivalent axes, which lead $\mathrm{BiFeO}_{3}$ to be competitive and a reference in the multiferroic world .

It is nowadays recognized that the large polarization of $\mathrm{BiFeO}_{3}$ mainly comes from the $\mathrm{Bi}^{3+}$ ion, but an additional source associated with the $\mathrm{Fe}^{3+}$ spin order is still under consideration. The $6 s^{2}$ lone pair of $\mathrm{Bi}^{3+}$, just like the $d^{0}$ orbitals, has a strong predisposition to form the coordinate bond along one direction. This $6 s^{2}$ lone pair mechanism for ferroelectricity is not new and a similar case can be found in ferroelectric 
$\mathrm{PbTiO}_{3}$. As for the magnetism of $\mathrm{BiFeO}_{3}$, it is now clear that the $\mathrm{Fe}^{3+}$ ion is in the high spin state, giving a local moment of $\sim 5 \mu_{B} / \mathrm{Fe}$. The spins form a G-type antiferromagnetic order below $T_{N} \sim 643 \mathrm{~K}$, namely all the nearest-neighbor moments are antiparallel. However, ideal G-type antiferromagnetism does not show nonzero net magnetization, a weakness for applications. Interestingly, careful studies revealed a spiral modulation superposed onto the G-type antiferromagnetic order. This modulation lasts a spatial period as long as 62-64 nm (Choi et al., 2009, Sosnowska et al., 1982, Przeniosło et al., 2006) due to the accumulation of $\mathrm{Fe}^{3+}$ spin canting (Ederer and Spaldin, 2005). This spiral modulation can be suppressed by spatial confinements, as found in thin films and nanostructures (Gao et al., 2007), giving rise to a weak magnetization as a result of the Dzyaloshinskii-Moriya (DM) interaction. It is implicit that a large magnetization may not be expected in spite of a large number of reports on the ferromagnetism in $\mathrm{BiFeO}_{3}$. The G-type antiferromagnetic alignment plus the spiral spin canting of $\mathrm{BiFeO}_{3}$ allows opportunities for interfacial magnetic coupling in multiferroic heterostructures, where $\mathrm{BiFeO}_{3}$ plays several roles as a ferroelectric substrate, antiferromagnetic pinning layer for exchange bias, interfacial quantum modulation donor, and so on. These are the reasons for $\mathrm{BiFeO}_{3}$ to be the best multiferroic material so far.

The second material that dictated the beginning of a new era in ME materials, was the orthorhombic $\mathrm{TbMnO}_{3}$, which has only a weak polarization $\left(\approx 0.1 \%\right.$ of that of $\left.\mathrm{BiFeO}_{3}\right)$ developed at low temperature (below $28 \mathrm{~K}$ ) (Kimura et al., 2003). In spite of its modest performance in terms of ferroelectric polarization and magnetism, $\mathrm{TbMnO}_{3}$ represents a milestone material that offers intrinsically a strong magnetoelectric coupling, providing a $100 \%$ polarization flip driven by a magnetic field of several Tesla.

As revealed by Kimura et al. (Kimura et al., 2003), $\mathrm{TbMnO}_{3}$ becomes antiferromagnetically ordered below $T_{N}=40 \mathrm{~K}$ (Figure 7). This antiferromagnetism is 
quite complicated, with a sinusoidal type of modulation of the b-axis components of $\mathrm{Mn}^{3+}$ magnetic moments. The modulation period is incommensurate to the lattice constant and decreases with decreasing temperature (Arima et al., 2006). At temperature $T_{\text {lock-in }}=28 \mathrm{~K}$, this incommensurate modulation is locked-in and the sinusoidal-type of modulation turns to be a cycloid spiral in the $b$-c plane as revealed by neutron studies (Kenzelmann et al., 2005). Further reducing temperature leads to the independent $\mathrm{Tb}^{3+}$ spin ordering below $T_{T b} \approx 7-8 K$, which is even more complex and has not been well understood so far. The most interesting property of $\mathrm{TbMnO}_{3}$ is the emergence of a ferroelectric polarization right below $T_{\text {lock-in }}$, coinciding with the cycloid spiral ordering (Figure c) and d)). In other words, the ferroelectricity shares the identical transition temperature with the magnetic ordering, implying an intrinsic entanglement between the spiral-type antiferromagnetism and ferroelectricity in $\mathrm{TbMnO}_{3}$. A magnetic field up to several Tesla can tune the spiral plane from the $b-c$ plane to the $a-b$ plane, together with a simultaneous switching of the polarization from the c-axis to the a-axis, further confirming the strong coupling between magnetism and ferroelectricity. This effect is absent in $\mathrm{BiFeO}_{3}$-like multiferroics. Similar multiferroic behaviors have been also found in isostructural $\mathrm{DyMnO}_{3}$ and $\mathrm{Eu}_{1-\mathrm{x}} \mathrm{Y}_{\mathrm{x}} \mathrm{MnO}_{3}$ (Kimura et al., 2005, Ishiwata et al., 2010). The polarization of DyMnO, somehow larger $\left(\approx 0.2 \mu \mathrm{C} / \mathrm{cm}^{2}\right)$ than that of $\mathrm{TbMnO}_{3}$, remains far smaller than the value of $\mathrm{BiFeO}_{3}$. The $T_{\text {lock-in }}$ of $\mathrm{DyMnO}, \approx 18 \mathrm{~K}$, is even lower than that of $\mathrm{TbMnO}_{3}$. For $\mathrm{Eu}_{0.75} \mathrm{Y}_{0.25} \mathrm{MnO}_{3}$, the phase competition between the Atype antiferromagnetic phase with weak canted ferromagnetism and the spiral spin phase allows possibilities to cross-control of magnetization and polarization by electric and magnetic fields, respectively (Choi et al., 2009), paving a route towards colossal magnetoelectricity. 


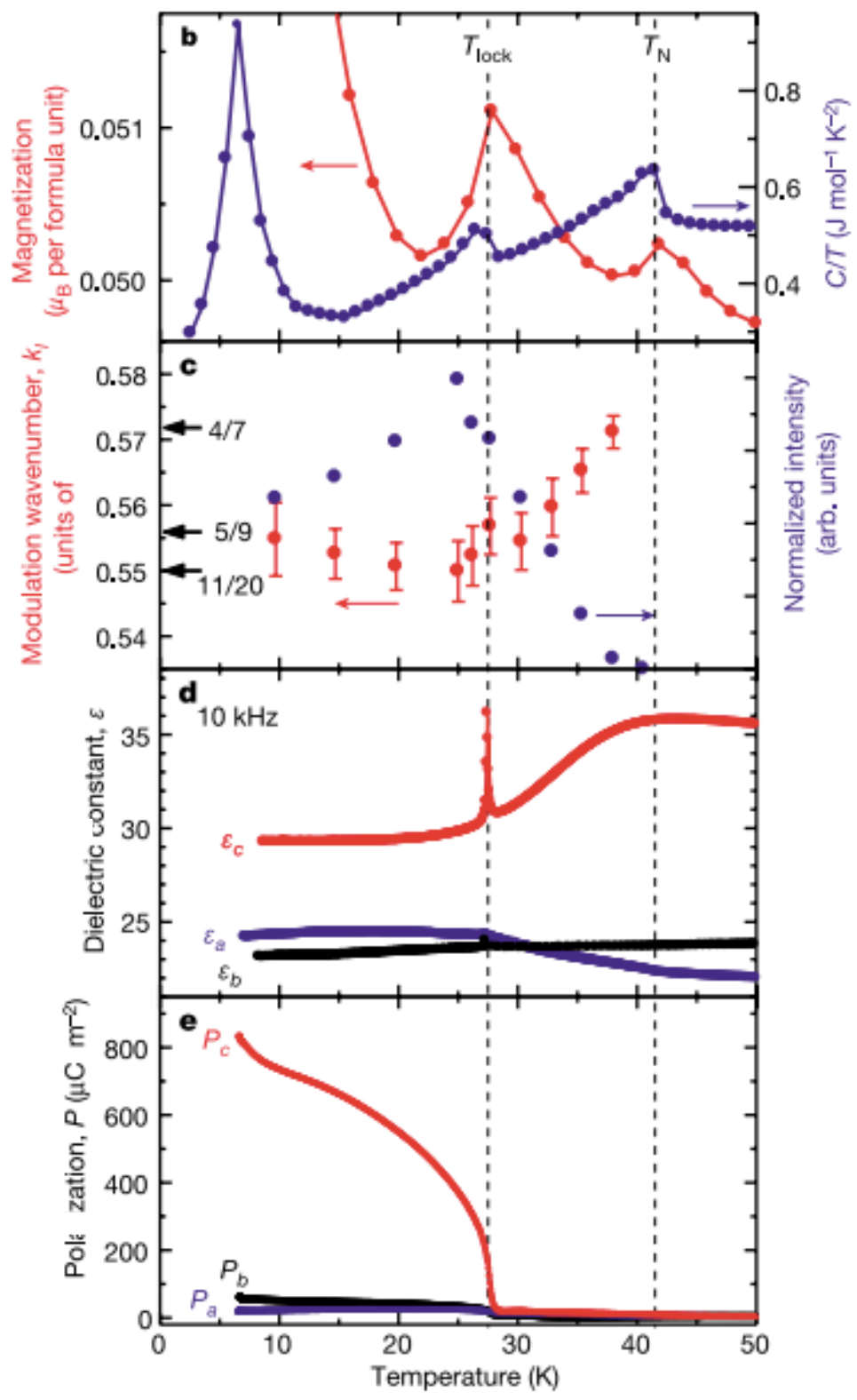

Figure 7. a) Magnetization (left) and specific heat/temperature (right). Two transitions (at $T_{N}$ and $\mathrm{T}_{\text {lock}}$ ) can be identified. b) Incommensurate modulation of magnetic moments. With decreasing temperature, the magnetic signal appears since TN and the wave number is (almost) fixed below $\mathrm{T}_{\text {lock. }} \mathrm{c}$ ) Dielectric constants along different crystalline axes. Only the one along the c-axis shows a sharp peak at $\mathrm{T}_{\text {lock. }}$ d) The pyroelectric polarization emerges below TC, with an additional tiny anomaly at $\sim 7 \mathrm{~K}$ corresponding to the independent ordering of $\mathrm{Tb}^{3+}$ magnetic moments. Reproduced with permission from (Kimura et al., 2003). 
In 2004, another two exciting multiferroic materials were discovered: orthorhombic $\mathrm{TbMn}_{2} \mathrm{O}_{5}$ (Hur et al., 2004) and hexagonal $\mathrm{HoMnO}_{3}$ (Lottermoser et al., 2004). Comparable to $\mathrm{TbMnO}_{3}, \mathrm{TbMn}_{2} \mathrm{O}_{5}$ also revealed a strong magnetoelectric coupling, providing a switchable polarization upon application of a magnetic field, though its ferroelectricity is reduced too (low ferroelectric Curie temperature of $38 \mathrm{~K}$ and small polarization of $\sim 0.04 \mu \mathrm{C} / \mathrm{cm}^{2}$ ). On the other hand, the magnetoelectric behavior of hexagonal $\mathrm{HoMnO}_{3}$ is highly appreciated because of its high ferroelectric Curie temperature (up to $875 \mathrm{~K}$ ) although its antiferromagnetic Néel temperature is quite low $(75 \mathrm{~K})$. The magnetoelectric demonstration was verified with electrical control of antiferromagnetic domains. In fact, as early as 2002, the coupling between antiferromagnetic domains and ferroelectric domains was observed in hexagonal $\mathrm{YMnO}_{3}$ (Fiebig et al., 2002), related to hexagonal $\mathrm{HoMnO}_{3}$, using the second harmonic generation technique.

The most frequently mentioned prototypes of ME devices which have been developed so far are magnetic field sensors (Bichurin et al., 2002, Chen et al., 2012) and energy harvesting devices (Duc and Giang, 2008). Among the new proposals for the use of ME coupling phenomenon, the most ground-braking and forward-looking ideas seem to be new-generation memories (Bibes and Barthélémy, 2008, Hu et al., 2010), spintronic devices (e.g., spin valves, magnetic tunnel junctions) (Fusil et al., 2014, Martin et al., 2007) microwave, millimeter-wave devices and miniature antennas (Ortega et al., 2015), as well as wireless medical tools (e.g., for endoscopy and brain imaging) (Srinivasan et al., 2015). The implementation of such devices requires, however, the elaboration of materials having high ME coupling coefficient such as the ones reported in multiferroic ME composites (both particulate and laminate). 
In particulate composites, such as $\mathrm{BaTiO}_{3} / \mathrm{CoFe}_{2} \mathrm{O}_{4}$, $\mathrm{PbZr}_{1}-\mathrm{xTixO}_{3}(\mathrm{PZT}) / \mathrm{Tb}_{1}-\mathrm{xDyxFe}$ (Terfenol-D), and $\mathrm{Ba}_{0.8} \mathrm{~Pb}_{0.2} \mathrm{TiO}_{3} / \mathrm{CuFe}_{1.8} \mathrm{Cr}_{0.2} \mathrm{O}_{4}$, the value of $\alpha_{\mathrm{ME}}$ is of the order of $\approx 100-130 \mathrm{mVcm}^{-1} \mathrm{Oe}^{-1}$ (Rivera, 2009). The laminated composites exhibit the largest value of $\alpha_{\mathrm{ME}}$, e.g., in PZT/Terfenol-D laminates, the ME response achieves $\approx 4.7 \mathrm{~V} \cdot \mathrm{cm}^{-1} \cdot \mathrm{Oe}^{-1}\left(\mathrm{Ryu} \mathrm{J}\right.$ and Kim, 2015) or even $90 \mathrm{~V} \cdot \mathrm{cm}^{-1} \cdot \mathrm{Oe}^{-1}$ in laminated PZT/Permendur composites (Laletsin et al., 2004).

Over time, the achievements of this exciting discipline have been enormous, featured by reports of a variety of novel materials and ME phenomena, revolutionary understanding of the microscopic mechanisms, and gradual establishment of a new interpretation and analysis framework of multiferroicity, thus making multiferroicity to be understandable and predictable in a microscopic quantum level, complementing the phenomenological scenario (Shuai Dong et al., 2016).

Simultaneously with the research progress, the essence and extension of multiferroics and MEs (also multiferroicity and magnetoelectricity) have been in continuing development. In the beginning, the terminology "multiferroic" in the narrow sense defined a material exhibiting both ferromagnetism and ferroelectricity, as schematically shown in Figure 8.

Today, "multiferroic" as a well-accepted concept can cover a material with one antiferroic-order plus another ferrioic-order, and "multiferroicity" refers to the coexistence of these ferroicities, as illustrative of the substantial expansion of the multiferroic/multiferroicity concepts. 
(a)
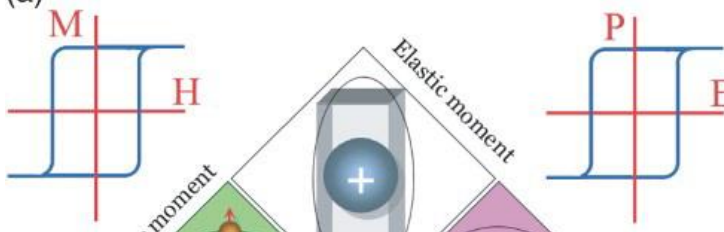

$+$
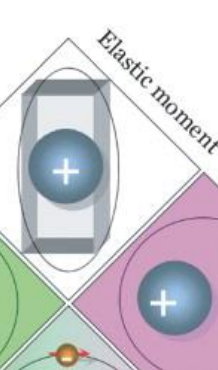

$\mathrm{H}$
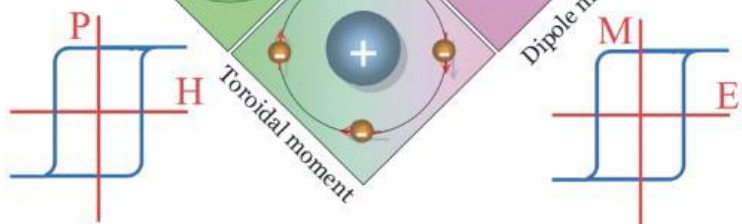

(b)

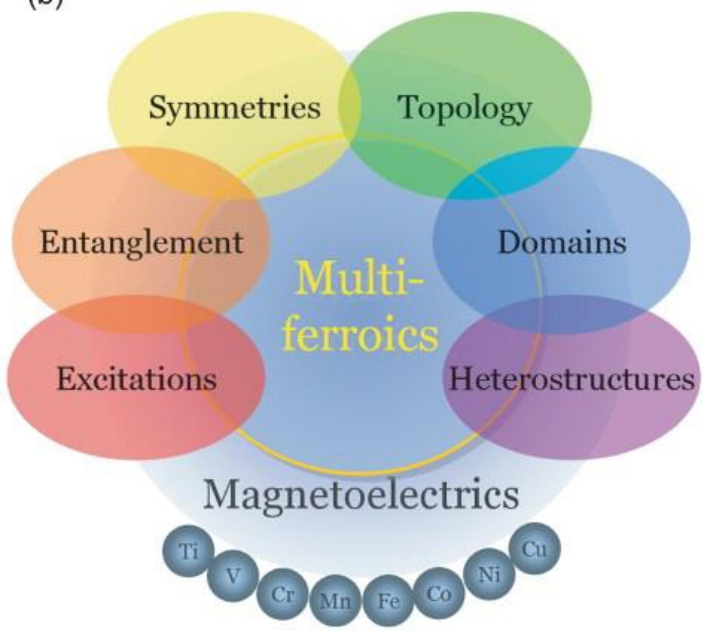

Figure 8. Multiferroicity and magnetoelectricity. a) A schematic representation of the four primary ferroic moments and their microscopic origins. In general, a magnetic moment, which breaks the time-reversal symmetry, originates from unpaired electrons and thus corresponding partially occupied orbitals (usually d or f orbitals). In contrast, an electric dipole moment, which breaks the space-inversion symmetry, is a relative displacement of positive and negative charges. Such a displacement usually occurs due to the preference for a coordinate (covalent) bond between an ion (cation) with empty d orbitals and another ion (anion) with fully occupied $\mathrm{p}$ orbitals. An elastic moment, which breaks neither the time-reversal symmetry nor the spaceinversion symmetry, comes from lattice distortions. A toroidal moment, which breaks both the time-reversal and space-inversion symmetries, can be visualized as a toroidal arrangement of magnetic moments. However, this intuitive interpretation seems to non-support the definition of toroidal moment as a primary ferroic order. In the past decade, attention of the multiferroic/magnetoelectric community has been paid to the entanglement between magnetic and electric dipole moments. The four hysteresis loops, each as the most important characteristic of one ferroic order, can be classified into two categories. The upper two loops are canonical: magnetization $(\mathrm{M})$ switched by magnetic field $(\mathrm{H})$ and polarization $(\mathrm{P})$ switched by electric field (E). The lower two loops denote the magnetoelectric cross-controls, which are the desired targets for magnetoelectric research. b) A grand garden of multiferroics and MEs, where several important physical issues, sub-disciplines, and crossovers with other disciplines. The small 
spheres on the bottom denote the most-commonly involved elements (ions) in ME materials. Reproduced with permission from (Shuai Dong et al., 2016).

Important efforts in this research area has been on substituting the ceramic piezoelectric materials of the ME particulate composites by insulating piezoelectric polymers to overcome technical problems such as fragility, high electrical conductivity and high dielectric losses, that lead to low output voltages (Lanceros-Méndez and Martins, 2017). The polymer-based ME composites strategy offered a new approach for developing new applications with easy production at low temperatures and additive manufacturing capability (inkjet printing or screen printing, for example), tuned

mechanical properties for flexible devices, large area applications, low-cost and biocompatible devices (Lanceros-Méndez and Martins, 2017), suitable for the internet of things (IoT) and Industry 4.0.

\section{Fundamental understanding of magnetoelectric coupling, its symbols and units}

ME coupling (MEC) allows to influence the magnetic state of matter through the application of an electric field, and is intermediated by subtle crystal structure changes induced by the electric field affecting the magnetic properties (Gerhard et al., 2010). MEC describes the bidirectional influence of magnetic and electronic properties and, so far, this phenomenon has mainly been reported in materials such as complex multiferroics oxides (Eerenstein et al., 2006). Multiferroic materials naturally display more than one of the following ferroic orders in a single phase: ferromagnetism, ferroelectricity or ferroelasticity. Those might couple to one another, directly, indirectly or by their corresponding fields (Feng et al., 2020). Figure 9 summarizes these possible interactions. 
a)

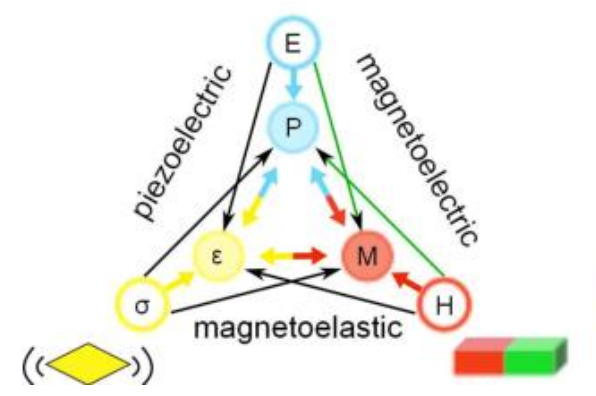

b)

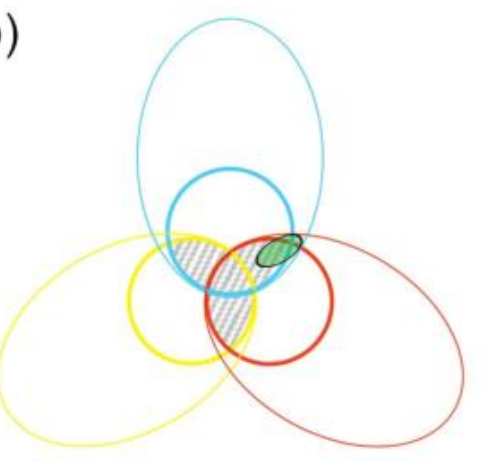

- Electrically polarizable

- Ferroelectric

- Magnetically polarizable

- Ferromagnetic Elastically polarizable Ferroelastic Multiferroic Magnetoelectric

Figure 9. a) Interaction triangle of electric field $\mathrm{E}$, stress $\sigma$, magnetic field $\mathrm{H}$ and the corresponding order parameters electric polarization $\mathrm{P}$, elastic deformation $(\varepsilon)$ and magnetization M. Particularly interesting is the possible influence of an applied electric field on the magnetization (shown as green arrows). b) Classification of polarizable materials: in multiferroic materials (hatched area), at least two ferroic orders (thick colored circles) coexist; Magnetoelectric coupling could appear in any material which is both magnetically (thin red circle) and electrically polarizable (blue thin circle), and it is not necessarily limited to ferroic materials. Reproduced with permission from (Gerhard et al., 2010).

While several materials are recognized for their magnetoelastic or piezoelectric performance, only few single-phase ME compounds exist. Though strong MEC is predictable for materials that are ferromagnetic and ferroelectric simultaneously, ferroism is not a requirement for MEC (Gerhard et al., 2010), as shown in Figure 9b.

The ME effect in a single-phase crystal is conventionally described (Schmid, 1994, Rivera, 1994) in Landau theory by writing the free energy $F$ of the system in terms of an applied magnetic field $\boldsymbol{H}$ whose $i$ th component is represented by $H_{i}$, and an applied electric field $\boldsymbol{E}$ whose $i$ th component is denoted $E_{i}$. It is important to refer, that this convention is unambiguous in free space, however that $E_{i}$ within a material encodes the resultant field that a test particle would experience. Considering a non-ferroic material, where both the temperature-dependent electrical polarization $P_{i}(T)(\mu \mathrm{C} / \mathrm{cm})$ and the magnetization $M_{i}(T)$ ( $\mu \mathrm{B}$ per formula unit, where $\mu \mathrm{B}$ is the Bohr magneton) are zero in 
the absence of applied fields and there is no hysteresis, the free energy of the system under the Einstein summation convention in S.I. units may be represented as an infinite, homogeneous and stress-free medium (Fiebig, 2005):

$$
-F(E, H)=\frac{1}{2} \varepsilon_{0} \varepsilon_{i j} E_{i} E_{j}+\frac{1}{2} \mu_{0} \mu_{i j} H_{i} H_{j}+\alpha_{i j} E_{i} H_{j}+\frac{\beta_{i j k}}{2}+\frac{\gamma_{i j k}}{2} H_{i} E_{j} E_{k}+\cdots \text { (eq.1) }
$$

In Equation 1, the first term on the right hand side defines the contribution resultant from the electrical response to an electric field, where the permittivity of free space is denoted $\varepsilon_{0}$, and the relative permittivity $\varepsilon_{i j}(T)$ is a second-rank tensor that is typically independent of $E_{i}$ in non-ferroic materials. The second term is the magnetic equivalent of the first term, where $\mu_{i j}(\mathrm{~T})$ is the relative permeability and $\mu_{0}$ is the permeability of free space. The third term describes linear magnetoelectric coupling via $\alpha_{i j}(\mathrm{~T})$; the third-rank tensors $\beta_{i j k}(T)$ and $\gamma_{i j k}(T)$ represent higher-order (quadratic) magnetoelectric coefficients (Guyonnet, 2008, Eerenstein et al., 2006).

The magnetoelectric effect can then be characterized under the form $P_{i}\left(H_{j}\right)$ and $M_{i}\left(E_{j}\right)$, which are obtained by differentiating $F$ with respect to $E_{i}$, or $H_{i}$, and then setting $E_{j}$, or $H_{j}$, to 0 , respectively:

$$
P_{i}=\alpha_{i j} H_{J}+\frac{\beta_{i j k}}{2} H_{J} H_{k}+\cdots(\text { eq. } 2)
$$

and

$$
\mu_{0} M_{i}=\alpha_{j i} E_{j}+\frac{\gamma_{i j k}}{2} E_{j} E_{k}+\cdots(\text { eq.3) }
$$

In ferroic materials, the above consideration is less rigorous because $\varepsilon_{i j}(T)$ and $\mu_{i j}(T)$ display field hysteresis. Also, ferroics are better parameterized in terms of resultant rather than applied fields. This is due the fact that it is possible to justify for the potentially significant depolarizing/demagnetizing factors in finite media, and also because the coupling constants would then be functions of temperature alone, as in standard Landau theory. Essentially, resultant electric and magnetic fields may 
occasionally be approximated (Lottermoser et al., 2004) by the polarization and magnetization, respectively. A multiferroic that is ferromagnetic and ferroelectric is predisposed to display large linear magnetoelectric effects. This is because ferroelectric and ferromagnetic materials typically show a large permittivity and permeability respectively, and $\alpha_{j i}$ is bound by the geometric mean of the diagonalized tensors $\varepsilon_{i i}$ and $\mu_{j j}$ such that:

$$
\alpha_{i j}^{2} \leq \varepsilon_{0} \mu_{0} \varepsilon_{i i} \mu_{j j} \text { (eq.4) }
$$

Equation 4 is obtained from Equation 1 by forcing the sum of the first three terms to be greater than zero, that is, ignoring higher-order coupling terms. It represents a stability condition on $\varepsilon_{i j}$ and $\mu_{i j}$, but if the coupling becomes so strong that it drives a phase transition to a more stable state, then $\alpha_{i j}, \varepsilon_{i j}$ and $\mu_{i j}$ take on new values in the new phase. Large $\varepsilon_{i j}$ is not a requirement for a material to be ferroelectric (or vice versa); and comparably ferromagnets do not necessarily acquire large $\mu_{i j}$ (Capra, 2014). For example, the ferroelectrics $\mathrm{KNO}_{3}$ and $\mathrm{BaTiO}_{3}$ have dielectric constants $\varepsilon=25$ and $\varepsilon=$ 100000 , respectively near their Curie temperature of $120{ }^{\circ} \mathrm{C}$.

The requirements for MEC can be extracted from symmetry arguments when the distinctive ferroic properties are studied: while the electric polarization is invariant under time inversion but reverses under space inversion, the magnetization is invariant under space inversion but changes sign under time inversion. Thus, MEC (in multiferroics) invariably requires a system in which both space and time inversion symmetry are broken (Velev et al., 2011). There are two possible realizations of MEC in insulators. In the first, single-phase multiferroics combine both electric and magnetic dipole moments in the same phase, but only display low ordering temperatures (Lottermoser et al., 2004, Ederer and Spaldin, 2005, Smolensky and Chupi, 1982). 
In the second, ferroelectric and ferromagnetic phases can be brought into close contact so that electric and magnetic dipoles couple via the interface, driven by elastic (Zheng et al., 2004) (Zavaliche et al., 2005) or electronic (Duan et al., 2006, Fechner et al., 2008) effects. In both methodologies, the electric polarization can be switched by an applied electric field. In metals, the electric field cannot penetrate deeply, prohibiting MEC in the bulk because the field is screened by a free electron charge near the surface (Lang and Kohn, 1970). This screening surface charge extends into the vacuum, forming a surface barrier, which is reflected in the work function. In the vicinity of the surface, however, the interaction of the surface barrier with an external electric field causes substantial displacements of free electrons (Weisheit et al., 2007). Comparably to the electrons, the cores of the surface atoms are also displaced, but in the opposite direction, as has been observed for non-magnetic palladium (Weissmüller et al., 2003). In magnetic systems these structural relaxations can in turn influence the magnetic order. This insinuates the possibility of finding MEC at the surfaces of magnetic metals. A scanning tunneling microscope (STM) is an ideal tool with which to investigate this, as it can image surface structures and it is possible to use the electric field underneath the STM tip to induce magnetic phase transitions.

ME coupling in composites and heterostructures relies on the interplay among the spin, orbit, charge, and lattice degrees of freedom across the interfaces (more precisely, the interphase boundaries). This is different from the case in single-phase multiferroics, where the magnetoelectric coupling arises from the interplay among the above-mentioned four fundamental degrees of freedom within one crystal lattice (Hu et al., 2015).

Direct ME coupling (that is, magnetic field control of electric polarization) in $\mathrm{ME}$ heterostructures has so far only been observed to occur through one single mechanism: magnetic-field-induced strain is transferred to a piezoelectric layer across the interface, 
and then such strain modulates the electric polarization through the piezoelectric coupling. In contrast, converse ME coupling (that is, electric field control of magnetism) in magnetoelectric heterostructures, can occur through multiple mechanisms (Zhaoming and Meng, 2018).

Remarkably, the number of distinctive mechanisms that the converse magnetoelectric coupling in a magnetoelectric heterostructure could possibly have is implied by the functionality of the constituent dielectric material (Figure 10). As an example, if the constituent dielectric layer is a pure dielectric (the outermost circle in Figure 10a), the converse magnetoelectric coupling will occur through at most two different mechanisms (indicated by the solid ellipses in Figure 10a). If the constituent dielectric layer is a ferroelectric-antiferromagnet (FE-AF), the number of possible converse magnetoelectric coupling mechanisms will be four, and so forth.
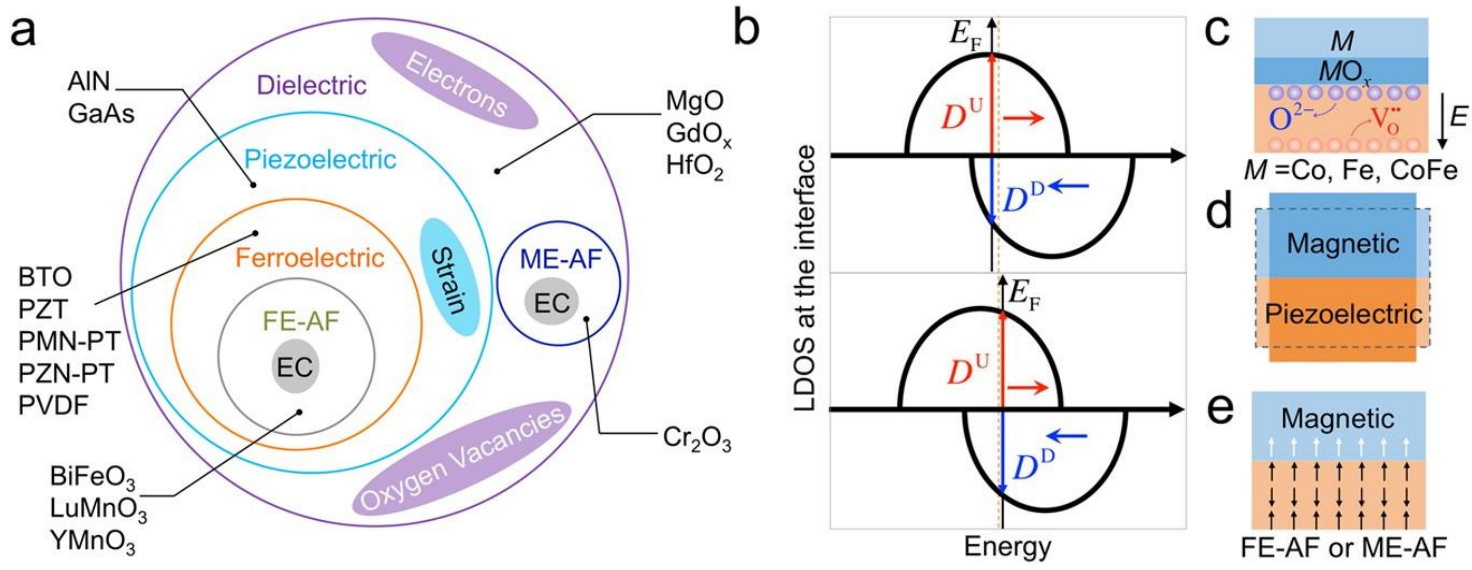

Figure 10. a) Classifying magnetoelectric (magnetic/dielectric) heterostructures by the functionality of the dielectric materials, along with the representative dielectric materials. The solid ellipses suggest the corresponding mechanisms of converse magnetoelectric coupling. Schematics explaining the mechanisms of converse magnetoelectric coupling enabled through electric field modulation of b) spin-polarized electron densities, c) degree of interfacial oxidation, d) strain, and e exchange coupling. In b) the change of electron densities shifts the Fermi level $E_{F}$ and hence the local density of states (LDOS). In c) the details of how the interfacial oxide $\left(\mathrm{MO}_{\mathrm{x}}\right)$ 
layer affects the magnetic anisotropy of the overlaying metal $\mathrm{M}$ remain unclear. In e) only one single AF domain with perpendicular sublattice magnetizations is shown for simplicity. The exchange coupling arises from the Heisenberg-type exchange interaction between the uncompensated surface magnetization (canted magnetization in $\mathrm{BiFeO}_{3}$ ) and the local magnetization at the bottom of the magnet. Note that the converse magnetoelectric coupling illustrated in c) involves the exchange of both matter and energy across the interface (that is, through an interfacial redox reaction), whereas the coupling illustrated in a, b, d, and e only involve the exchange of (magnetic, elastic, electric) energy. FE-AF Ferroelectricantiferromagnetic, ME-AF: Magnetoelectric-antiferromagnetic, $\mathrm{BTO} \mathrm{BaTiO}_{3}, \mathrm{PZT} \mathrm{Pb}(\mathrm{Zr}, \mathrm{Ti}) \mathrm{O}_{3}$, PMN-PT $\left[\mathrm{Pb}\left(\mathrm{Mg}_{1 / 3} \mathrm{Nb}_{2 / 3}\right) \mathrm{O}_{3}\right]_{1-\mathrm{x}}-[\mathrm{PbTiO}] \quad$ x $\quad, \quad \mathrm{PZN}-\mathrm{PT} \quad\left[\mathrm{Pb}\left(\mathrm{Zn}_{1 / 3} \mathrm{Nb}_{2 / 3}\right) \mathrm{O}_{3}\right]_{1-\mathrm{x}} \quad-\left[\mathrm{PbTiO}_{3}\right]_{\mathrm{x}}$. Reproduced with permission from (Hu et al., 2017).

When the dielectric layer is a pure dielectric with reduced ionic conductivity (e.g., $\mathrm{MgO}$ with low concentration of ionic defects, represented in Figure 10a), modulation of the spin polarization and magnetic moment (Duan et al., 2008) at the interface happens through the modulation of the surface electron density of the dielectric as a voltage is applied. An electrically enhanced (reduced) surface electron density of the dielectric would reduce (enhance) the electron density in the magnetic layer through the electrostatic interaction, which would shift the Fermi energy $\left(E_{F}\right)$ in the interface region of the magnet to a lower (higher) level. Based on the thermodynamics of electronic defects proposed by (Maier, 2004), (Hu et al., 2017) suggested that such electrically shifted Fermi energy can be estimated by $\Delta E_{F}=E_{F}(E)-E_{F}(E=0)=$ $k_{B} \operatorname{Tln}\left[\left(n_{0}+\Delta n\right) / n_{0}\right]$, where $k_{B}$ is the Boltzmann constant, $n_{0}$ the electron density under zero electric field $(\mathrm{E}=0) ; \Delta n=-\kappa_{0} \kappa_{r} \Delta E$ is the change of the spin-polarized screening electron density in the interface region of the magnet, where $\kappa_{r}$ is the relatively permittivity. Shifting $E_{F}$ can modulate the local density of states (LDOS) and thereby modulate the spin polarization $\eta=\left(D^{U}-D^{D}\right) /\left(D^{U}+D^{D}\right)$ with $0<\eta \leq 1$, where $D^{D}$ 
and $D^{U}$ represent the LDOS of the spin-down and spin-up electrons, correspondingly. First-principles DFT (Density Functional Theory) calculations can be used to quantify such a LDOS change. Also, the voltage-induced interface magnetic moment $(\Delta m)$ is given by $\Delta m=\left(\Delta n \eta \mu_{B}\right) / e$, (Cai et al., 2009) where $\mu_{B}$ is the Bohr magneton and $e$ the elementary charge. These analyses suggest that magnetoelectric heterostructures with a higher $\kappa_{r}$ dielectric layer should exhibit a larger change in both the interface spin polarization and magnetic moment. Additionally, if employing a ferroelectric that has an electric-field-switchable spontaneous polarization as the dielectric, a nonvolatile voltagemodulation of the $\Delta n$ (indicated by a typically hysteric P-E loop in ferroelectrics) and thereby a nonvolatile converse magnetoelectric coupling would be enabled ( $\mathrm{Hu}$ et al., 2017).

\section{Types of ME materials}

\subsection{Single phase multiferroics}

The field of multiferroics has greatly expanded in the last few years, particularly with the discovery of many different types of multiferroic materials. Generally speaking, there are two main groups of multiferroics (Khomskii, 2009). The first group, which can be called type-I multiferroics, where ferroelectricity and magnetism are originated from two different cations (such in case of $\mathrm{BiFeO}_{3}$ where the 6 s lone pair electrons of $\mathrm{Bi}$ give rise to ferroelectricity and the 3d-electrons of $\mathrm{Fe}$ lead to canted G-Type antiferromagnetism order) ( $\mathrm{Lu}$ et al., 2019). Type-I multiferroics include, $\mathrm{BiFeO}_{3}$, Hexagonal manganites $\mathrm{RMnO}_{3}, \mathrm{RFeO}_{3}, \mathrm{BaMF}_{4}(\mathrm{M}=\mathrm{Mn}, \mathrm{Ni}, \mathrm{Co}, \mathrm{Fe}, \mathrm{Cu})$, among others.

Type II multiferroics exhibit an electric polarization that is generated by a specific magnetic order, such in the case of orthorhombic $\mathrm{RMnO}_{3}$ and $\mathrm{RMnO}_{2}$ ( $\mathrm{Lu}$ et al., 2019). Type-II multiferroic also include $\alpha-\mathrm{NaFeO}_{2}, \mathrm{Mn}_{2} \mathrm{O}_{3},(\mathrm{La}, \mathrm{Bi}) \mathrm{Mn}_{3} \mathrm{Cr}_{4} \mathrm{O}_{12}, \mathrm{Ni}_{3} \mathrm{TeO}_{6},(\mathrm{Fe}$, 
$\mathrm{Mn})_{2} \mathrm{Mo}_{3} \mathrm{O}_{8}, \mathrm{Co}_{4} \mathrm{Nb}_{2} \mathrm{O}_{9}, \mathrm{Mn}_{2} \mathrm{MnWO}_{6}, \mathrm{RFe}_{3}\left(\mathrm{BO}_{3) 4}, \mathrm{KCu}_{3} \mathrm{As}_{2} \mathrm{O}_{7}(\mathrm{OD})_{3}, \mathrm{NaFeSi}_{2} \mathrm{O}_{6}\right.$, $\mathrm{In}_{2} \mathrm{NiMnO}_{6}$, among others (Lu et al., 2019).

Hybrid improper multiferroics, where ferroelectricity and magnetism arise from the same cation, allowing ME control via spin-lattice coupling (Figure 11). These materials show several advantages such as the fact that ferroelectric and magnetic transition may occur above room temperature, weak ferromagnetism and polar phase above $\mathrm{T} \sim 300 \mathrm{~K}$.

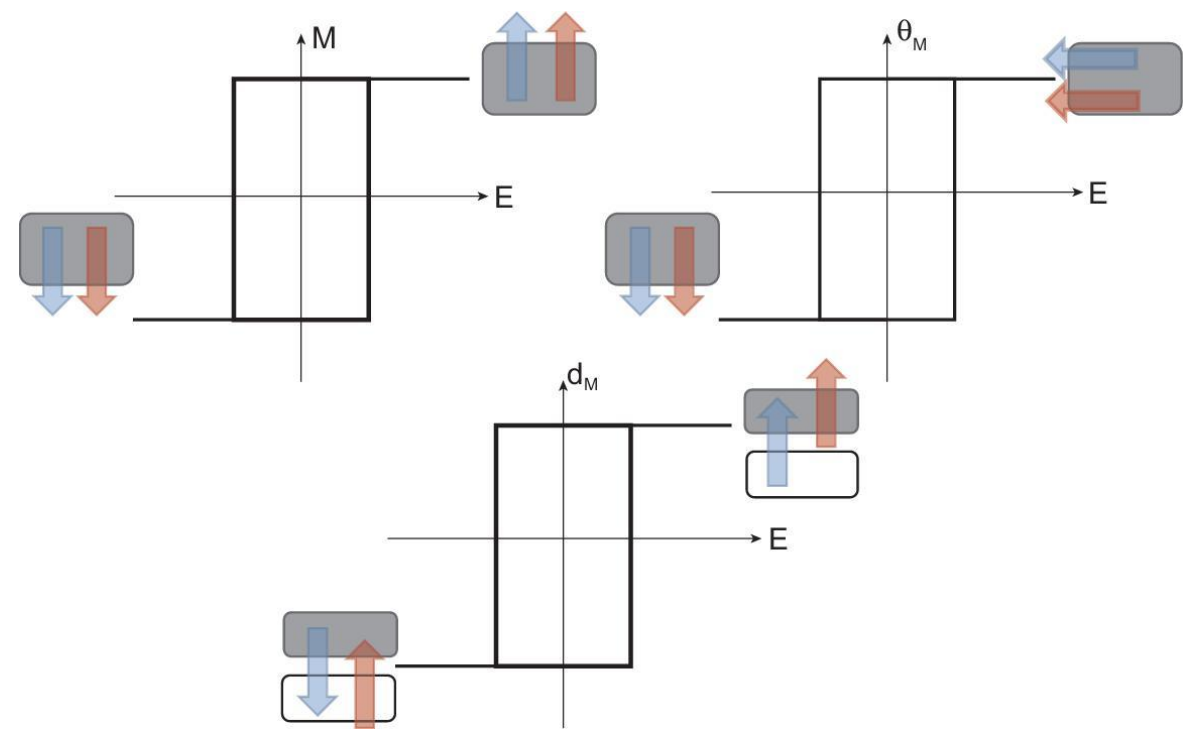

Figure 11. Three types of ME coupling: reversal of net magnetization $M$ upon ferroelectric switching; change of magnetic easy axis upon ferroelectric switching; change of magnetic distribution upon ferroelectric switching in 2D bilayer systems. Red and blue arrows denote the polarization and magnetization directions, respectively. $\theta_{\mathrm{M}}$ and $\mathrm{d}_{\mathrm{M}}$, respectively, denote the angle of the magnetic easy axis and the center coordinate of magnetic dipoles. Reproduced with permission from (Lu et al., 2019).

Double layered perovskite $\mathrm{A}_{3} \mathrm{~B}_{2} \mathrm{O}_{7}$ can be designed by chemical considerations (special magnetic configurations that could generate type-II multiferroicity), being its multiferroicity due to structural distortions (a combination of non-polar rotation of $\mathrm{BO}_{6}$ octahedra induces net electric polarization) (Lu et al., 2019). 
The integration of type-II mechanism into hybrid multiferroics enables at the same time good ferroelectricity, giant ME coupling and high ferroelectric/magnetic transition temperatures in a single material (Lu et al., 2019)

A promising joint concept, 2 D multiferroics and domain wall multiferroics enable cross-controls of multiple ferroic orders, allowing new device architectures for information processing and storage. For the application standpoint, atomically thin ferroelectrics would allow ultra-high density data storage.

\subsection{Composites}

ME composites can be prepared with 0-3, 1-3, and 2-2 connectivity, here the number correspond to the connectivity of the magnetic and piezoelectric phases (Figure 12):

- 0-3 particle matrix composites, where magnetic particles are embedded in the piezoelectric matrix;

- $\quad 1-3$ cylinder-matrix composites, formed by embedding magnetic fibers/rods/tubes or wires in the piezoelectric matrix

Please note that both particles in 0-3 and fibers in 1-3 composites can be randomly dispersed or periodically aligned.

- 2-2 laminate composites that consist of alternating magnetic and piezoelectric layers can be prepared in different topologies, such as discs, squares, rectangles, and rings with different sizes. These laminates can be arranged as unimorph and bimorph as well as bilayered and multi-layered structures and be poled at a higher degree since the piezoelectric and the low resistivity magnetic phases are separated. The 2-2 layered composites exhibit higher ME responses compared to 0-3 and 1-3 composites (Palneedi et al., 2016). 


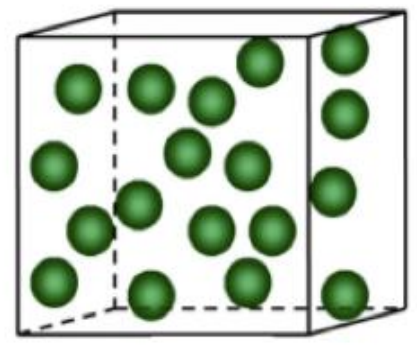

(a)

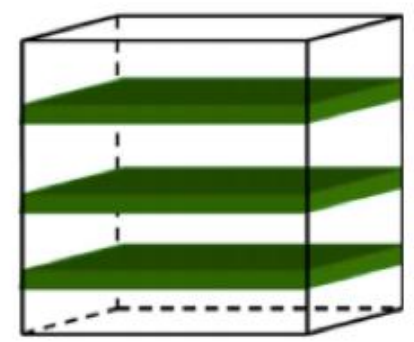

(b)

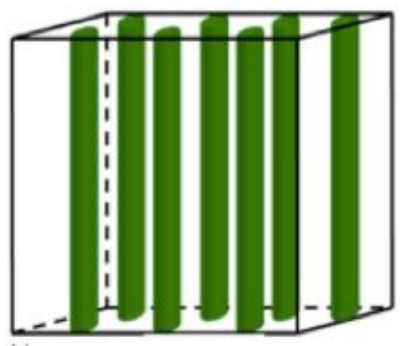

(c)

Figure 12. Schematic illustration of three bulk composites with the three most common connectivity schemes: (a) 0-3 particulate composite, (b) 2-2 laminate composite, and (c) 1-3 fiber/rod composite. Reproduced with permission from (Nan et al., 2008)

For all composite's structures, the connectivity as interface bonding of the piezoelectric and magnetostrictive components have influence on elastic coupling and on the ME response. Good interface facilitates efficient strain transfer (Palneedi et al., 2016). Additionally, the connectivity as interface bonding of the piezoelectric and magnetostrictive components has influence on elastic coupling and on the ME response: good interface facilitates efficient strain transfer (Palneedi et al., 2016).

ME composites can be fabricated from various material (Table II), both for the piezoelectric and magnetostrictive phases. Among piezoelectric materials, lead zirconate titanate (PZT) ceramics have been widely employed to fabricate ME composites due to its low cost, high piezoelectric response, and flexibility on modifying the composition. For the magnetic phase in ME composites, Terfenol-D with high magnetostriction and Metglas with high magnetic permeability, have been the most used materials (magnetic materials production and properties will be discussed in more detail in a separated section). Other properties such as processing temperatures, electrical resistance, 
magnitude of the bias field or phase connectivity are factors affecting the selection of the magnetostrictive materials (Palneedi et al., 2016).

Table II. List of piezoelectric and magnetostrictive materials used as constituents of ME composites (Palneedi et al., 2016).

\begin{tabular}{|c|c|}
\hline Piezoelectric phase & Magnetostrictive Phase \\
\hline Lead-based: & Metals: \\
\hline $\mathrm{Pb}(\mathrm{Zr}, \mathrm{Ti}) \mathrm{O} 3$ (PZT) & $\mathrm{Fe}, \mathrm{Co}, \mathrm{Ni}$ \\
\hline $\mathrm{Pb}(\mathrm{Mg} 1 / 3 \mathrm{Nb} 2 / 3) \mathrm{O} 3-\mathrm{PbTiO} 3$ (PMN-PT) & Alloys: \\
\hline $\mathrm{Pb}(\mathrm{Zn} 1 / 3 \mathrm{Nb} 2 / 3) \mathrm{O} 3-\mathrm{PbTiO} 3$ (PZN-PT) & FeNi-based \\
\hline $\mathrm{Pb}(\mathrm{Mg} 1 / 3 \mathrm{Nb} 2 / 3)$ y (ZrxTi1'x)1'yO3 (PMN-PZT) & FeCo-based \\
\hline $\begin{array}{l}\mathrm{Pb}(\mathrm{In} 1 / 2 \mathrm{Nb} 1 / 2) \mathrm{O} 3-\mathrm{Pb}(\mathrm{Mg} 1 / 3 \mathrm{Nb} 2 / 3) \mathrm{O} 3-\mathrm{PbTiO} 3 \text { (PIN- } \\
\mathrm{PMN}-\mathrm{PT})\end{array}$ & CoNi-based \\
\hline Lead-free: & $\mathrm{Ni} 2 \mathrm{MnGa}$ \\
\hline BaTiO3 (BTO)-based & Permendur $(\mathrm{FeCoV})$ \\
\hline$(\mathrm{K} 0.5 \mathrm{Na} 0.5) \mathrm{NbO3}(\mathrm{KNN})-$ based & Galfenol (FeGa), FeGaB \\
\hline Na0.5Bi0.5TiO3 (NBT)-based & Samfenol (SmFe2) \\
\hline Others: & Terfenol-D (Tb1'xDyxFe2) \\
\hline AlN & $\begin{array}{l}\text { Fe-based metallic glasses (FeBSi, FeBSiC, } \\
\text { FeCoB, }\end{array}$ \\
\hline $\mathrm{ZnO}$ & FeCoSi, FeCoSiB, FeCuNbSiB) \\
\hline (Sr, Ba) Nb2O5 & Ceramics: \\
\hline Ba1'xSrxTiO3 (BSTO) & $\mathrm{Fe} 3 \mathrm{O} 4$ \\
\hline Bi1'xSrxTiO3 (BST) & $\mathrm{Zn0.1Fe2.9O4} \mathrm{(ZFO)}$ \\
\hline La3Ga5.5SiO14 (LGS) & LaxSryMnO3 (LSMO) \\
\hline La3Ga5.5Ta0.5O14 (LGT) & LaxCayMnO3 (LCMO) \\
\hline Polyurethane (PU) & $\begin{array}{l}\text { Ferrites or doped Ferrites (e.g., } \mathrm{NiFe} 2 \mathrm{O} 4 \\
(\mathrm{NFO})\end{array}$ \\
\hline
\end{tabular}




\begin{tabular}{l|l}
\hline \hline Polyvinylidene difluoride (PVDF) & $\begin{array}{l}\mathrm{CoFe} 2 \mathrm{O} 4 \text { (CFO), Li ferrite, NiFe2O4, NiZn } \\
\text { Fe2O4, Fe3O4, Cu ferrite, Mn ferrite) }\end{array}$ \\
\hline Polyvinylidene difluoride -trifluoroethylene (PVDF-TrFE) & $\begin{array}{l}\mathrm{CoFe} 2 \mathrm{O} 4 \text { (CFO), Li ferrite, NiFe2O4, NiZn } \\
\mathrm{Fe} 2 \mathrm{O} 4, \mathrm{Fe} 3 \mathrm{O} 4, \mathrm{Cu} \text { ferrite, Mn ferrite) }\end{array}$ \\
\hline \hline
\end{tabular}

In the development of ME composites the main material properties that need to be optimized in order to obtain ME coupling are (Palneedi et al., 2016): dielectric constant, dielectric loss, Curie temperature, Remnant polarization, coercive electric field, piezoelectric strain constant, piezoelectric voltage constant, electromechanical coupling factor, mechanical quality factor and acoustic impedance. Magnetic properties include magnetic permeability, remanent magnetization, coercive magnetic field, magnetostriction; piezomagnetic coefficient and Neel Temperature.

In composites, the geometrical degrees of freedom, the relative orientation of the active phases to each other, the applied DC magnetic/electric field, the direction of the AC probe will also determine the magnitude of the ME response (Fiebig, 2005).

\section{Magnetic phases in ME materials}

Single-phase ME materials exhibit low ME voltage coefficients, a higher ME response can be achieved by the combination of a material with high piezoelectric voltage constant and low dielectric and piezoelectric losses and a magnetostrictive material with high magnetostriction coefficient, allied to a good interfacial coupling between the two phases (Palneedi et al., 2016). In the next sub-sections, examples of magnetic materials developments that allowed ME coupling in single-phase and in composite materials will be presented and discussed. 


\subsection{Single phase:}

Polycrystalline single-phase $\mathrm{Bi}_{4-\mathrm{x}} \mathrm{SmxTi}_{3-\mathrm{x}} \mathrm{Fe}_{\mathrm{x}} \mathrm{O}_{12 \pm \delta}(0 \leq \mathrm{x} \leq 0.3)$

Single-phase ME polycrystalline $\mathrm{Bi}_{4-x} \mathrm{Sm}_{x} \mathrm{Ti}_{3-x} \mathrm{Fe}_{x} \mathrm{O}_{12 \pm \delta}(0 \leqslant x \leqslant 0.3)$ ceramics can synthesized by solid state reaction method. Stoichiometric amounts of $\mathrm{Bi}_{2} \mathrm{O}_{3}, \mathrm{TiO}_{2}$, $\mathrm{Sm}_{2} \mathrm{O}_{3}$ and $\mathrm{Fe}_{2} \mathrm{O}_{3}$ with purity $\geqslant 99.95 \%$ are usually used as starting material. For better homogeneity, the weighed powder of each composition with 3 wt.\% excess of $\mathrm{Bi}_{2} \mathrm{O}_{3}$ is ball milled in a high energy ball milling system at room temperature. All compositions are milled for $5 \mathrm{~h}$ in tungsten carbide jars. The milled powder of each composition are again properly mixed and calcined at $700{ }^{\circ} \mathrm{C}$ for $12 \mathrm{~h}$. The post calcined powder is then pressed into pellets of diameter $12 \mathrm{~mm}$ and thickness of 1-2 $\mathrm{mm}$ using hydraulic press at a pressure of $120 \mathrm{MPa}$. The pellets were finally sintered at $1000{ }^{\circ} \mathrm{C}$ for $4 \mathrm{~h}$ with a heating rate of $5{ }^{\circ} \mathrm{C} \min ^{-1}$, with cooling in air atmosphere (Paul et al., 2015). The prepared samples show at room temperature a ME coefficient of $0.84 \mathrm{mV} \mathrm{cm}^{-1} \cdot \mathrm{Oe}^{-1}\left(\mathrm{H}_{\mathrm{DC}}=600 \mathrm{Oe}\right)$ for $\mathrm{x}=0.3$ at $993 \mathrm{~Hz}$ with an applied AC field of 3 Oe (Figure 13).

a)
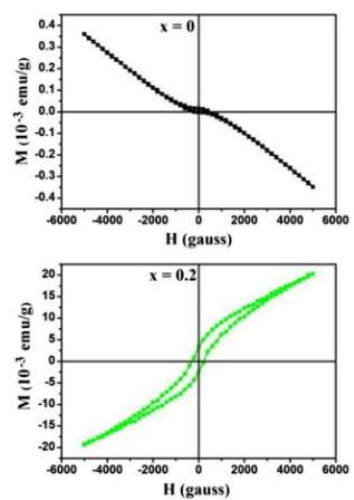
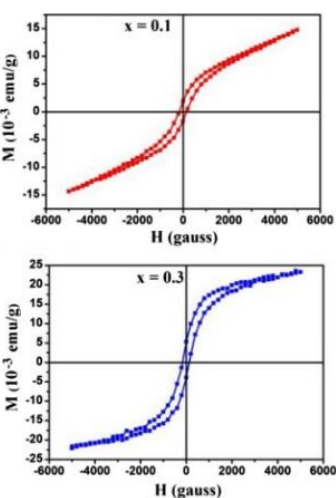

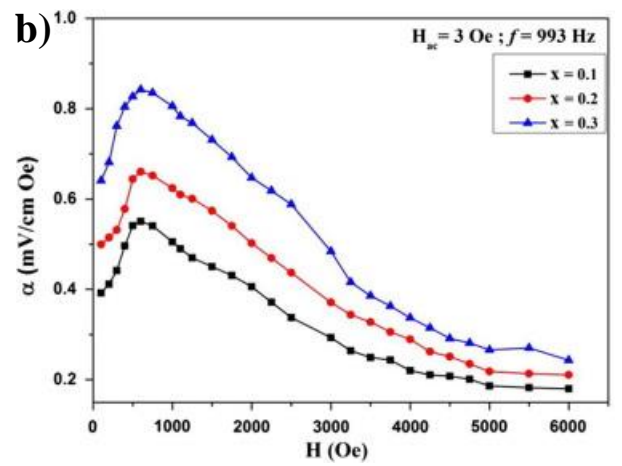

Figure 13. a) Isothermal magnetization hysteresis $(M-H)$ of $\mathrm{Bi}_{4-x} \mathrm{Sm}_{x} \mathrm{Ti}_{3-x} \mathrm{Fe}_{x} \mathrm{O}_{12 \pm \delta}(x=0,0.1$, $0.2,0.3)$ samples at room temperature; b) Magnetoelectric coupling coefficient $(\alpha)$ as a function of dc magnetic field under $H_{a c}=3 \mathrm{Oe}$ at $993 \mathrm{~Hz}$. Reproduced with permission from (Paul et al., 2015). 


\section{$\mathrm{LiFe}_{5} \mathrm{O}_{8}$ powders}

$\mathrm{LiFe}_{5} \mathrm{O}_{8}$ is usually prepared by the solid-state reaction method: $\alpha-\mathrm{Fe}_{2} \mathrm{O}_{3}$ and $\mathrm{Li}_{2} \mathrm{CO}_{3}$ are milled and heated at $800{ }^{\circ} \mathrm{C}$ for $5 \mathrm{~h}\left(\alpha-\mathrm{Fe}_{2} \mathrm{O}_{3}\right.$ and $\mathrm{Li}_{2} \mathrm{CO}_{3}$ are previously dried at $200{ }^{\circ} \mathrm{C}$ for $7 \mathrm{~h}$ ). The as-prepared $\mathrm{LiFe}_{5} \mathrm{O}_{8}$ powders are then grounded into fine powders and pressed into pellets with 6 wt.\% polyvinyl alcohol as a binding agent. The pellets are finally sintered in a furnace at $950{ }^{\circ} \mathrm{C}$ for $5 \mathrm{~h}$ in an ambient atmosphere to form dense ceramics. Both surfaces of the sintered ceramics can be finely polished and coated with silver paste electrodes (Liu et al., 2019).

The $\mathrm{LiFe}_{5} \mathrm{O}_{8}$ coercive field is $\approx 100$ Oe and the remnant magnetization is about 9 emu.g ${ }^{-1}$. The reported values of the saturation magnetization were 63.6, 63.2, 62.2, 60.3 and 58.9 emu.g ${ }^{-1}$ at 120, 150, 200, 250, and $300 \mathrm{~K}$, respectively (Liu et al., 2019). The ME coefficient increases with decreasing temperature and its value reaches $2 \mathrm{mV}$ $\mathbf{c m}^{-1} \cdot \mathbf{O e}^{-1}$ at $120 \mathrm{~K}$, which indicates a significant ME effect at a relatively high coupling temperature (Liu et al., 2019).

\section{$\mathrm{BiFeO}_{3}(\mathrm{BFO})$ powders}

BFO and the three duals doped BFO such as $\mathrm{Bi}_{0.95} \mathrm{Er}_{0.05} \mathrm{Fe}_{0.98} \mathrm{TM}_{0.02} \mathrm{O}_{3}(\mathrm{TM}=\mathrm{Nb}$, $\mathrm{Mn}$ and Mo) can be synthesized using the sol-gel method. $\mathrm{BiFeO}_{3}$, $\mathrm{Bi}_{0.95} \mathrm{Er}_{0.05} \mathrm{Fe}_{0.98} \mathrm{Nb}_{0.02} \mathrm{O}_{3}, \quad \mathrm{Bi}_{0.95} \mathrm{Er}_{0.05} \mathrm{Fe}_{0.98} \mathrm{Mn}_{0.02} \mathrm{O}_{3}$ and $\mathrm{Bi}_{0.95} \mathrm{Er}_{0.05} \mathrm{Fe}_{0.98} \mathrm{Mo}_{0.02} \mathrm{O}_{3}$ are denoted as $\mathrm{BFO}, \mathrm{BEFNO}, \mathrm{BEFMO}$ and $\mathrm{BEFMoO}$ respectively. Analytical grade $\mathrm{Bi}$ $\left(\mathrm{NO}_{3}\right)_{3} \cdot 5 \mathrm{H}_{2} \mathrm{O}, \mathrm{Fe}\left(\mathrm{NO}_{3}\right)_{3} \cdot 9 \mathrm{H}_{2} \mathrm{O}, \mathrm{Er}\left(\mathrm{NO}_{3}\right)_{3} \cdot \mathrm{H}_{2} \mathrm{O}, \mathrm{Nb}_{2} \mathrm{O}_{5}, \mathrm{Mn}\left(\mathrm{NO}_{3}\right)_{2} \cdot \mathrm{H}_{2} \mathrm{O}, \mathrm{MoO}$, anhydrous citric acid and nitric acid are used as starting materials. The starting materials need to be mixed in the required composition in distilled water and the solution stirred at $400 \mathrm{rpm}$ until homogenization is reached. Then, the mixture is heated at $80^{\circ} \mathrm{C}$ on a hot plate under continuous stirring until the gel is formed. The gel is then converted into 
powders by auto-combustion, which is then grounded and annealed at $600^{\circ} \mathrm{C}$ for 12 hours. Pellets of $8 \mathrm{~mm}$ are prepared from the annealed powders by a Hydraulic Pellet Press under six tons pressure and then sintered at $800^{\circ} \mathrm{C}$ for 12 hours (Divya Lakshmi and Shameem Banu, 2019).

BFO presents a remnant magnetization of 0.004 emu. $\mathrm{g}^{-1}$, a saturation magnetization of 0.034 emu. $\mathrm{g}^{-1}$ and a coercivity of 200 Oe while BEFNO presents a remanence of $0.093 \mathrm{emu} . \mathrm{g}^{-1}$, a saturation of $0.308 \mathrm{emu} . \mathrm{g}^{-1}$ and a coercive field of 449.07 Oe (Divya Lakshmi and Shameem Banu, 2019).

The $(\mathrm{Er}, \mathrm{Nb})$ doped $\mathrm{BiFeO}_{3}$ yields enhanced ferroelectric response with the maximum polarization value of $0.46 \mu \mathrm{C} / \mathrm{cm}^{2}$, maximum $\mathrm{ME}$ coupling of $0.22 \mathrm{mV} \mathrm{cm}-$ ${ }^{1} . \mathrm{Oe}^{-1}$ at a magnetic field of $130 \mathrm{Oe}$, an improved magnetization with a remanence value of 0.0903 emu.g ${ }^{-1}$ and the lowest leakage current density (Divya Lakshmi and Shameem Banu, 2019).

\section{$\mathrm{Bi}_{4} \mathrm{SmFeTi}_{3} \mathrm{O}_{15}$ (BSFTO) films}

BSFTO thin films are traditionally coated on (111) $\mathrm{Pt} / \mathrm{Ti} / \mathrm{SiO} 2 / \mathrm{Si}$ substrates using sol-gel processes. The high-purity bismuth nitrate $(\mathrm{Bi}(\mathrm{NO} 3) 3 \cdot 5 \mathrm{H} 2 \mathrm{O} 98 \%)$, samarium oxide (Sm2O3 99.9\%), iron acetylacetonate $(\mathrm{C} 15 \mathrm{H} 21 \mathrm{FeO} 698 \%)$ and titanium n-butoxide $\mathrm{Ti}(\mathrm{C} 4 \mathrm{H} 9 \mathrm{O} 4)(99 \%)$ are the main materials for the precursor solution. Due to the $\mathrm{Bi}$ element being extremely volatile during the subsequent heat treatment, $\mathrm{Bi}(\mathrm{NO} 3) 3 \cdot 5 \mathrm{H} 2 \mathrm{O}$ is excessively $4 \mathrm{wt} . \%$ used. After weighing the raw materials, dissolving $\mathrm{Bi}(\mathrm{NO} 3) 3 \cdot 5 \mathrm{H} 2 \mathrm{O}$ in acetic acid $(\mathrm{CH} 3 \mathrm{COOH})$ and $\mathrm{Sm} 2 \mathrm{O} 3$ in nitric acid $(\mathrm{HNO} 3)$ using a magnetic stirrer, then the titanium n-butoxide $(\mathrm{Ti}(\mathrm{C} 4 \mathrm{H} 9 \mathrm{O} 4))$ solution and iron acetylacetonate $(\mathrm{C} 15 \mathrm{H} 21 \mathrm{FeO})$ are slowly added to the mixed precursor solution. The solution needs to be further stirred at room temperature for $5 \mathrm{~h}$. The stability of the solution can be adjusted 
by using n-propanol $(\mathrm{CH} 3 \mathrm{CH} 2 \mathrm{CH} 2 \mathrm{OH})$ and acetylacetone $(\mathrm{CH} 3 \mathrm{COCH} 2 \mathrm{COCH} 3)$ as a stabilizer. Finally, the total metal ion concentrations are controlled to be $0.1 \mathrm{~mol} / \mathrm{L}$ by adding proper amount of $\mathrm{CH} 3 \mathrm{COOH}$. The precursor solution can be dropped on the substrate and spin-coated at $3600 \mathrm{rpm}$ for $30 \mathrm{~s}$ with viscosity $7500 \mathrm{cps}$. Subsequently, the spin-coated wet gel thin films are placed in a rapid annealing furnace, dried at $200{ }^{\circ} \mathrm{C}$ for $180 \mathrm{~s}$, pyrolyzed at $450{ }^{\circ} \mathrm{C}$ for $240 \mathrm{~s}$, rapidly annealed at $950{ }^{\circ} \mathrm{C}$ for $480 \mathrm{~s}$ in flowing $\mathrm{O} 2$ (heating rate of $50{ }^{\circ} \mathrm{C} / \mathrm{s}$ ). The above procedure should be repeated six times to obtain a thickness of about $350 \mathrm{~nm}$ (Luo et al., 2019). At room temperature, the coercive field and the saturation magnetization are 120 Oe and 0.43 emu.cm-3, respectively (Luo et al., 2019).

A ME voltage coefficient of $41.16 \mathrm{mV} \mathrm{cm}-1.0 e-1$ at $0.9 \mathrm{~T}$ was reported from the electric field induced under an ac magnetic field of 1 Oe (generated by Helmholtz coils) superimposed onto a dc magnetic bias (generated by an electromagnet) in this material (Luo et al., 2019).

\section{$\mathrm{Bi}_{5} \mathrm{Ti}_{3} \mathrm{FeO}_{15}$ (BTFO) films}

BTFO can be deposited using pulsed laser deposition (PLD) on $\mathrm{Pt} / \mathrm{Ti} / \mathrm{SiO}_{2} / \mathrm{Si}$ substrates. BTFO targets are usually 5-10\% Bi-enriched sintered ceramics. The growth takes place at the temperature of $520{ }^{\circ} \mathrm{C}$ and under an oxygen pressure of 120 mTorr. The obtained thin film was $\approx 400 \mathrm{~nm}$ in thickness (Zhao et al., 2014). The magnetic properties of the BTFO film indicate weak ferromagnetism at room temperature, observed in the saturated M-H loop with a saturated magnetic moment of $\approx 8$ emu.cm ${ }^{-3}$ (Zhao et al., 2014). The ME effect on BTFO films can be observed by a measurement setup, composed by external magnet ac magnetic field of a 5 Oe at a frequency from DC to $100 \mathrm{kHz}$. The induced ME 
voltage across the sample thickness can be measured by a lock-in amplifier at the same frequency.

Zhao el al. (Zhao et al., 2014) reported that the background voltage noise due to the Faraday's Law has been successfully reduced by a careful design of the voltage detecting circuit with twisting and electric field shielding. The AC magnetic field was applied parallel to the direction of the induced ME voltage. The room temperature ME coefficient, determined through direct measurement of the magnetic field induced electric voltage in the thin film, showed a value of $\approx 400 \mathrm{mV} \mathrm{cm}{ }^{-1} . \mathrm{Oe}^{-1}$ at $\mathrm{H}=0$ (Zhao et al., 2014).

\subsection{Particulated composites}

\subsubsection{AIN/FeCoBSi}

Aluminum nitride $(\mathrm{AlN})$ and amorphous $\left(\mathrm{Fe}_{90} \mathrm{Co}_{10}\right)_{78} \mathrm{Si}_{12} \mathrm{~B}_{10}$ layers can be produced by magnetron sputtering on $\mathrm{Si}(100)$ substrates. Aluminum nitride and a ferromagnetic metallic glass alloy $\left[\left(\mathrm{Fe}_{90} \mathrm{Co}_{10}\right)_{78} \mathrm{Si}_{12} \mathrm{~B}_{10}\right]$ have been prepared by magnetron sputter deposition. A $300 \mathrm{~nm}$ Mo film was deposited on a (100)-oriented Si substrate, then the piezoelectric, $1800 \mathrm{~nm}$ thick AlN layer was deposited by reactive sputtering. As a masking layer a $500 \mathrm{~nm}$ thick silicon nitride $\left(\mathrm{Si}_{3} \mathrm{~N}_{4}\right)$ film was deposited by plasma enhanced chemical vapor deposition. Reactive ion etching (RIE) with $\mathrm{SF}_{6} / \mathrm{Ar}$ and wet chemical etching with $85 \%$ phosphoric acid at $80{ }^{\circ} \mathrm{C}$ was used for a part of the $\mathrm{Si}_{3} \mathrm{~N}_{4}$ and AlN films, respectively, to expose the Mo bottom electrode. After removing the rest of the $\mathrm{Si}_{3} \mathrm{~N}_{4}$ film a $20 \mathrm{~nm}$ thick $\mathrm{Cr}$ adhesion layer was deposited and then the magnetostrictive layer with a thickness of $1750 \mathrm{~nm}$. During deposition of the magnetostrictive layer a bias field of 100 Oe was applied in the film plane to induce an in-plane anisotropy. The samples were thinned to about $140 \mu \mathrm{m}$ thickness by RIE and were cut with a dicing saw into $20 \times 2 \mathrm{~mm}$ cantilevers. The measured ME coefficients 
(Figure 14) of $737 \mathrm{~V} \mathrm{~cm}^{-1}$.Oe-in resonance at $753 \mathrm{~Hz}$ and of $3.1 \mathrm{~V}^{-\mathrm{cm}^{-1}} . \mathrm{Oe}^{-1}$ at $100 \mathrm{~Hz}$ represent by far the highest values obtained in thin film composites (Greve et al., 2010).

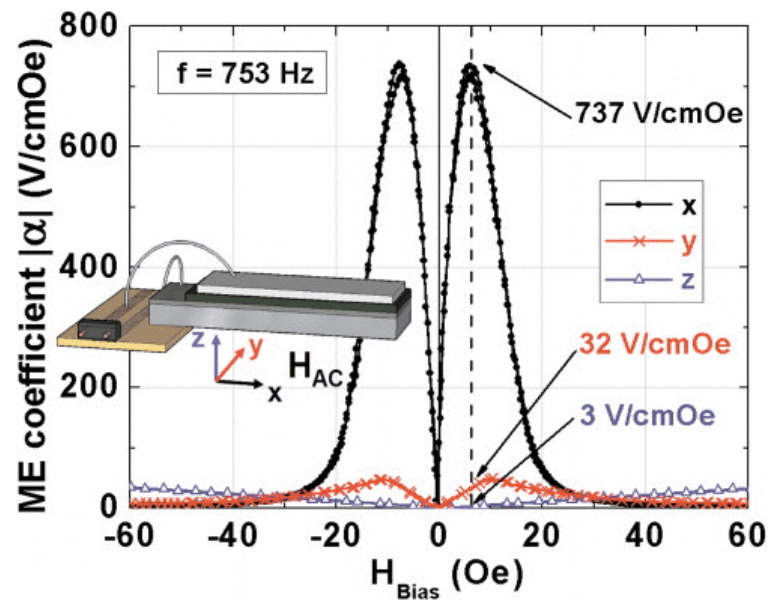

Figure 14. Absolute value of the ME coefficient $\alpha$ of a cantilever with a $1.75 \mu \mathrm{m} \mathrm{FeCoBSi}$ and $1.8 \mu \mathrm{m}$ AlN film at the resonance frequency of $753 \mathrm{~Hz}$. The ME signal was determined with HAC applied in all three dimensions and shows a clear anisotropy. The maximum ME coefficient of $737 \mathrm{~V} / \mathrm{cm}$ Oe is achieved in parallel orientation. Reproduced with permission from (Greve et al., 2010).

\subsubsection{P(VDF-TrFE) /CFO by spray printing}

In order to obtain a spray-printed ME sensor (Figure 15) a selected amount of CFO ferrite (20 wt.\%) was added to the solvent (DMF - $10 \mathrm{~mL}$ ) and positioned in ultrasounds for $8 \mathrm{~h}$ to ensure good magnetic dispersion. Then $2 \mathrm{~g}$ of $\mathrm{P}(\mathrm{VDF}-\mathrm{TrFE})$ were added and a $\mathrm{CoFe}_{2} \mathrm{O}_{4} / \mathrm{P}(\mathrm{VDF}-\mathrm{TrFE}) / \mathrm{DMF}$-based ink was obtained. Flexible films were obtained by spray-printing the $\mathrm{CoFe}_{2} \mathrm{O}_{4} / \mathrm{P}(\mathrm{VDF}-\mathrm{TrFE}) / \mathrm{DMF}$ ink, using a commercial airbrush, at $10 \mathrm{~cm}$ of the glass substrate using a pressure of 3 psi. Solvent evaporation was performed inside an oven at a controlled temperature of $210{ }^{\circ} \mathrm{C}$ for $10 \mathrm{~min}$. At the end of the process, $\approx 50 \mu \mathrm{m}$ thick films were removed from the oven and allowed to cool at room temperature (Martins et al., 2020). 
The $\mathrm{CoFe}_{2} \mathrm{O}_{4} / \mathrm{P}(\mathrm{VDF}-\mathrm{TrFE})$ printed film shows good mechanical stability with the typical thermoplastic behavior of pristine $\mathrm{P}(\mathrm{VDF}-\mathrm{TrFE})$ polymer.

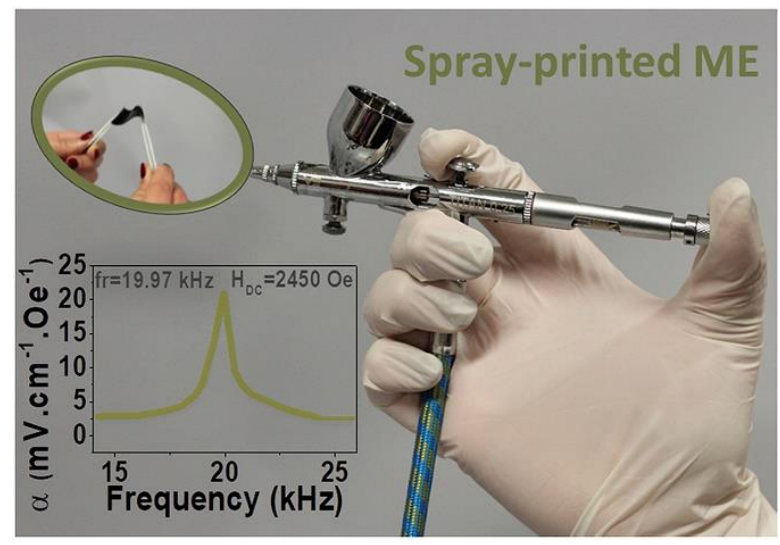

Figure 15. Stray-printed ME composite. Reproduced with permission from (Martins et al., 2020). The spray-printed $\mathrm{P}(\mathrm{VDF}-\mathrm{TrFE}) / \mathrm{CoFe}_{2} \mathrm{O}_{4}$ exhibited room-temperature ferromagnetism with a saturation magnetization of $11.2 \mathrm{emu} . \mathrm{g}^{-1}, 6.0 \mathrm{emu} . \mathrm{g}^{-1}$ remanence and coercivity of 2050 Oe. The magnetic saturation occurs at $\approx 7 \mathrm{~T}$ (Martins et al., 2020). A ME voltage coefficient of $\approx 21.2 \mathrm{mV} \mathrm{cm}^{-1} \mathrm{Oe}^{-1}$ at an optimum magnetic field of $\approx 2450$ Oe under a applied ac magnetic field of $1 \mathrm{Oe}$ at $20 \mathrm{kHz}$, which is suitable for sensor/actuator applications was obtained (Martins et al., 2020).

\subsubsection{P(VDF-TrFE) /ferrites}

Magnetostrictive $\mathrm{Zn}_{0.2} \mathrm{Mn}_{0.8} \mathrm{Fe}_{2} \mathrm{O}_{4}$ (ZMFO), $\mathrm{CoFe}_{2} \mathrm{O}_{4}$ (CFO) and $\mathrm{Fe}_{3} \mathrm{O}_{4}$ (FO) ferrite nanoparticles were synthesized using a hydrothermal method. $14 \mathrm{mmol}$ of $\mathrm{Fe}^{3+}$ precursor and $8 \mathrm{mmol}$ of $\mathrm{M}^{2+}$ precursor $(\mathrm{M}=\mathrm{Zn} / \mathrm{Mn}, \mathrm{Co}, \mathrm{Fe})$ were dissolved in $10 \mathrm{~mL}$ of ultrapure water. A solution containing $0.5 \mathrm{~g}$ of sodium oleate dissolved in $10 \mathrm{~mL}$ of water was slowly added, following by a fast addition of $15 \mathrm{~mL}$ of concentrated ammonia solution. The hydrothermal treatment was performed at $200{ }^{\circ} \mathrm{C}$ for 1 day. The product of the treatment was collected by decantation, thoroughly washed with water and dried overnight at room temperature under reduced pressure $(\approx 0.08 \mathrm{MPa})$. The resulting dry 
powder was re-dispersed in cyclohexane and centrifuged at $3000 \mathrm{rpm}$ for $10 \mathrm{~min}$. Two products were obtained: a colloidal solution of small ferrite nanoparticles and precipitated large ferrite nanoparticles. The centrifuged precipitate was dried at room temperature under reduced pressure and, finally, was homogenized in an agate mortar using a pestle (Martins et al., 2015). The desired amount of the magnetostrictive phase (ZMFO, CFO and FO) was added into DMF and placed in an ultrasound bath for $8 \mathrm{~h}$ in order to ensure a good dispersion of the nanoparticles. $\mathrm{P}(\mathrm{VDF}-\mathrm{TrFE})$ polymer was then added and mixed during 2 hours with the help of a mechanical Teflon stirrer in an ultrasound bath to avoid magnetic agglomeration during the mixing process. After that, the solution was spread on a clean glass substrate and solvent evaporation/samples crystallization was performed inside an oven at $210{ }^{\circ} \mathrm{C}$ for $10 \mathrm{~min}$. Polymer crystallization was obtained by cooling down films to room temperature. At the end of the process, the $\approx 50 \mu \mathrm{m}$ thick films were peeled from the glass substrate. Flexible ME composite films were thus prepared with 10 wt.\% of nanoparticles since obtaining films with good ME coupling and flexibility is expected with such a ferrite content. Additionally ZMFO/P(VDF-TrFE) composite films with 20 and 50 wt.\% ferrite content were also prepared in order to evaluate the effect of the nanoparticle content in the piezoelectric, magnetic and ME response of the these composites (Martins et al., 2015). Composite films with $10 \mathrm{wt} . \%$ of ferrite content showed that the ME coefficient increases with increasing DC magnetic field until a maximum of $6.5 \mathrm{mV} \cdot \mathrm{cm}^{-1} \cdot \mathrm{Oe}^{-1}$ and $0.8 \mathrm{mV} \cdot \mathrm{cm}^{-1} \cdot \mathrm{Oe}^{-1}$ (at an optimum magnetic field of $0.26 \mathrm{~T}$ ) for the CFO/P(VDF-TrFE) and FO/P(VDF-TrFE) composites, respectively (Martins et al., 2015). On the contrary, the ME response of the ZMFO/P(VDF-TrFE) exposed no hysteresis with a ME coefficient of $\approx 0.04 \mathrm{mV} \cdot \mathrm{cm}^{-1} \cdot \mathrm{Oe}^{-1}$ at $0.5 \mathrm{~T}$. 


\subsection{Laminated composites}

\section{PZT/Metglas-film}

PZT/Metglas films were produced with a combination of room temperature deposition (GSV, Granule Spray in Vacuum) and localized annealing of PZT thick films by laser radiation. Using GSV for fabrication of dense (relative density of over 96\%) polycrystalline ceramic thick films with a relatively high deposition rate (over $1 \mu \mathrm{m} / \mathrm{min}$ depending on the deposition area) were obtained at room temperature. Laser annealing is a localized phenomenon and laser radiation can be used effectively for annealing of ferroelectric films through its selective absorption in the film (Figure 16). Thanks to the greatly enhanced properties of laser annealed PZT films by crystallinity improvement and grain growth together with the unaltered magnetic properties of Metglas, the fabricated composite exhibited a voltage coefficient as high as $\approx 3 \mathrm{~V} \cdot \mathrm{cm}^{-1} \cdot \mathrm{Oe}^{-1}$. This value is two orders higher than the output reported for PZT/Metglas film-composites prepared by other methods (Palneedi et al., 2015). 


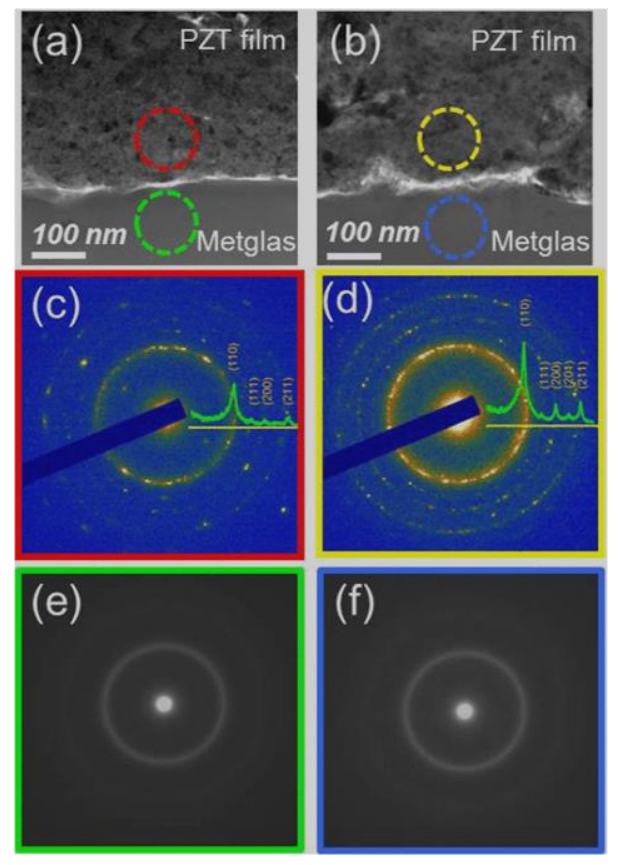

Figure 16. TEM images of the as-deposited and laser annealed samples a) and b)), respectively. SAED patterns of c) and d)) PZT film and e) and f) Metglas recorded near PZT/Metglas interfaces circled in the cross-sectional. Reproduced with permission from (Palneedi et al., 2015).

The PZT film was deposited on $25 \mu \mathrm{m}$ thick Metglas foil (2605SA1, Metglas, Inc., USA) by GSV using commercially available PZT granules ( $\mathrm{d}_{50}$ of granule $\sim 100 \mu \mathrm{m}, \mathrm{JA}-$ 1, JK Precision Electric, Korea). This PZT material exhibits high voltage coefficient $\mathrm{g}_{\mathrm{ij}}$ $\left(\approx 50 \mathrm{mVm} / \mathrm{N}\right.$ ), and electro-mechanical coupling factor $k_{\mathrm{ij}}$. The PZT granules were mixed with a carrier gas using a granule feeding system, ejected through a nozzle and bombarded onto a moving substrate in a vacuum chamber. Laser annealing of the deposited film was carried out using a continuous wave $(\mathrm{CW}), 560 \mathrm{~nm}$, frequency doubled, Ytterbium $(\mathrm{Yb})$ fiber laser attached with a wet aerosol jet deposition system. The sample placed on a computer controlled X-Y linear stage was annealed by the laser beam by fixing the laser power and the sample scanning speed at $220 \mathrm{~mW}$ and $0.05 \mathrm{~mm} / \mathrm{s}$, respectively (Palneedi et al., 2015). 
The change in ME voltage coefficient as a function of DC magnetic field at an offresonance frequency of $1 \mathrm{kHz}$. A maximum ME coefficient of $2.96 \mathrm{~V} . \mathrm{cm}^{-1}$.Oe was recorded at a low bias field of $H_{D C}=53$ Oe (Palneedi et al., 2015).

\section{P(VDF-TrFE)/CFO film by screen printing}

Screen printing $\mathrm{P}(\mathrm{VDF}-\mathrm{TrFE})$ ink was developed by adding $4 \mathrm{~g}$ of the polymer powder to $10 \mathrm{~mL}$ of $\mathrm{DMF}$. The mixture was magnetically stirred during 2 hours at room temperature $\left(\approx 25^{\circ} \mathrm{C}\right)$ until complete dissolution of the polymer. A layer of silver ink (Novacentrix HPS-021LV, top electrode: 0.8 Pa s viscosity) was screen printed using a polyester mesh with 64 wires on a Teflon flexible substrate. The resulting layer was placed in an oven at $80{ }^{\circ} \mathrm{C}$ for one hour. The $\mathrm{P}(\mathrm{VDF}-\mathrm{TrFE})$ ink was screen printed using a polyester mesh with 64 wires on the previous laminate. The resulting laminate was placed in an oven at $210{ }^{\circ} \mathrm{C}$ for 10 minutes. After cured in an oven at $210{ }^{\circ} \mathrm{C}$ for 10 minutes another layer of silver ink was screen printed using a polyester mesh with 64 wires and cured at $80{ }^{\circ} \mathrm{C}$ for one hour (Lima et al., 2019).

A PVDF/CFO magnetostrictive ink was obtained by adding $11.3 \mathrm{~g}$ of CFO in $9 \mathrm{~mL}$ of DMF. $2 \mathrm{~g}$ of PVDF polymer were then added to the former mixture as a binder and mechanically stirred during 2 hours at room temperature with a Teflon stirrer. After solvent evaporation, the CFO content on the PVDF matrix will be $85 \%$ in weight percentage (wt\%). Such content was selected in order to obtain a high magnetostrictive layer (Lima et al., 2019). The full screen-printing process is presented in Figure 17. 


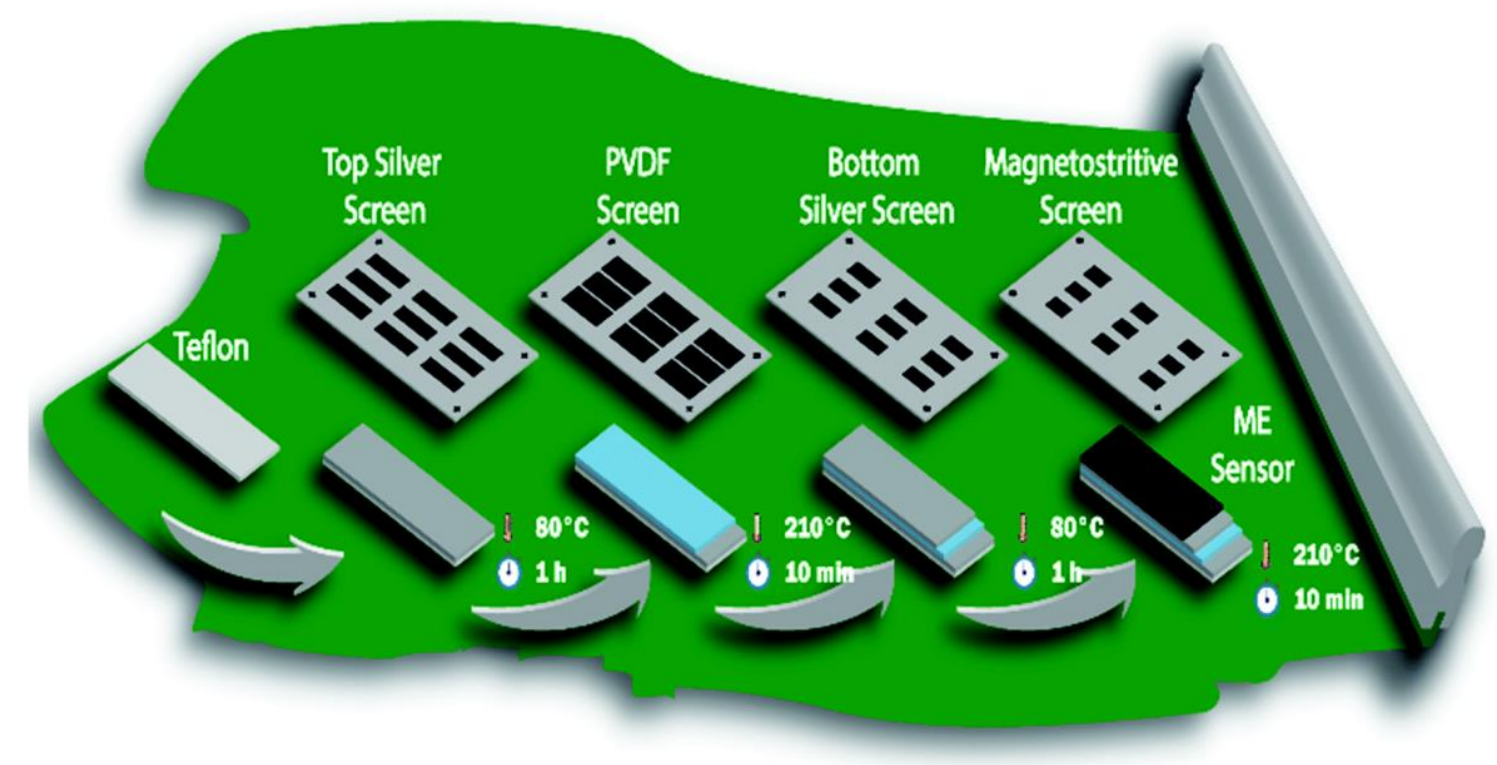

Figure 17. Schematic representation of the experimental procedure used to obtain the hybrid ME layered composite. Reproduced with permission from (Lima et al., 2019).

The PVDF-CFO magnetostrictive ink was screen printed using a polyester mesh with 64 wires on the laminate of step. The resulting laminate was placed on an oven at $210{ }^{\circ} \mathrm{C}$ for one hour (Lima et al., 2019).

The transversal poling of the piezoelectric layer was achieved with 60 min of corona poling at $120{ }^{\circ} \mathrm{C}$ in a home-made chamber. The electric field was kept applied when the samples were cooled to room temperature. The composite sample was magnetized along the length direction for 60 minutes at 3000 Oe DC magnetic field (Lima et al., 2019).

The resonance frequency of the composite was found to be $16.2 \mathrm{kHz}$ on the longitudinal direction and $32.1 \mathrm{kHz}$ on the transversal direction. The ME voltage response as a function of the DC field is highly dependent on the direction of the applied magnetic field, reaching a maximum response of $164 \mathrm{mV} \mathrm{cm}{ }^{-1} . \mathrm{Oe}^{-1}$ at $260 \mathrm{mT}$ and $83 \mathrm{mV} \cdot \mathrm{cm}^{-1} . \mathrm{Oe}^{-1}$ at $405 \mathrm{mT}$ for the sample characterized longitudinally and transversely (Lima et al., 2019). 


\section{PVDF/Metglas by partial screen printing}

The ME PVDF/Metglas laminate composite to be used as magnetic sensor was designed with an overall dimension of $30 \times 6 \times 0.052 \mathrm{~mm}$ and consists of three layers: flexible Metglas, PVDF and Ag. PVDF ink was screen printed, as the piezoelectric layer, on the Metglas substrate followed by curing at $130^{\circ} \mathrm{C}$ for 5 hours. Then, Ag ink was bar coated on the printed PVDF layer as top electrode and cured at $120^{\circ} \mathrm{C}$ for 20 minutes. The printed PVDF layer was poled by applying an electric field of $80 \mathrm{~V} / \mu \mathrm{m}$ for 2 hours. The total thickness of the PVDF layer and Metglas substrate was measured to be 28.06 $\mu \mathrm{m}$ (Chlaihawi et al., 2016).

An electromechanical resonance of $50 \mathrm{kHz}$, with a maximum voltage of $21.1 \mathrm{mV}$, was obtained for the induced voltage-frequency dependence measurements. A linear

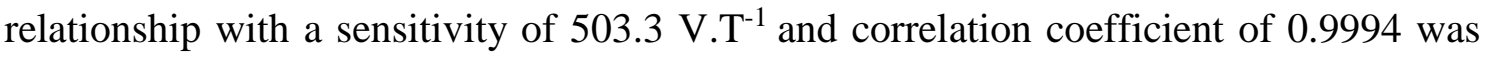
also obtained towards varying AC magnetic fields $\left(1 \times 10^{-7}<\mathrm{H}_{\mathrm{AC}}<1 \times 10^{-4} \mathrm{~T}\right)$. In addition, an ME voltage coefficient of $685.99 \mathrm{~V} \cdot \mathrm{cm}^{-1} \mathrm{Oe}^{-1}$ (Chlaihawi et al., 2016).

\section{PVDF/Metglas by direct bonding}

Another PVDF/Metglas ME laminate to be used as a sensor was fabricated with a commercial $\beta$-PVDF (Measurement Specialties, Hampton, VA, USA) layer with dimensions of $10 \mathrm{~mm} \times 30 \mathrm{~mm} \times 52 \mu \mathrm{m}$, poled along the thickness direction and a magnetostrictive layer of Metglas with dimensions of $5 \mathrm{~mm} \times 27 \mathrm{~mm} \times 25 \mu \mathrm{m}$, and magnetized along the longitudinal direction. The polymer-based laminate was produced by bonding the PVDF and Metglas layers with M-Bond 600 epoxy in a vacuum process for three hours at $50{ }^{\circ} \mathrm{C}$, electromechanical resonant frequency of $25.4 \mathrm{kHz}$ (Reis et al., 2017). 
The ME response increases with increasing $\mathrm{H}_{\mathrm{DC}}$ up to $\approx 2 \mathrm{Oe}$, at which the maximum $\mathrm{ME}$ voltage is reached $\left(112 \mathrm{mV}\right.$ : ME coefficient $\left.\alpha_{33}=30 \mathrm{~V} \cdot \mathrm{cm}^{-1} \cdot \mathrm{Oe}^{-1}\right)$. Such increase is related with the increase in the piezomagnetic coefficient up to the optimum 2 Oe DC magnetic field. With a further increase of the DC magnetic field, a decrease in the induced ME voltage will occur, resulting from the saturation of the magnetostriction response (Reis et al., 2017)

\section{P(VDF-HFP) /Metglas}

Regarding the development of $\mathrm{P}(\mathrm{VDF}-\mathrm{HFP})$ /Metglas laminate composite, a standard extrusion-blown process was used to fabricate films for the copolymer. In this process, a one-inch Brabender single-screw extruder was employed to extrude the polymer film, whose temperature can be varied from $190^{\circ} \mathrm{C}$ to $250^{\circ} \mathrm{C}$ to get different film thicknesses. Crystalline copolymer was prepared using a hot-press process. In this method, the copolymer powders were first hot-pressed to films with $40-50 \mu \mathrm{m}$ in thickness at $220^{\circ} \mathrm{C}$, and then immediately quenched to liquid nitrogen to keep the low crystallinity for prospective uniaxial stretching (Lu et al., 2011).

The P(VDF-HFP) films were uniaxially stretched to four to six times their original lengths at about $100{ }^{\circ} \mathrm{C}$ in a narrow heating zone. The final film thickness ranged from 10 to 20 $\mu \mathrm{m}$ (Lu et al., 2011).

The Metglas ribbon used has a composition $\mathrm{B}_{\mathrm{x}} \mathrm{Fe}_{\mathrm{y}} \mathrm{Si}_{\mathrm{z}}(\mathrm{x}=1-5 \mathrm{wt} \%, \mathrm{y}=85-95$ $\mathrm{wt} \%, \mathrm{z}=5-10 \mathrm{wt} \%)$ and an amorphous structure obtained using a melt-quench method. The thickness of Metglas ribbon was $25 \mu \mathrm{m}$ (Lu et al., 2011). An Au electrode was sputtered on both surfaces of the polymer film and the film was glued with Metglas using non-conductive epoxy resin (5 min Epoxy, ITW Devcon, MA). 
Considering the magnetic flux concentration effect of Metglas due to its high permeability $\left(\mu_{\mathrm{r}}=45000\right)$, a rectangular shape of the piezoelectric polymer was designed in the way that its size was less than that of Metglas, and it was placed at the central area to get the largest magnetic flux concentration effect (Lu et al., 2011). The piezoelectricity of P(VDF-HFP) copolymer was established and enhanced by the electric poling. A DC electric field ranging from 100 to $300 \mathrm{MV} . \mathrm{m}^{-1}$ was applied for $300 \mathrm{~s}$ duration at room temperature. The magnetic field employed was $\approx 1$ Oe AC field superimposed on a DC magnetic field ranging from -40 to 40 Oe. The $\mathrm{P}(\mathrm{VDF}-\mathrm{HFP}) / \mathrm{Metglas}$ demonstrates a ME coupling coefficient of $12 \mathrm{~V} \cdot \mathrm{cm}^{-1} \mathrm{Oe}^{-1}$ (Figure 18).

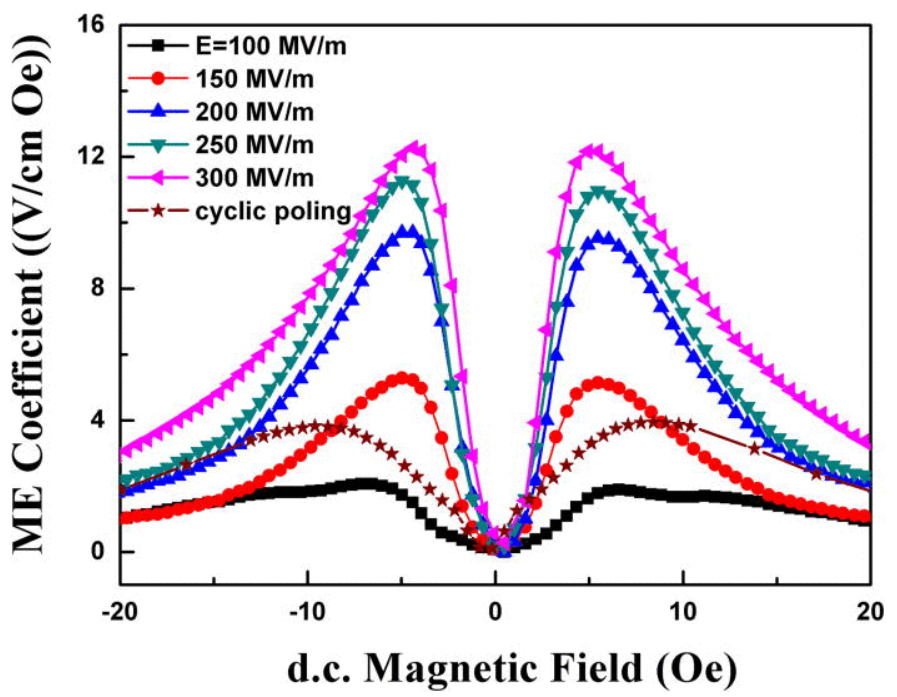

Figure 18. ME coefficient of hot-pressed $\mathrm{P}(\mathrm{VDF}-\mathrm{HFP}) /$ Metglas laminates as a function of d.c. magnetic field for conventional poling. The ME coefficient vs d.c. magnetic field for cyclic poling $(\mathrm{Ep}=225 \mathrm{~V} / \mathrm{m}$ for extruded film) is also shown. Reproduced with permission from (Lu et al., 2011).

\section{Magnetic materials for ME composites}

In this last section, the physical characteristics, the production/synthesis procedures, the type of magnetism, the magnetostriction coefficient and magnetic field range of applicability in ME applications of magnetic structures will be addressed. 


\section{$\underline{\mathrm{CoFe}_{2}} \underline{\mathrm{O}}_{4}$}

Cobalt ferrite, $\mathrm{CoFe}_{2} \mathrm{O}_{4}$, belongs to the inverse spinel ferrites where $\mathrm{Co}^{+2}$ ions occupy the octahedral sites of lattice structure and half of the $\mathrm{Fe}^{+3}$ cations occupy octahedral sites and the other half stay at the tetrahedral sites of a fcc lattice formed by the oxygen ions and is a well-known hard magnetic material with high coercivity, moderate magnetization, high Curie temperature and large magnetostrictive coefficient (Grössinger et al., 2014). These properties, along with its physical and chemical stability, make $\mathrm{CoFe}_{2} \mathrm{O}_{4}$ nanoparticles suitable for magnetic recording applications such as audio and videotape and high-density digital recording disks, , among others (Maaz et al., 2007).

Conventional techniques for preparation of nanoparticles include sol-gel processing (Omri et al., 2013) sometimes with auto combustion (Figure 19) (Maaz et al., 2007), hot spraying (Mingda et al., 2019), evaporation condensation (Martínez et al., 2005), matrix isolation(Sharma et al., 2016), laser-induced vapor phase reactions (Oyama, 1997) and aerosols (Kim et al., 2007). Generally, in most types of nanoparticles prepared by these methods, control of size and size distribution is difficult or even not possible.

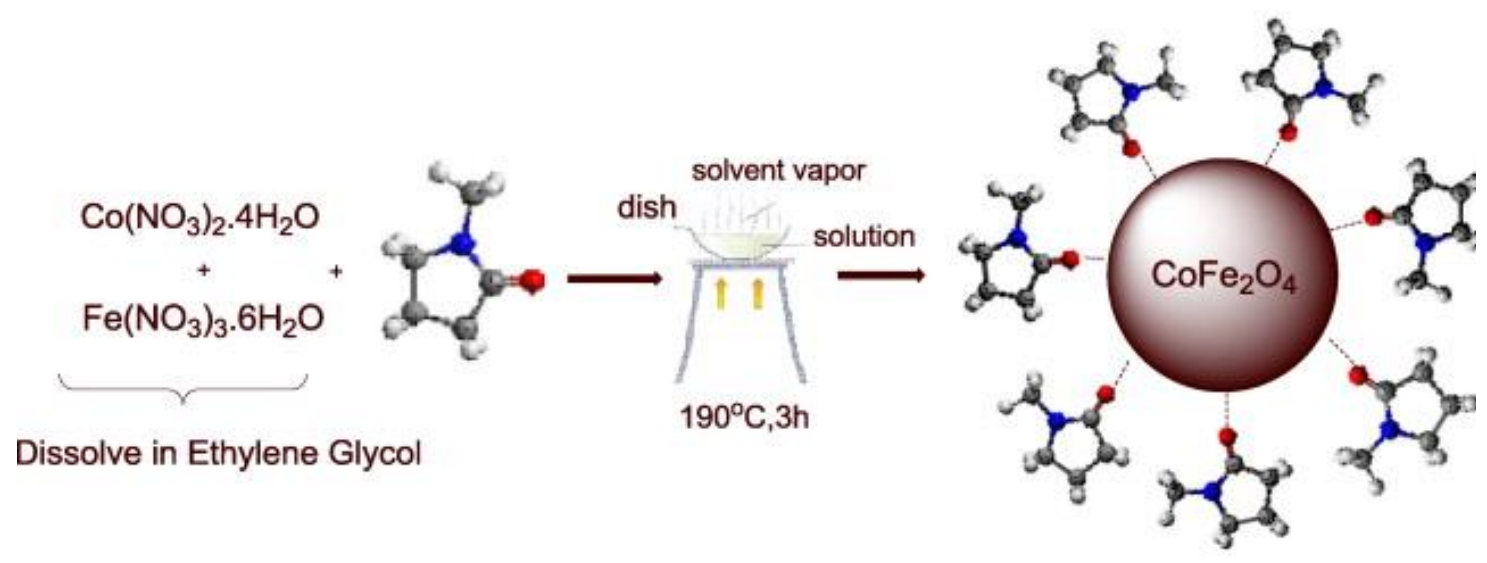

Figure 19. Schematic presentation of synthesis of the $\mathrm{CoFe}_{2} \mathrm{O}_{4}-1$-methyl-2-pyrrolidone particles. Reproduced with permission from (Maaz et al., 2007). 
In order to overcome these difficulties, nanometer size reactors for the formation of homogeneous nanoparticles of cobalt ferrite are used. To protect the oxidation of these nanoparticles from the atmospheric oxygen and also to prevent their agglomeration, the particles are coated and dispersed in some medium like sodium dodecyl sulfate (NaDS), oleic acid or -methyl-2-pyrrolidone (Maaz et al., 2007).

$\mathrm{CoFe}_{2} \mathrm{O}_{4}$ has magnetostriction up to $-400 \mathrm{ppm}$, ferromagnetism (10-90 emu.g ${ }^{-1}$ remanence and 600-2100 Oe coercivity), and magnetic field ME applicability range of $0-0.5 \mathrm{~T}$.

\section{$\underline{\mathrm{NiFe}_{2}} \underline{\mathrm{O}}_{4}$}

$\mathrm{NiFe}_{2} \mathrm{O}_{4}$ belongs to the inverse spinel ferrites where $\mathrm{Ni}^{+2}$ ions occupy the octahedral sites of lattice structure and half of the $\mathrm{Fe}^{+3}$ cations occupy octahedral sites and the other half stay at the tetrahedral sites of a fcc lattice formed by the oxygen ions and is a soft magnetic n-type semiconducting material that is traditionally prepared by the classical solid-state reaction that requires a number of stages, including homogenization of the powder precursors, compaction of the reactants, and finally prolonged heat treatment at considerably elevated temperatures (Ceylan et al., 2008). One goal of $\mathrm{NiFe}_{2} \mathrm{O}_{4}$ research and development has been to identify simpler processing schemes that do not rely upon high-temperature treatments for inducing solid-state reactions. As a result several techniques have already been used to produce $\mathrm{NiFe}_{2} \mathrm{O}_{4}$ nanostructures, including hydrothermal reactions (Figure 20) (Kesavan et al., 2020), coprecipitation(FaShen et al., 1988), combustion synthesis (Kooti and Sedeh, 2013), thermal decomposition (Karpova et al., 2012), sol-gel method (Pradeep et al., 2008), microwave processing (Köseoğlu, 2013), electrospinning (Saensuk et al., 2015), reverse micelle technique(Kale et al., 2004), plasma deposition method (Nawale et al., 2011), radio frequency thermal 
plasma torch technique (Son et al., 2002), pulsed wire discharge (Yatsui, 2002), sonochemical synthesis (Lu et al., 2006), and high-energy milling (Šepelák et al., 2007, Marinca et al., 2011). This last method can deliver nanocrystalline ferrites (and oxides in general) either by particle size reduction of bulk material to the nanometer scale without changes in its chemical composition or by inducing a heterogeneous solid-state chemical reaction between the ferrite precursors, i.e., by the mechanically induced formation reaction (mechanosynthesis) (Šepelák et al., 2007).

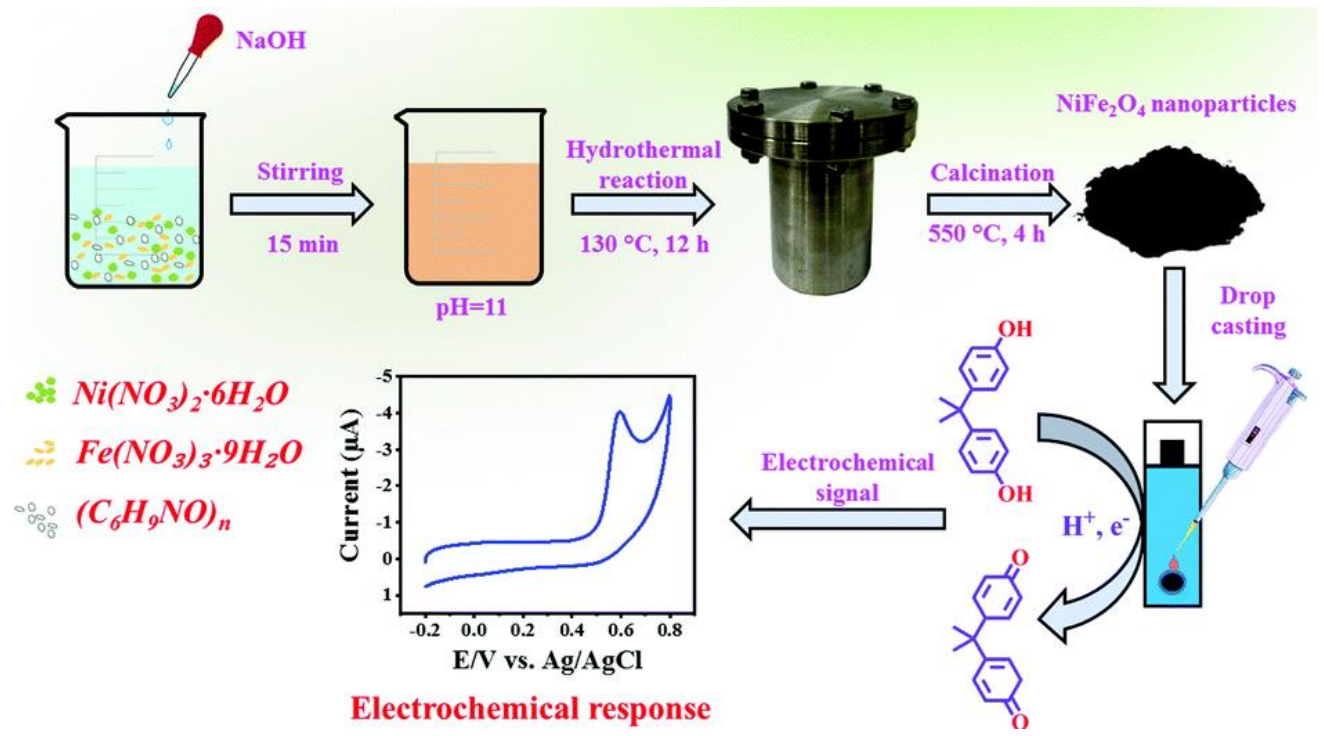

Figure 20. Schematic representation of the preparation of the nickel ferrite nanoparticles by hydrothermal synthesis that later are used on electrochemical detection of Bisphenol A. Due to their soft magnetic properties $\mathrm{NiFe}_{2} \mathrm{O}_{4}$ nanoparticles find application in magnetic resonance imaging, drug delivery, cancer therapies, sensors in electronics, telecommunications, highfrequency transformers and catalysts. Reproduced with permission from (Kesavan et al., 2020).

$\mathrm{NiFe}_{2} \mathrm{O}_{4}$ has magnetostriction up to $-50 \mathrm{ppm}$, ferromagnetism/superparamagnetism (0-20 emu. $\mathrm{g}^{-1}$ remanence and 0-150 Oe coercivity), and magnetic field ME applicability range of $0-0.4 \mathrm{~T}$. 


\section{$\underline{\mathrm{MnFe}_{2}} \underline{\mathrm{O}}_{4}$}

$\mathrm{MnFe}_{2} \mathrm{O}_{4}$ belongs to the inverse spinel ferrites where $\mathrm{Mn}^{+2}$ ions occupy the octahedral sites of lattice structure and half of the $\mathrm{Fe}^{+3}$ cations occupy octahedral sites and the other half stay at the tetrahedral sites of a fcc lattice formed by the oxygen ions and is a wellknown soft ferrite which has been used in various technological applications such as magnetic materials, gas sensors, biomedical tools and absorbent material for hot gas, among others (Stoia et al., 2015). Several methods have been developed to synthesize $\mathrm{MnFe}_{2} \mathrm{O}_{4}$ nanoparticles (Mishra et al., 2006), such as solid-phase reactions, mechanical ball-milling (Chen et al., 2013), thermal decomposition (Gabal and Ata-Allah, 2004), hydrothermal method (Hou et al., 2010), coprecipitation (Amighian et al., 2006), combustion(Zhong et al., 2015), microemulsion (Scano et al., 2011) and sol-gel autocombustion (Figure 21) (Shafiu et al., 2013, Shanmugavel et al., 2014).

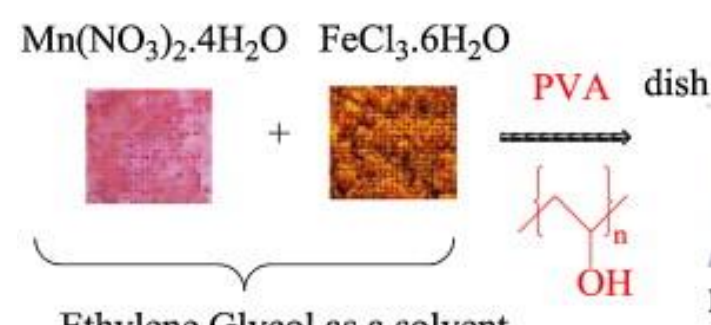

Ethylene Glycol as a solvent

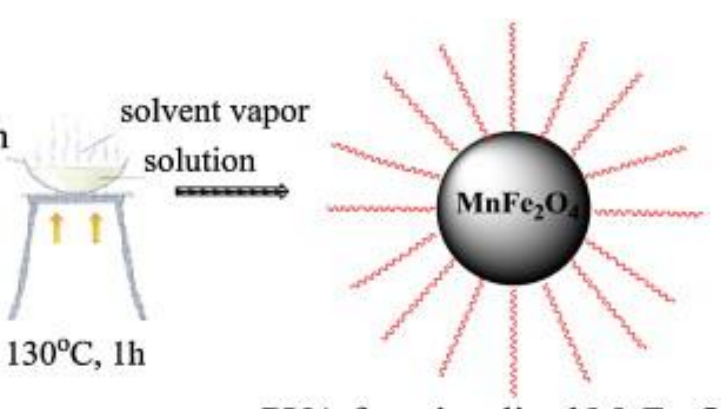

PVA functionalized $\mathrm{MnFe}_{2} \mathrm{O}_{4}$

Figure 21. Schematic representation of synthesis of $\mathrm{MnFe}_{2} \mathrm{O}_{4}$ functionalized with polyvinyl alcohol (PVA) to avoid nanoparticle agglomeration. Reproduced with permission from (Shafiu et al., 2013).

It was reported that at elevated temperatures, $\mathrm{MnFe}_{2} \mathrm{O}_{4}$ is unstable in air and $\mathrm{Mn}^{2+}$ ions on the surface oxidize to form $\mathrm{Mn}^{3+}$ ions resulting in the dissociation of the formed $\mathrm{MnFe}_{2} \mathrm{O}_{4}$. Thus, it was concluded that any preparation method involving a calcination step is not suitable for the preparation of manganese ferrite nanoparticles (Stoia et al., 
2015). $\mathrm{MnFe}_{2} \mathrm{O}_{4}$ has magnetostriction up to $-50 \mathrm{ppm}$, superparamagnetism (up to 70 emu.g ${ }^{-1}$ a magnetization saturation), and magnetic field ME applicability range of $0-0.4 \mathrm{~T}$.

\section{$\underline{\mathrm{Ni}_{0.5} \underline{\mathrm{Zn}}_{0.5} \underline{\mathrm{Fe}}_{2} \underline{\mathrm{O}_{4}}}$}

$\mathrm{Ni}_{0.5} \mathrm{Zn}_{0.5} \mathrm{Fe}_{2} \mathrm{O}_{4}$ belongs to the inverse spinel ferrites wherein tetrahedral (A) sites are occupied by $\mathrm{Fe}^{3+}$ and $\mathrm{Zn}^{2+}$ ions and octahedral [B] sites are occupied by $\mathrm{Fe}^{3+}$ and $\mathrm{Ni}^{2+}$ ions of a fcc lattice formed by the oxygen ions and is a well-known soft ferrimagnetic spinel ferrite which has large value of resistivity, permeability, moderate magnetization, low coercive field, small dielectric loss and good chemical stability (Atif, 2019).

Different synthesis methods such as sol-gel (Zhang et al., 2013), citrate gel method(Jiang et al., 2011), reverse microemulsion(Kumar et al., 2010), sonochemical method (Meskin et al., 2006), hydrothermal process (Meskin et al., 2006), co-precipitation (Thakur et al., 2016) and auto-combustion method (Wu et al., 2005) have been used to synthesize $\mathrm{Ni}_{0.5} \mathrm{Zn}_{0.5} \mathrm{Fe}_{2} \mathrm{O}_{4}$ nanoparticles. All these methods can fulfill the requirements of singlephase and single-domain nanoparticles production; however, to have cost effective route for the high-yield synthesis of nanoparticles for practical applications is still a concern (Atif, 2019). Regarding the sol-gel method there is a need to calcinate powders at the different temperatures to identify the lowest temperature, the condition in which the amorphous gel could be transferred to the crystalline phase (Figure 22). 


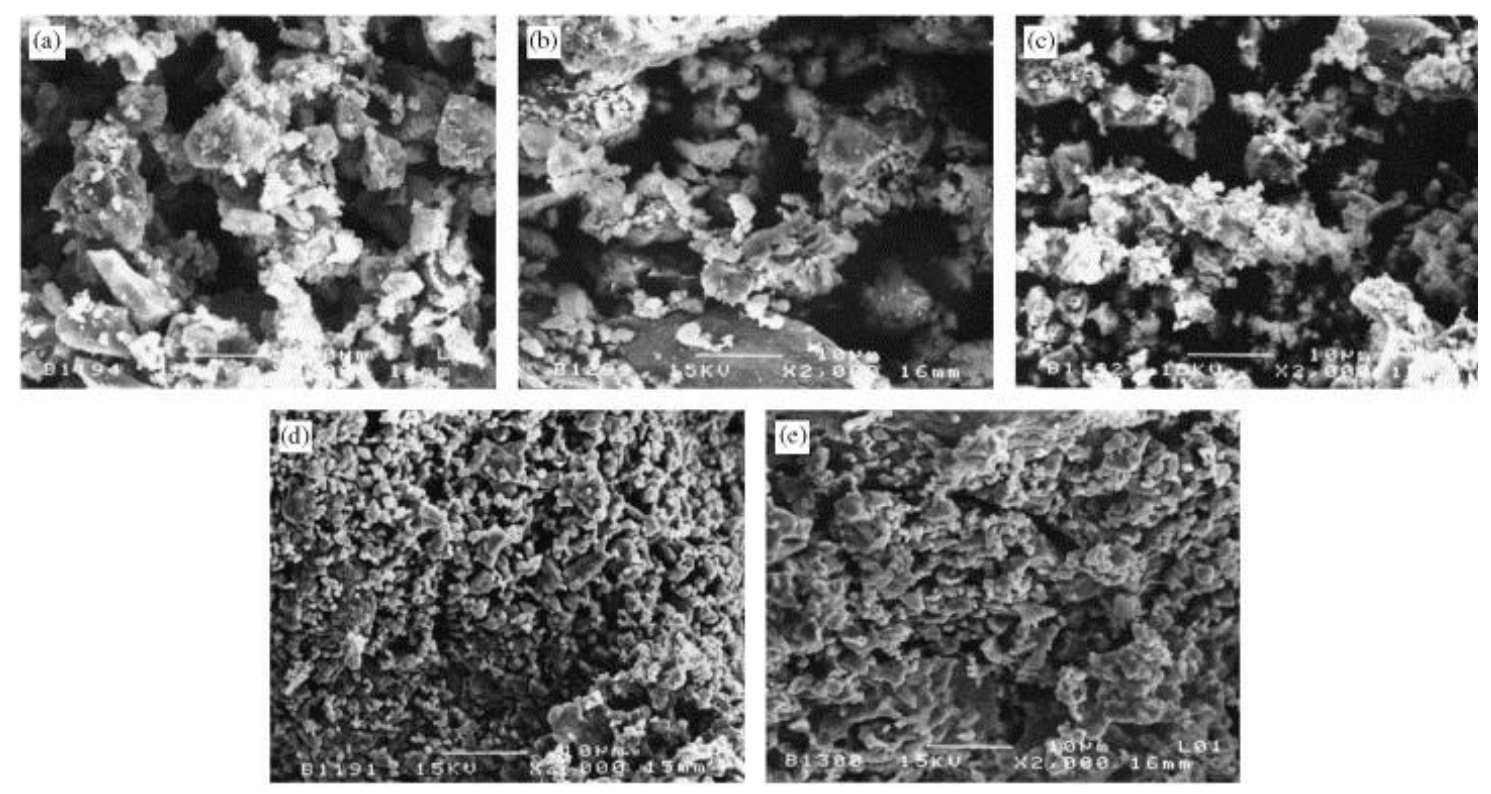

Figure 22. The morphology of sol-gel- $\mathrm{Ni}_{0.5} \mathrm{Zn}_{0.5} \mathrm{Fe}_{2} \mathrm{O}_{4}$ calcined at various temperatures: (b) 200, (c) 400, (d) 600, (e) $1000{ }^{\circ} \mathrm{C}$ and (a) gel in air. Reproduced with permission from (Zahi et al., 2007).

$\mathrm{Ni}_{0.5} \mathrm{Zn}_{0.5} \mathrm{Fe}_{2} \mathrm{O}_{4}$ has magnetostriction up to $14 \mathrm{ppm}$, superparamagnetism (up to $60 \mathrm{emu} . \mathrm{g}^{-}$

${ }^{1}$ a magnetization saturation), and magnetic field ME applicability range of $0-0.4 \mathrm{~T}$ (Atif, 2019, Kumar et al., 2010, Martins et al., 2015).

\section{$\underline{\text { Terfenol-D }}$}

Terfenol-D $\left(\mathrm{Tb}_{0.3} \mathrm{Dy}_{0.7} \mathrm{Fe}_{1.93}\right)$ is a highly magnetostrictive alloy of iron and the rare-earth elements, terbium and dysprosium. The name Terfenol stems from the composition of the alloy $\mathrm{TbFe}_{2}$ and its place of origin, the Naval Ordnance Laboratory (NOL) (now NSWC), where rare-earth magnetic materials development has been conducted over the past decades. The addition of dysprosium to the original formulation of Terfenol was found to lower the amplitude required of the magnetic field drive, and so it is Terfenol-D that has been the subject of recent transducer design studies (Moffett et al., 1991). The giant magnetostrictive material Terfenol-D offers the highest strain of any 
magnetostrictive material at room temperature using practical drive fields. The increasing use of Terfenol-D in a wide variety of devices and systems such as sensors, actuators and transducers has driven the development of advanced manufacturing techniques to provide greater levels of strain performance, repeatability, rod size and production capacity (Issindou et al., 2018, Snodgrass and McMasters, 1997). Such techniques include the free stand zone melting (FSZM)(Slaughter et al., 2004), modified bridgman (MB)(Moffett et al., 1991), sintered powder compact(Zhao et al., 2006), the ETREMA Crystal Growth (ECG) system(Snodgrass et al., 1997), plasma processes(Issindou et al., 2018) and molecular beam epitaxy(Oderno et al., 1996). In order to produce nanoparticles of Terfenol-D Laser Ablation of Microparticles (LAM) can be used (Figure 23). 


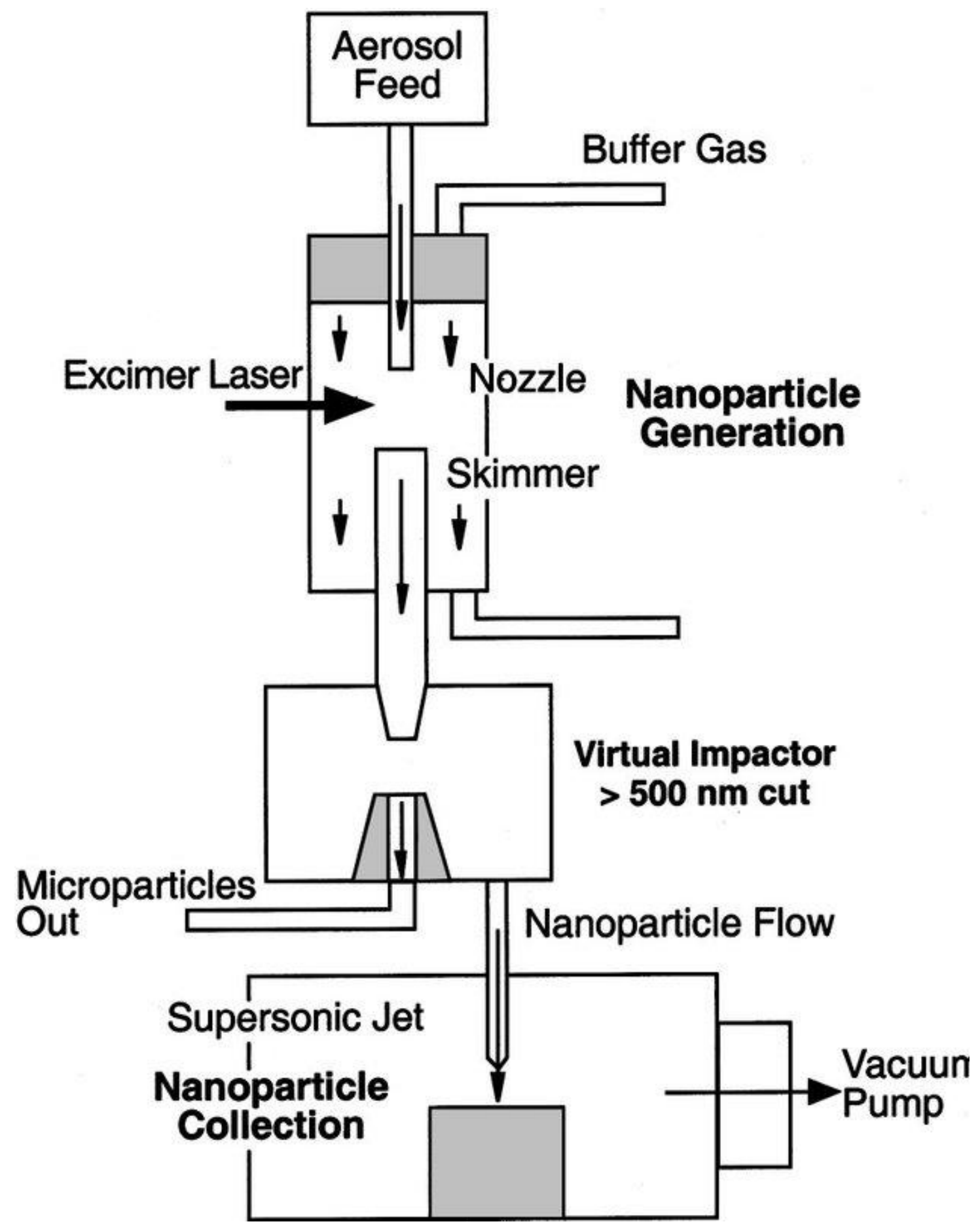

Figure 23. Laser ablation system used to manufacture nanoparticles in a flowing aerosol.

Reproduced with permission from (Nichols et al., 2001).

In such aerosol LAM process, an aerosol of microparticles, ideally having diameters of the order of a few micrometers, is confined in a laminar flow by a sheath gas and passes through the focus of a pulsed ultraviolet (UV) laser. The gas flow speed is such that new 
microparticles are ablated with each shot (and theoretically none are missed) forming a continuous nanoparticle aerosol. This nanoparticle aerosol is directed through a virtual impactor assembly to separate any unablated microparticles from the gas stream. The separate nanoparticle stream is accelerated through a nozzle into vacuum where the nanoparticles impact upon a substrate. In order to create films, the substrate is translated in a closely spaced $\mathrm{X}-\mathrm{Y}$ raster pattern, thus depositing overlapping lines of nanoparticles) Terfenol-D shows magnetostriction up to $1700 \mathrm{ppm}$, superparamagnetic (up to $80 \mathrm{emu} . \mathrm{g}^{-}$ ${ }^{1}$ a magnetization saturation), and magnetic field ME applicability range of $0-0.6 \mathrm{~T}$ (Yang et al., 2008, Song, 2007, Grössinger et al., 2014).

\section{$\underline{\mathrm{FeCo}}$}

FeCo is a system with a focus on the $(\mathrm{fcc}+\mathrm{bcc}) / \mathrm{bcc}$ phase boundary around the $\mathrm{Fe}_{0.25} \mathrm{Co}_{0.75}$ composition. The bulk FeCo-phase diagrams shows that the $\alpha$-Fe bcc phase exists at higher temperatures for all compositions. At temperatures lower than $912{ }^{\circ} \mathrm{C}$ and Co concentrations $>50 \mathrm{wt}$. $\%$, the bcc phase intersects with a mixed phase region of facecentred-cubic (fcc) Co and bcc Fe phases (Figure 24).
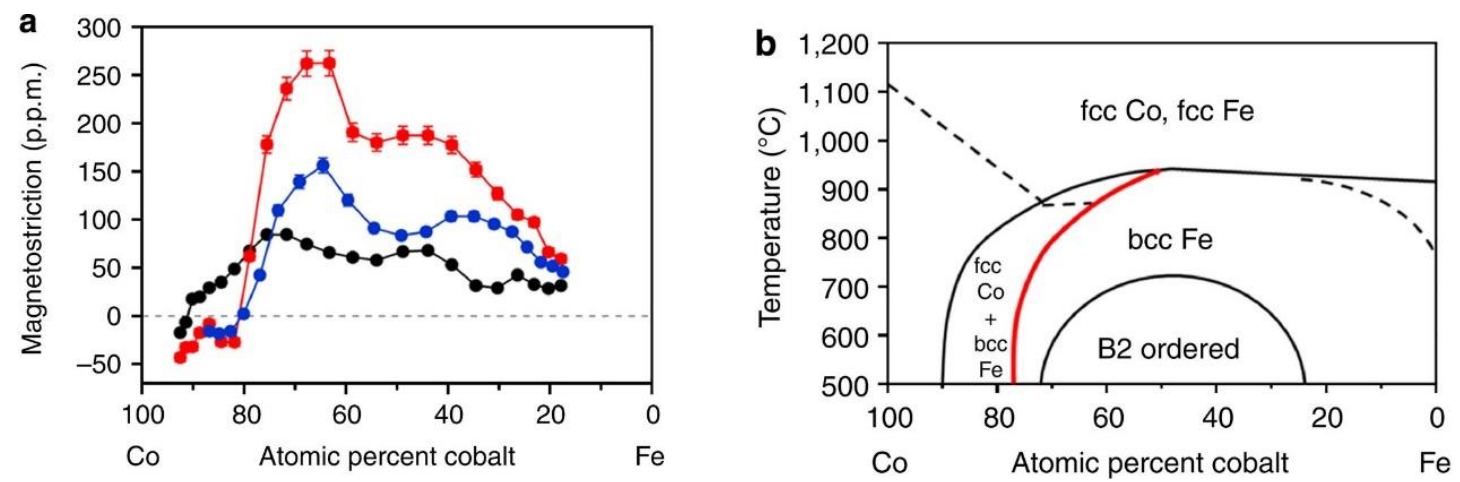

Figure 24. a) Magnetostriction variation versus atomic percent cobalt for three differently prepared $\mathrm{Co}_{1-\mathrm{x}} \mathrm{Fex}$ composition spreads, as-deposited (black dots), slow-cooled (blue dots), quenched (red dots), b) Co-Fe-phase diagram. The error bars in (a) are calculated from the uncertainty in Young's modulus and the standard deviation in cantilever displacement due to 
magnetostriction. The red curve highlights the approximate phase boundary between ( $\mathrm{fcc} \mathrm{Co}+$ bcc Fe) and bcc Fe. Reproduced with permission from (Hunter et al., 2011)

FeCo alloys have been used as smart materials as they can generate large strains and are also advantageous in terms of availability and cost since they do not contain any rare-earth elements or precious metals. Various fabrication methods exist for fabricating FeCo such as sputtering, chemical vapor deposition, polyol reduction or electrodeposition (Fukuzawa et al., 2002, Hunter et al., 2011, Özkale et al., 2017, Yang et al., 2016). FeCo has magnetostriction up to $260 \mathrm{ppm}$, ferromagnetism (up to 270 emu.g $\mathrm{g}^{-1}$ magnetization saturation and 110 Oe coercivity), and magnetic field ME applicability in the range of 00.2T (Fukuzawa et al., 2002, Hunter et al., 2011, Özkale et al., 2017, Yang et al., 2016).

\section{$\underline{\mathrm{FeCOSiB}}$}

FeCo based amorphous alloys, as indicated before, can generate large strains and for such reason have been the subject of several investigations. The of Co into FeB system increases the magnetization and the addition of $\mathrm{Si}$ increases the crystallization temperature of these amorphous alloys. Moreover, these alloys present positive saturation magnetostrictions in the Fe-rich side and negative on the Co-rich end. The resulting FeCoSiB alloys show good soft magnetic properties, combined with high permeability, crystallization temperatures and Curies temperatures (Vazquez and Hernando, 1995). As a highly magnetostrictive material, $\mathrm{FeCoSiB}$ is one of the most commonly used composition in Metglas foils (Liang et al., 2020).

FeCoSiB amorphous alloys can be produced by sputtering, single-roller, rotatingwater quenching (Figure 25), rained growth, and stress annealing methods (Liang et al., 2020, Zhao et al., 2018, Sarkar et al., 2013) and find technological applications as 
distribution transformers, anti-theft tags, motors, high frequency inductors, sensors and actuators.

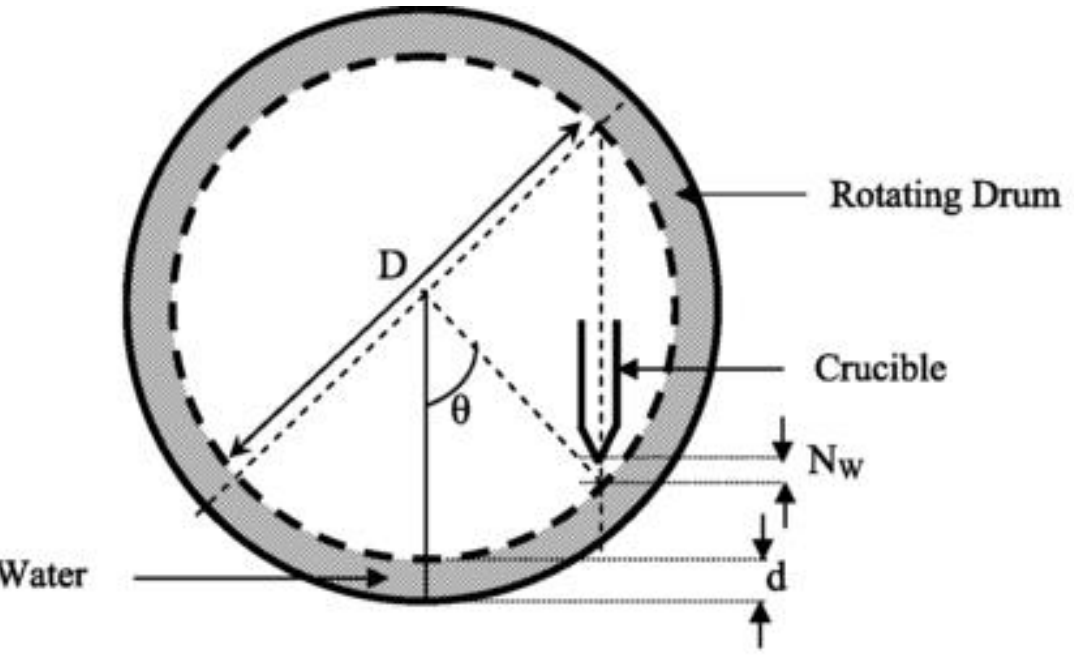

\section{D: Diameter of drum $\quad \mathrm{N}_{\mathrm{w}}$ : separation distance between nozzle and water surface \\ $\mathrm{d}$ : Depth of water level $\quad \theta$ : Ejection angle of the melt}

Figure 25. Schematic presentation of in-rotating-water quenching instrument. Reproduced with permission from (Sarkar et al., 2013).

FeCoSiB shows a magnetostriction up to $70 \mathrm{ppm}$, ferromagnetism $\left(60 \mathrm{emu} \cdot \mathrm{g}^{-1}\right.$ magnetization saturation) and magnetic field ME applicability in the range of $0-0.01 \mathrm{~T}$.

\section{$\underline{F e G a}$}

FeGa has been prepared using conventional Bridgman growth, electrodeposition, mechanochemical synthesis and arc-melting techniques to produce single crystals of various compositions (Martirosyan et al., 2009, Clark et al., 2000). The production of single crystal samples has allowed for detailed analysis of the various crystallographic directions present in the body centered cubic structure (Eric M. Summers, 2004).

The magnetostriction of bcc Fe is greatly enhanced by the addition of $\mathrm{Ga}$, being the magnetostrictive coefficients strongly depend on the atomic arrangement. The $\mathrm{B}_{2}$-like 
structure, although it is unstable in the small unit cell chosen here, appears to play a crucial rule for the large positive magnetostriction in the FeGa alloys. Analyses in electronic properties of $\mathrm{Fe}_{3} \mathrm{Ga}$ indicate that the spin-orbit coupling interactions among states localized in the $\mathrm{Fe}^{2+}$ layer are of key importance for the enhancement in magnetostriction. In the $\mathrm{DO}_{3}$ structure, the negative magnetostriction is associated with strain dependence of Fermi surface of the $\mathrm{Fe}^{2+}-\mathrm{dxz}$, yz state (majority spin) around the center of Brillouin zone. For the B2-like structure, the strain-induced change in magneto-crystalline anisotropy energy (obtained by integrating contributions in the $\mathrm{kx}$, ky planes) occurs merely in the top 2/5 portion of the three-dimensional (3D) Brillouin zone. Like results for the $\mathrm{DO}_{3}$ structure, the $\mathrm{Fe}^{2+}-\mathrm{t} 2 \mathrm{~g}$ bands are narrowed owing to the weakness of $\mathrm{Fe}-\mathrm{Ga}$ hybridization, and strong $\mathrm{Fe}^{2+}-$ density of states peaks (in solid lines) form across the Fermi level(Wu, 2002). Due to such properties room temperature magnetostriction $\mathrm{Fe}_{1-}$ ${ }_{\mathrm{x}} \mathrm{Ga}_{\mathrm{x}}$, depending on $\mathrm{x}$ and also the quenching condition, can reach to $200 \mathrm{ppm}$, a value which corresponds to a tenfold increase above the magnetostriction of the pure bcc bulk Fe (16 ppm) (Wu, 2002).

A unique combination of low hysteresis (170 emu.g ${ }^{-1}$ magnetization saturation), moderate magnetostriction $(350 \mathrm{ppm})$ at low magnetic fields (100 Oe $)$, good tensile strength (500 MPa), machinability and recent progress in commercially viable methods of processing FeGa alloys make them well poised for actuator and sensing applications such as the reliable low-frequency high-precision magnetic field sensor able to operate in specific (harsh) environments represented in Figure 26 (Atulasimha and Flatau, 2011, Caponero et al., 2014). 


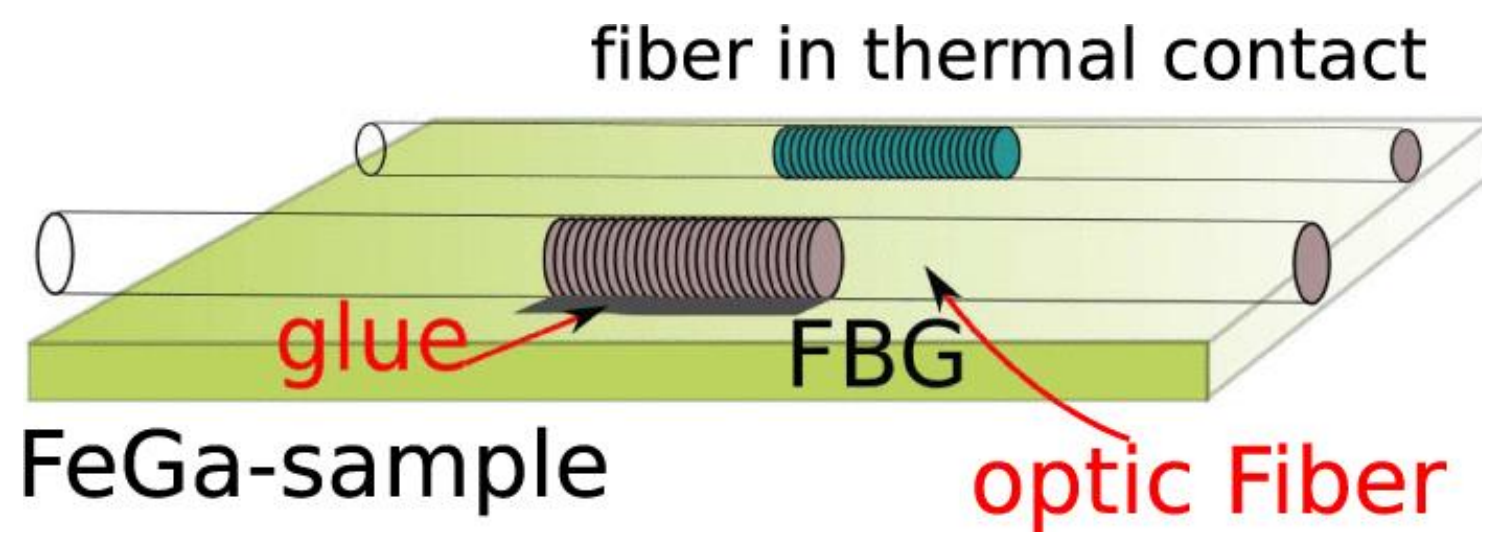

Figure 26. Representation of the of the high-precision magnetic field sensor able to operate in specific environments. The smart material actuates the fiber glued to it through its field-induced deformation (Caponero et al., 2014).

All above materials characteristics are summarized in Table III. It is to stress that all materials present suitable and specific characteristics for the development of $\mathrm{ME}$ materials and devices. 
Table III. Magnetostrictive materials suitable for ME applications.

\begin{tabular}{|c|c|c|c|c|c|}
\hline Material & Type & Production & $\begin{array}{l}\text { Room-temperature Magnetic } \\
\text { properties (magnetostriction, type } \\
\text { of magnetism) }\end{array}$ & $\begin{array}{l}\text { Applicability } \\
\text { range }\end{array}$ & Ref. \\
\hline $\mathrm{CoFe}_{2} \mathrm{O}_{4}$ & nanoparticle & $\begin{array}{l}\text { sol-gel processing, hot spraying, } \\
\text { evaporation condensation, matrix isolation, } \\
\text { laser-induced vapor phase reactions, } \\
\text { aerosols }\end{array}$ & $\begin{array}{l}\text { up to }-400 \text { ppm; Ferromagnetism (10- } \\
90 \text { emu.g }{ }^{-1}, 600-2100 \text { Oe) }\end{array}$ & $0-0.5 \mathrm{~T}$ & $\begin{array}{l}\text { (Maaz et al., 2007, } \\
\text { Kumar and Shirage, } \\
\text { 2017, Grössinger et } \\
\text { al., 2014) }\end{array}$ \\
\hline $\mathrm{NiFe}_{2} \mathrm{O}_{4}$ & & $\begin{array}{l}\text { solid-state reaction, hydrothermal reactions, } \\
\text { coprecipitation, combustion synthesis, } \\
\text { thermal decomposition, the sol-gel method, } \\
\text { microwave processing, electrospinning, } \\
\text { Aloe vera extract solution, the reverse } \\
\text { micelle technique, the plasma deposition } \\
\text { method, the radio frequency thermal plasma } \\
\text { torch technique, the pulsed wire discharge, }\end{array}$ & $\begin{array}{l}\text { up to } \quad-50 \quad \mathrm{ppm} \text {; } \\
\text { Ferromagnetism/superparamagnetism } \\
\left(0-20 \text { emu.g }{ }^{-1}, 0-150 \text { Oe }\right)\end{array}$ & $0-0.4 \mathrm{~T}$ & $\begin{array}{l}\text { (Kesavan et al., } \\
\text { 2020, Alarifi et al., } \\
\text { 2009, Fritsch and } \\
\text { Ederer, 2012, Zhou } \\
\text { et al., 2011) }\end{array}$ \\
\hline
\end{tabular}




\begin{tabular}{|c|c|c|c|c|c|}
\hline & & $\begin{array}{l}\text { sonochemical synthesis, and high-energy } \\
\text { milling }\end{array}$ & & & \\
\hline $\mathrm{MnFe}_{2} \mathrm{O}_{4}$ & & $\begin{array}{l}\text { solid-phase reactions, . mechanical ball- } \\
\text { milling, thermal decomposition, } \\
\text { hydrothermal, coprecipitation, combustion, } \\
\text { and microemulsion method }\end{array}$ & $\begin{array}{l}\text { up to }-50 \mathrm{ppm} \text {; superparamagnetism } \\
\text { (up to } 70 \mathrm{emu}^{-1} \text { ) }^{-1}\end{array}$ & $0-0.4 \mathrm{~T}$ & $\begin{array}{l}\text { (Stoia et al., 2015, } \\
\text { Kisan Zipare and } \\
\text { Shahane, 2015, } \\
\text { Song, 2007) }\end{array}$ \\
\hline $\mathrm{Ni}_{0.5} \mathrm{Zn}_{0.5} \mathrm{Fe}_{2} \mathrm{O}_{4}$ & & $\begin{array}{l}\text { as sol-gel, citrate gel method, reverse } \\
\text { microemulsion, sonochemical method, } \\
\text { hydrothermal process, co-precipitation and } \\
\text { auto-combustion method }\end{array}$ & $\begin{array}{l}\text { up to } 14 \mathrm{ppm} \text {; superparamagnetism } \\
\text { (up to } 60 \mathrm{emu}^{-1} \text { ) }^{-1}\end{array}$ & & $\begin{array}{l}\text { (Atif, 2019, Kumar } \\
\text { et al., 2010, Martins } \\
\text { et al., 2015) }\end{array}$ \\
\hline Terfenol-D & Alloy/particle & $\begin{array}{l}\text { free stand zone melting (FSZM), modified } \\
\text { bridgman (MB), sintered powder compact, } \\
\text { the ETREMA Crystal Growth (ECG) } \\
\text { system, plasma processes and molecular } \\
\text { beam epitaxy }\end{array}$ & $\begin{array}{l}\text { up to } 1700 \mathrm{ppm} \text {; superparamagnetic } \\
\text { (up to } 80 \mathrm{emu}^{-1} \text { a magnetization } \\
\text { saturation) }\end{array}$ & $0-0.6 \mathrm{~T}$ & $\begin{array}{l}\text { (Yang et al., 2008, } \\
\text { Song, } \\
\text { Grössinger et al., } \\
\text { 2014) }\end{array}$ \\
\hline $\mathrm{FeCo}$ & Alloy & $\begin{array}{l}\text { sputtering, chemical vapor deposition, } \\
\text { polyol reduction or electrodeposition }\end{array}$ & $\begin{array}{l}260 \mathrm{ppm} \text {; ferromagnetism (up to } 270 \\
\text { emu.g }{ }^{-1} \text { magnetization saturation and } \\
110 \text { Oe coercivity) }\end{array}$ & $0-0.2 \mathrm{~T}$ & $\begin{array}{l}\text { electrodeposition } \\
\text { (Fukuzawa et al., } \\
\text { 2002, Hunter et al., }\end{array}$ \\
\hline
\end{tabular}




\begin{tabular}{|c|c|c|c|c|c|}
\hline & & & & & $\begin{array}{l}\text { 2011, Özkale et al., } \\
\text { 2017, Yang et al., } \\
\text { 2016) }\end{array}$ \\
\hline $\mathrm{FeCoSiB}$ & Alloy & $\begin{array}{l}\text { Sputtering, single-roller, strained growth, } \\
\text { stress annealing, rotating-water quenching }\end{array}$ & $\begin{array}{l}\text { 70ppm; } 60 \text { emu.g }{ }^{-1} \text { magnetization } \\
\text { saturation }\end{array}$ & $0-0.01 \mathrm{~T}$ & $\begin{array}{l}\text { (Liang et al., 2020, } \\
\text { Zhao et al., 2018) }\end{array}$ \\
\hline $\mathrm{FeGa}$ & Alloy & $\begin{array}{l}\text { Bridgman growth, electrodeposition, } \\
\text { mechanochemical synthesis and arc-melting }\end{array}$ & $\begin{array}{l}350 \mathrm{ppm} \text {, superparamagnetism (170 } \\
\text { emu.g }{ }^{-1} \text { magnetization saturation), }\end{array}$ & $0-0.1 \mathrm{~T}$ & $\begin{array}{l}\text { (Atulasimha and } \\
\text { Flatau, 2011) }\end{array}$ \\
\hline
\end{tabular}


This works evidences the great work on tailoring magnetic materials for $\mathrm{ME}$ applications. Nevertheless, topics such as increasing magnetostriction in magnetic nanostructures, decreasing mechanical losses in laminate MEs, and the tailoring magnetostrictive materials specifically for ME composites need to be successfully addressed.

Additionally, it is needed a closer correlation between the development on magnetostrictive and piezoelectric materials, as just a multidisciplinary approach will allow to take full advantage of the materials listed in Table III in the development of ME materials and applications.

During this unexpected journey, from sea navigators from séc. XV to web navigators of séc. XXI, magnetic materials were the precious enabling materials which never let us to lose the good way, and that will probably allow us to continue to oceans never sailed before. May these materials take us to good scientific ports.

Acknowledgments: The authors thank the FCT- Fundação para a Ciência e Tecnologia- for financial support in the framework of the Strategic Funding UID/FIS/04650/2020 and under projects PTDC/BTM-MAT/28237/2017 and PTDC/EMD-EMD/28159/2017. P.M., A.C.L. and N.P. also support from FCT (for the contract under the Stimulus of Scientific Employment, Individual Support - 2017 Call (CEECIND/03975/2017, for the SFRH/BD/132624/2017 and for the SFRH/BD/131729/2017 grant, respectively). Finally, the authors acknowledge funding by the Spanish State Research Agency (AEI) and the European Regional Development Fund (ERFD) through the project PID2019-106099RB-C43/AEI/10.13039/501100011033 and from the Basque Government Industry and Education Department under the ELKARTEK, HAZITEK and PIBA (PIBA-2018-06) programs, respectively. 


\section{REFERENCES}

ACETO, G., PERSICO, V. \& PESCAPÉ, A. 2020. Industry 4.0 and Health: Internet of Things, Big Data, and Cloud Computing for Healthcare 4.0. Journal of Industrial Information Integration, 18, 100129.

ALARIFI, A., DERAZ, N. M. \& SHABAN, S. 2009. Structural, morphological and magnetic properties of NiFe2O4 nano-particles. Journal of Alloys and Compounds, 486, 501-506.

AMIGHIAN, J., MOZAFFARI, M. \& NASR, B. 2006. Preparation of nano-sized manganese ferrite (MnFe2O4) via coprecipitation method. Physica Status Solidi (C) Current Topics in Solid State Physics, 3, 3188-3192.

ARIMA, T., TOKUNAGA, A., GOTO, T., KIMURA, H., NODA, Y. \& TOKURA, Y. 2006. Collinear to Spiral Spin Transformation without Changing the Modulation Wavelength upon Ferroelectric Transition in Tb1-xDyxMnO3. Physical Review Letters, 96, 097202.

ASTROV, D. N. 1960. MAGNETOELECTRIC EFFECT IN CHROMIUM OXIDE SOVIET PHYSICS JETP, 13, 729-732.

ATIF, M. 2019. Synthesis and temperature dependent magnetic properties of nanocrystalline Ni0.5Zn0.5Fe2O4 ferrites. Materials Research Express, 6.

ATULASIMHA, J. \& FLATAU, A. B. 2011. A review of magnetostrictive iron-gallium alloys. Smart Materials and Structures, 20.

BEIER, G., ULLRICH, A., NIEHOFF, S., REIßIG, M. \& HABICH, M. 2020. Industry 4.0: How it is defined from a sociotechnical perspective and how much sustainability it includes - A literature review. Journal of Cleaner Production, 259, 120856. 
BIBES, M. \& BARTHÉLÉMY, A. 2008. Multiferroics: towards a magnetoelectric memory. Nat Mater. England.

BICHURIN, M. I., PETROV, V. M., KILIBA, Y. V. \& SRINIVASAN, G. 2002. Magnetic and magnetoelectric susceptibilities of a ferroelectric/ferromagnetic composite at microwave frequencies. Physical Review B, 66, 134404.

CAI, T., JU, S., LEE, J., SAI, N., DEMKOV, A. A., NIU, Q., LI, Z., SHI, J. \& WANG, E. 2009. Magnetoelectric coupling and electric control of magnetization in ferromagnet/ferroelectric/normal-metal superlattices. Physical Review B, 80, 140415.

CAPONERO, M., CIANFARANI, C., DAVINO, D., GROSSO, A., PIERGOTTI, V., POLIMADEI, A., ROCCHI, G., TUDISCO, O. \& VISONE, C. 2014. Galfenol-based devices for magnetic field sensing in harsh environments. IEEE Transactions on Magnetics, 50.

CAPRA, W. 2014. The magnetic phase diagram of

the magnetoelectric EUTiO3 studied by

neutron powder diffraction. Master, Politecnico di Milano.

CEYLAN, A., HASANAIN, S. K. \& ISMAT SHAH, S. 2008. Experimental observations of fielddependent activation of core and surface spins in Ni-ferrite nanoparticles. Journal of Physics Condensed Matter, 20.

CHEN, D., ZHANG, Y. \& KANG, Z. 2013. A low temperature synthesis of MnFe2O4 nanocrystals by microwave-assisted ball-milling. Chemical Engineering Journal, 215-216, 235-239. 
CHEN, L., LI, P., WEN, Y. \& QIU, J. 2012. The magnetostrictive material effects on magnetic field sensitivity for magnetoelectric sensor. Journal of Applied Physics, $111,07 E 503$.

CHLAIHAWI, A. A., EMAMIAN, S., NARAKATHU, B. B., ALI, M. M., MADDIPATLA, D., BAZUIN, B. J. \& ATASHBAR, M. Z. 2016. Novel Screen Printed Flexible Magnetoelectric Thin Film Sensor. Procedia Engineering, 168, 684-687.

CHOI, T., LEE, S., CHOI, Y. J., KIRYUKHIN, V. \& CHEONG, S. W. 2009. Switchable Ferroelectric Diode and Photovoltaic Effect in BiFeO3. Science, 324, 63.

CLARK, A. E., RESTORFF, J. B., WUN-FOGLE, M., LOGRASSO, T. A. \& SCHLAGEL, D. L. 2000. Magnetostrictive properties of body-centered cubic Fe-Ga and Fe-Ga-Al alloys. IEEE Transactions on Magnetics, 36, 3238-3240.

CUI, J., KRAMER, M., ZHOU, L., LIU, F., GABAY, A., HADJIPANAYIS, G., BALASUBRAMANIAN, B. \& SELLMYER, D. 2018. Current progress and future challenges in rare-earth-free permanent magnets. Acta Materialia, 158, 118137.

CURIE, P. J. J. D. P. 1894. First consideration of an intrinsic correlation of magnetic and electric properties in a solid. 3, 393-415.

DALENOGARE, L. S., BENITEZ, G. B., AYALA, N. F. \& FRANK, A. G. 2018. The expected contribution of Industry 4.0 technologies for industrial performance. International Journal of Production Economics, 204, 383-394.

DIAS, D. \& PAULO SILVA CUNHA, J. 2018. Wearable Health Devices-Vital Sign Monitoring, Systems and Technologies. Sensors (Basel, Switzerland), 18, 2414. 
DIVYA LAKSHMI, S. \& SHAMEEM BANU, I. B. 2019. Tailoring the multiferroic properties of $\mathrm{BiFeO} 3$ by co-doping $\mathrm{Er}$ at $\mathrm{Bi}$ site with aliovalent $\mathrm{Nb}, \mathrm{Mn}$ and $\mathrm{Mo}$ at Fe site. International Journal of Applied Ceramic Technology, 16, 1622-1631.

DUAN, C. G., JASWAL, S. S. \& TSYMBAL, E. Y. 2006. Predicted magnetoelectric effect in Fe/BaTiO3 multilayers: ferroelectric control of magnetism. Phys Rev Lett, 97, 047201.

DUAN, C. G., VELEV, J. P., SABIRIANOV, R. F., ZHU, Z., CHU, J., JASWAL, S. S. \& TSYMBAL, E. Y. 2008. Surface magnetoelectric effect in ferromagnetic metal films. Phys Rev Lett, 101, 137201.

DUC, N. H. \& GIANG, D. T. H. 2008. Magnetic sensors based on piezoelectricmagnetostrictive composites. Journal of Alloys and Compounds, 449, 214-218.

DUTTA PRAMANIK, P., UPADHYAYA, B., PAL, S. \& PAL, T. 2018. Internet of Things, Smart Sensors, and Pervasive Systems: Enabling the Connected and Pervasive Health Care.

DZYALOSHINSKII, I. E. On the magneto-electrical effects in antiferromagnets. 1960.

EDERER, C. \& SPALDIN, N. A. 2005. Weak ferromagnetism and magnetoelectric coupling in bismuth ferrite. Physical Review B, 71, 060401.

EERENSTEIN, W., MATHUR, N. \& SCOTT, J. F. 2006. Multiferroic and Magnetoelectric Materials. Nature, 442, 759-65.

ERIC M. SUMMERS, T. A. L., JONATHAN D. SNODGRASS AND JULIE C. SLAUGHTER 2004. Magnetic and Mechanical Properties of Polycrystalline Galfenol. Ames Laboratory Conference Papers, Posters, and Presentations, lowa State University, . 
FA-SHEN, L., DE-SHENG, Y., HUA-XIN, Z., XIN-FEN, L. \& ZHENG, Y. 1988. A study of formation process of $\mathrm{NiFe} 2 \mathrm{O} 4$ and $\mathrm{ZnFe} 2 \mathrm{O} 4$ prepared bij oxalate coprecipitation. Hyperfine Interactions, 41, 525-528.

FECHNER, M., MAZNICHENKO, I. V., OSTANIN, S., ERNST, A., HENK, J., BRUNO, P. \& MERTIG, I. 2008. Magnetic phase transition in two-phase multiferroics predicted from first principles. Physical Review B, 78, 212406.

FENG, X., LIU, J., MA, X. \& ZHAO, M. 2020. Ferroelectricity and multiferroicity in twodimensional Sc2P2Se6 and ScCrP2Se6 monolayers. Physical Chemistry Chemical Physics, 22, 7489-7496.

FIEBIG, M. 2005. Revival of the magnetoelectric effect. Journal of Physics D: Applied Physics, 38, R123-R152.

FIEBIG, M., LOTTERMOSER, T., FRÖHLICH, D., GOLTSEV, A. V. \& PISAREV, R. V. 2002. Observation of coupled magnetic and electric domains. Nature, 419, 818-20.

FRITSCH, D. \& EDERER, C. 2012. First-principles calculation of magnetoelastic coefficients and magnetostriction in the spinel ferrites CoFe2O4 and NiFe2O4. Physical Review B - Condensed Matter and Materials Physics, 86.

FUENTES-COBAS, L., MATUTES-AQUINO, J. A., BOTELLO-ZUBIATE, M., GONZÁLEZVÁZQUEZ, A., FUENTES-MONTERO, M. E. \& CHATEIGNER, D. 2015. Advances in Magnetoelectric Materials and Their Application.

FUKUZAWA, H., KAMIGUCHI, Y., KOI, K., IWASAKI, H. \& SAHASHI, M. 2002. Saturation magnetostriction of an ultrathin CoFe free-layer on double-layered underlayers. Journal of Applied Physics, 91, 3120-3124.

FUSIL, S., GARCIA, V., BARTHÉLÉMY, A. \& BIBES, M. 2014. Magnetoelectric Devices for Spintronics M. Annual Review of Materials Research, 44:91-116 
GABAL, M. A. \& ATA-ALLAH, S. S. 2004. Concerning the cation distribution in MnFe2O4 synthesized through the thermal decomposition of oxalates. Journal of Physics and Chemistry of Solids, 65, 995-1003.

GAO, F., CHEN, X. Y., YIN, K. B., DONG, S., REN, Z. F., YUAN, F., YU, T., ZOU, G. \& LIU, J. M. 2007. Visible-Light Photocatalytic Properties of Weak Magnetic BiFeO 3 Nanoparticles. Advanced Materials, 19, 2889-2892.

GERHARD, L., YAMADA, T. K., BALASHOV, T., TAKÁCS, A. F., WESSELINK, R. J. H., DÄNE, M., FECHNER, M., OSTANIN, S., ERNST, A., MERTIG, I. \& WULFHEKEL, W. 2010. Magnetoelectric coupling at metal surfaces. Nature Nanotechnology, 5, 792-797. GREVE, H., WOLTERMANN, E., QUENZER, H.-J., WAGNER, B. \& QUANDT, E. 2010. Giant magnetoelectric coefficients in (Fe90Co10)78Si12B10-AIN thin film composites. Applied Physics Letters, 96, 182501.

GRÖSSINGER, R., TURTELLI, R. S. \& MEHMOOD, N. 2014. Materials with high magnetostriction. IOP Conference Series: Materials Science and Engineering, 60, 012002.

GUTFLEISCH, O., WILLARD, M. A., BRÜCK, E., CHEN, C. H., SANKAR, S. G. \& LIU, J. P. 2011. Magnetic materials and devices for the 21st century: stronger, lighter, and more energy efficient. Adv Mater, 23, 821-42.

GUYONNET, J. 2008. Studies of magnetoelectric coupling in BiFeO3-CoFe2O4 nanocomposites Master, Université de Genève.

HILL, N. A. 2000. Why Are There so Few Magnetic Ferroelectrics? The Journal of Physical Chemistry B, 104, 6694-6709. 
HOU, X., FENG, J., XU, X. \& ZHANG, M. 2010. Synthesis and characterizations of spinel MnFe2O4 nanorod by seed-hydrothermal route. Journal of Alloys and Compounds, 491, 258-263.

HU, J.-M., DUAN, C.-G., NAN, C.-W. \& CHEN, L.-Q. 2017. Understanding and designing magnetoelectric heterostructures guided by computation: progresses, remaining questions, and perspectives. npj Computational Materials, 3, 18.

HU, J.-M., LI, Z., WANG, J. \& NAN, C. W. 2010. Electric-field control of strain-mediated magnetoelectric random access memory. Journal of Applied Physics, 107, 093912.

HU, J., NAN, T., SUN, N. \& CHEN, L. Q. 2015. Multiferroic magnetoelectric nanostructures for novel device applications. MRS Bulletin, 40, 728-735.

HUNTER, D., OSBORN, W., WANG, K., KAZANTSEVA, N., HATTRICK-SIMPERS, J., SUCHOSKI, R., TAKAHASHI, R., YOUNG, M. L., MEHTA, A., BENDERSKY, L. A., LOFLAND, S. E., WUTTIG, M. \& TAKEUCHI, I. 2011. Giant magnetostriction in annealed C1-xFex thin-films. Nature Communications, 2.

HUR, N., PARK, S., SHARMA, P. A., AHN, J. S., GUHA, S. \& CHEONG, S. W. 2004. Electric polarization reversal and memory in a multiferroic material induced by magnetic fields. Nature. England.

ISHIWATA, S., KANEKO, Y., TOKUNAGA, Y., TAGUCHI, Y., ARIMA, T.-H. \& TOKURA, Y. 2010. Perovskite manganites hosting versatile multiferroic phases with symmetric and antisymmetric exchange strictions. Physical Review B, 81, 100411. 
ISSINDOU, V., VIALA, B., GIMENO, L., CUGAT, O., RADO, C. \& BOUAT, S. 2018. Fabrication methods for high-performance miniature disks of Terfenol-D for energy harvesting. Sensors and Actuators, A: Physical, 284, 1-5.

JAĆIMOVIĆ, J., BINDA, F., HERRMANN, L. G., GREUTER, F., GENTA, J., CALVO, M., TOMSE, T. \& SIMON, R. A. 2017. Net Shape 3D Printed NdFeB Permanent Magnet. Advanced Engineering Materials, 19.

JIANG, C., LIU, R., SHEN, X., ZHU, L. \& SONG, F. 2011. Ni0.5Zn0.5Fe2O4 nanoparticles and their magnetic properties and adsorption of bovine serum albumin. Powder Technology, 211, 90-94.

KALE, A., GUBBALA, S. \& MISRA, R. D. K. 2004. Magnetic behavior of nanocrystalline nickel ferrite synthesized by the reverse micelle technique. Journal of Magnetism and Magnetic Materials, 277, 350-358.

KARPOVA, T., VASSILIEV, V., VLADIMIROVA, E., OSOTOV, V., RONKIN, M. \& NOSOV, A. 2012. Synthesis of ultradisperse NiFe2O4 spinel by thermal decomposition of citrate precursors and its magnetic properties. Ceramics International, 38, 373379.

KENZELMANN, M., HARRIS, A. B., JONAS, S., BROHOLM, C., SCHEFER, J., KIM, S. B., ZHANG, C. L., CHEONG, S. W., VAJK, O. P. \& LYNN, J. W. 2005. Magnetic Inversion Symmetry Breaking and Ferroelectricity in $\$\{\backslash$ mathrm $\{\mathrm{TbMnO}\}\}\{3\} \$$. Physical Review Letters, 95, 087206.

KESAVAN, G., NATARAJ, N., CHEN, S. M. \& LIN, L. H. 2020. Hydrothermal synthesis of NiFe2O4 nanoparticles as an efficient electrocatalyst for the electrochemical detection of bisphenol A. New Journal of Chemistry, 44, 7698-7707.

KHOMSKII, D. 2009. Classifying multiferroics: Mechanisms and effects. Physics, 2. 
KIM, D., VASILIEVA, E. S., NASIBULIN, A. G., LEE, D. W., TOLOCHKO, O. V. \& KIM, B. K. 2007. Aerosol synthesis and growth mechanism of magnetic iron nanoparticles. Materials Science Forum.

KIMURA, T., GOTO, T., SHINTANI, H., ISHIZAKA, K., ARIMA, T. \& TOKURA, Y. 2003. Magnetic control of ferroelectric polarization. Nature, 426, 55-8.

KIMURA, T., LAWES, G., GOTO, T., TOKURA, Y. \& RAMIREZ, A. P. 2005. Magnetoelectric phase diagrams of orthorhombic RMnO3 ( $\mathrm{R}=\mathrm{Gd}, \mathrm{Tb}$, and Dy). Physical Review $B$, $71,224425$.

KISAN ZIPARE, J. D., SUSHIL BANDGAR, VIKAS MATHE, \& SHAHANE, G. 2015. Superparamagnetic Manganese Ferrite Nanoparticles: Synthesis and Magnetic Properties. Journal of Nanoscience and Nanoengineering, 1, 178-182.

KOOTI, M. \& SEDEH, A. N. 2013. Synthesis and Characterization of NiFe2O4 Magnetic Nanoparticles by Combustion Method. Journal of Materials Science and Technology, 29, 34-38.

KÖSEOǦLU, Y. 2013. Rapid synthesis of nanocrystalline NiFe2O4 and CoFe2O4 powders by a microwave-assisted combustion method. Journal of Superconductivity and Novel Magnetism, 26, 1391-1396.

KUMAR, S., SINGH, V., AGGARWAL, S., MANDAL, U. K. \& KOTNALA, R. K. 2010. Synthesis of nanocrystalline Ni0.5Zn0.5Fe2O4 ferrite and study of its magnetic behavior at different temperatures. Materials Science and Engineering: $B, 166,76-82$.

KUMAR, Y. \& SHIRAGE, P. M. 2017. Highest coercivity and considerable saturation magnetization of CoFe2O4 nanoparticles with tunable band gap prepared by thermal decomposition approach. Journal of Materials Science, 52, 4840-4851. 
LALETSIN, U., PADUBNAYA, N., SRINIVASAN, G. \& DEVREUGD, C. P. 2004. Frequency dependence of magnetoelectric interactions in layered structures of ferromagnetic alloys and piezoelectric oxides. Applied Physics A, 78, 33-36.

LANCEROS-MÉNDEZ, S. \& MARTINS, P. 2017. Magnetoelectric Polymer-based Composites: Fundamentals and Applications, John Wiley \& Sons.

LANDAU , L. D. \& LIFSHITZ , E. M. 1960. Electrodynamics of Continuous Media, Course of Theoretical Physics, UK, Pergamon Press.

LANG, N. D. \& KOHN, W. 1970. Theory of Metal Surfaces: Charge Density and Surface Energy. Physical Review B, 1, 4555-4568.

LEWIS, L. H. \& JIMÉNEZ-VILLACORTA, F. 2013. Perspectives on Permanent Magnetic Materials for Energy Conversion and Power Generation. Metallurgical and Materials Transactions A, 44, 2-20.

LIANG, X., DONG, C., CHEN, H., WANG, J., WEI, Y., ZAEIMBASHI, M., HE, Y., MATYUSHOV, A., SUN, C. \& SUN, N. 2020. A review of thin-film magnetoelastic materials for magnetoelectric applications. Sensors (Switzerland), 20.

LIMA, A. C., PEREIRA, N., POLICIA, R., RIBEIRO, C., CORREIA, V., LANCEROS-MENDEZ, S. \& MARTINS, P. 2019. All-printed multilayer materials with improved magnetoelectric response. Journal of Materials Chemistry C, 7, 5394-5400.

LIU, R., PAN, L., PENG, S., QIN, L., BI, J., WU, J., WU, H. \& YE, Z. G. 2019. The magnetoelectric effect in a cubic ferrimagnetic spinel LiFe 508 with high coupling temperature. Journal of Materials Chemistry C, 7, 1999-2004.

LONGO, F., NICOLETTI, L. \& PADOVANO, A. 2017. Smart operators in industry 4.0: A human-centered approach to enhance operators' capabilities and competencies 
within the new smart factory context. Computers \& Industrial Engineering, 113, 144-159.

LORENZ, B. 2013. Hexagonal Manganites-(RMnO3): Class (I) Multiferroics with

Strong Coupling of Magnetism and Ferroelectricity. ISRN Condensed Matter Physics, 43.

LOTTERMOSER, T., LONKAI, T., AMANN, U., HOHLWEIN, D., IHRINGER, J. \& FIEBIG, M. 2004. Magnetic phase control by an electric field. Nature, $430,541-544$.

LU, C., WU, M., LIN, L. \& LIU, J.-M. 2019. Single-phase multiferroics: new materials, phenomena, and physics. National Science Review, 6, 653-668.

LU, S. G., JIN, J. Z., X., Z., FANG, Z., WANG, Q. \& ZHANG, Q. M. 2011. Large magnetoelectric coupling coefficient in poly(vinylidene fluoridehexafluoropropylene)/Metglas laminates. Appl. Phys. , 110.

LU, W. Z., LIU, B. \& WEI, S. H. 2006. Preparation of nanosized nickel ferrite spinel by a sonochemical method. Shenzhen Daxue Xuebao (Ligong Ban)/Journal of Shenzhen University Science and Engineering, 23, 329-331.

LUO, L., SUN, L., LONG, Y., WANG, X., LI, Q., LIANG, K., ZHAO, J., YAN, W., SUN, Q., SU, J., LU, X. \& ZHU, J. 2019. Multiferroic properties of aurivillius structure Bi4SmFeTi3015 thin films. Journal of Materials Science: Materials in Electronics, 30, 9945-9954.

MAAZ, K., MUMTAZ, A., HASANAIN, S. K. \& CEYLAN, A. 2007. Synthesis and magnetic properties of cobalt ferrite (CoFe2O4) nanoparticles prepared by wet chemical route. Journal of Magnetism and Magnetic Materials, 308, 289-295.

MAIER, J. 2004. Physical Chemistry of Ionic Materials: Ions and Electrons in Solids, Wiley. MARINCA, T. F., CHICINAŞ, I., PRICǍ, V. C. \& POPA, F. 2011. Nickel ferrite powder obtained by high energy reactive ball milling. Materials Science Forum. 
MARTIN, L. W., CHU, Y.-H., ZHAN, Q., RAMESH, R., HAN, S.-J., WANG, S. X., WARUSAWITHANA, M. \& SCHLOM, D. G. 2007. Room temperature exchange bias and spin valves based on BiFeO3/SrRuO3/SrTiO3/Si (001) heterostructures. Applied Physics Letters, 91, 172513.

MARTÍNEZ, B., SANDIUMENGE, F., BALCELLS, L., ARBIOL, J., SIBIEUDE, F. \& MONTY, C. 2005. Structure and magnetic properties of Co-doped $\mathrm{ZnO}$ nanoparticles. Physical Review B - Condensed Matter and Materials Physics, 72.

MARTINS, P., NUNES, J. S., OLIVEIRA, J., PEŘINKA, N. \& LANCEROS-MÉNDEZ, S. 2020. Spray-printed magnetoelectric multifunctional composites. Composites Part B: Engineering, 187, 107829.

MARTINS, P., SILVA, M. \& LANCEROS-MENDEZ, S. 2015. Determination of the magnetostrictive response of nanoparticles via magnetoelectric measurements. Nanoscale, 7, 9457-9461.

MARTIROSYAN, K. S., GALSTYAN, E. \& LITVINOV, D. 2009. Fabrication and magnetic properties of submicro-textured magnetostrictive alloys. International Journal of Self-Propagating High-Temperature Synthesis, 18, 207.

MATIZAMHUKA, W. 2018. The Impact of Magnetic Materials in Renewable EnergyRelated Technologies in the 21st Century Industrial Revolution: The Case of South Africa. Advances in Materials Science and Engineering, 2018, 3149412.

MESKIN, P. E., IVANOV, V. K., BARANTCHIKOV, A. E., CHURAGULOV, B. R. \& TRETYAKOV, Y. D. 2006. Ultrasonically assisted hydrothermal synthesis of nanocrystalline ZrO2TiO2, NiFe2O4 and Ni0.5Zn0.5Fe2O4 powders. Ultrasonics Sonochemistry, $13,47-53$. 
MINGDA, X., XIAOXIA, T. \& SHAOBO, Q. 2019. A microwave absorbing material with soft magnetic nanoparticles based on negative refraction loss characteristics. International Journal of Electrical Engineering Education, 56, 305-314.

MISHRA, S., KUNDU, T. K., BARICK, K. C., BAHADUR, D. \& CHAKRAVORTY, D. 2006. Preparation of nanocrystalline $\mathrm{MnFe} 2 \mathrm{O} 4$ by doping with Ti4+ ions using solidstate reaction route. Journal of Magnetism and Magnetic Materials, 307, 222226.

MOFFETT, M. B., LINBERG, J. \& MCLAUGHLIN, E. A. 1991. Characterization of Terfenol-D for magnetostrictive transducers. Journal of the Acoustical Society of America, $89,1448-1455$.

NAN, C. W., BICHURIN, M., DONG, S., VIEHLAND, D. \& SRINIVASAN, G. 2008. Multiferroic Magnetoelectric Composites: Historical Perspective, Status, and Future Directions. Journal of Applied Physics, 103, 031101-031101.

NAWALE, A. B., KANHE, N. S., PATIL, K. R., BHORASKAR, S. V., MATHE, V. L. \& DAS, A. K. 2011. Magnetic properties of thermal plasma synthesized nanocrystalline nickel ferrite (NiFe2O4). Journal of Alloys and Compounds, 509, 4404-4413.

NIARCHOS, D., GIANNOPOULOS, G., GJOKA, M., SARAFIDIS, C., PSYCHARIS, V., RUSZ, J., EDSTRÖM, A., ERIKSSON, O., TOSON, P., FIDLER, J., ANAGNOSTOPOULOU, E., SANYAL, U., OTT, F., LACROIX, L. M., VIAU, G., BRAN, C., VAZQUEZ, M., REICHEL, L., SCHULTZ, L. \& FÄHLER, S. 2015. Toward Rare-Earth-Free Permanent Magnets: A Combinatorial Approach Exploiting the Possibilities of Modeling, Shape Anisotropy in Elongated Nanoparticles, and Combinatorial Thin-Film Approach. JOM, 67, 1318-1328. 
NICHOLS, W. T., KETO, J. W., HENNEKE, D. E., BROCK, J. R., MALYAVANATHAM, G., BECKER, M. F. \& GLICKSMAN, H. D. 2001. Large-scale production of nanocrystals by laser ablation of microparticles in a flowing aerosol. Applied Physics Letters, $78,1128-1130$.

ODERNO, V., DUFOUR, C., DUMESNIL, K., MANGIN, P. \& MARCHAL, G. 1996. Epitaxial growth of (110) DyFe2, TbFe2 and Dy0.7Tb0.3Fe2 thin films by molecular beam epitaxy. Journal of Crystal Growth, 165, 175-178.

OMRI, K., EL GHOUL, J., LEMINE, O. M., BOUOUDINA, M., ZHANG, B. \& EL MIR, L. 2013. Magnetic and optical properties of manganese doped $\mathrm{ZnO}$ nanoparticles synthesized by sol-gel technique. Superlattices and Microstructures, 60, 139-147. ORTEGA, N., ASHOK, K., SCOTT, J. F. \& S., K. R. 2015. Multifunctional Magnetoelectric Materials for Device Applications. Journal of Physics: Condensed Matter, 27.

OYAMA, T. 1997. Synthesis of fine particles of Sn, Ti, and V Oxides by laser-induced vapor-phase reaction. Journal of Photopolymer Science and Technology, 10, 211216.

ÖZKALE, B., SHAMSUdHIN, N., BUGMANN, T., NELSON, B. J. \& PANÉ, S. 2017. Magnetostriction in electroplated CoFe alloys. Electrochemistry Communications, 76, 15-19.

PALNEEDI, H., ANNAPUREDDY, V., PRIYA, S. \& RYU, J. 2015. Status and Perspectives of Multiferroic Magnetelectric Composite Materials and Applications. Actuators 5. PALNEEDI, H., ANNAPUREDDY, V., PRIYA, S. \& RYU, J. 2016. Status and perspectives of multiferroic magnetoelectric composite materials and applications. Actuators, 5. PAUL, J., BHARDWAJ, S., SHARMA, K. K., KOTNALA, R. K. \& KUMAR, R. 2015. Room temperature multiferroic behaviour and magnetoelectric coupling in $\mathrm{Sm} / \mathrm{Fe}$ 
modified Bi4Ti3O12 ceramics synthesized by solid state reaction method. Journal of Alloys and Compounds, 634, 58-64.

PRADEEP, A., PRIYADHARSINI, P. \& CHANDRASEKARAN, G. 2008. Production of single phase nano size NiFe2O4 particles using sol-gel auto combustion route by optimizing the preparation conditions. Materials Chemistry and Physics, 112, $572-576$.

PRZENIOSŁO, R., REGULSKI, M. \& SOSNOWSKA, I. 2006. Modulation in Multiferroic BiFeO 3 : Cycloidal, Elliptical or SDW? J. Phys. Soc. Jpn. , 75, 3.

RAWLINGS, R. D. 2009. MATERIALS SCIENCE AND ENGINEERING, Oxford, UK, EOLSS Publishers.

REIS, S., CASTRO, N., SILVA, M. P., CORREIA, V., ROCHA, J. G., MARTINS, P. \& LANCEROSMENDEZ, S. 2017. Fabrication and Characterization of High-Performance Polymer-Based Magnetoelectric DC Magnetic Field Sensors Devices. IEEE Transactions on Industrial Electronics, 64, 4928-4934.

RIVERA, J.-P. 1994. On definitions, units, measurements, tensor forms of the linear magnetoelectric effect and on a new dynamic method applied to $\mathrm{Cr}$ - $\mathrm{Cl}$ boracite. Ferroelectrics, 161, 165-180.

RIVERA, J. P. 2009. A short review of the magnetoelectric effect and relatedexperimental techniques on single phase (multi-) ferroics. The European Physical Journal B, 71, 299.

RÖNTGEN, W. C. 1888. Ueber die durch Bewegung eines im homogenen electrischen Felde befindlichen Dielectricums hervorgerufene electrodynamische Kraft. Annalen der Physik, 271, 264-270. 
RYU J, K. J. E. Z. Y. C. S. Y. Y. W. H. P. D. S. C. J. J. H. B. D. A. C. \& KIM, J. W. 2015. Energy Environ. Sci., 8, 2402.

SAENSUK, O., PHOKHA, S., BOOTCHANONT, A., MAENSIRI, S. \& SWATSITANG, E. 2015. Fabrication and magnetic properties of $\mathrm{NiFe}<\mathrm{inf}>2</$ inf $>0<$ inf $>4</$ inf $>$ nanofibers obtained by electrospinning. Ceramics International, 41, 8133-8141.

SARKAR, P., ROY, R. K., PANDA, A. K. \& MITRA, A. 2013. Optimization of process parameters for developing FeCoSiB amorphous microwires through in-rotatingwater quenching technique. Applied Physics A: Materials Science and Processing, $111,575-580$.

SATISHCHANDRA B. OGALE, THIRUMALAI V. VENKATESAN \& BLAMIRE, M. G. 2013. Functional Metal Oxides: New Science and Novel Applications, Verlag, WileyVCH.

SCANO, A., ENNAS, G., FRONGIA, F., LA BARBERA, A., LÓPEZ-QUINTELA, M. A., MARONGIU, G., PASCHINA, G., PEDDIS, D., PILLONI, M. \& VÁZQUEZ-VÁZQUEZ, C. 2011. Mn-ferrite nanoparticles via reverse microemulsions: Synthesis and characterization. Journal of Nanoparticle Research, 13, 3063-3073.

SCHMID, H. 1994. Multi-ferroic magnetoelectrics. Ferroelectrics, 162, 317-338.

ŠEPELÁK, V., BERGMANN, I., FELDHOFF, A., HEITJANS, P., KRUMEICH, F., MENZEL, D., LITTERST, F. J., CAMPBELL, S. J. \& BECKER, K. D. 2007. Nanocrystalline nickel ferrite, NiFe $<$ inf $>2</$ inf $>0<$ inf $>4</$ inf $>$ : Mechanosynthesis, nonequilibrium cation distribution, canted spin arrangement, and magnetic behavior. Journal of Physical Chemistry C, 111, 5026-5033.

SGOBBA, S. 2011. Physics and measurements of magnetic materials. PHYSICS AND MEASUREMENTS OF MAGNETIC MATERIALS. 
SHAFIU, S., TOPKAYA, R., BAYKAL, A. \& TOPRAK, M. S. 2013. Facile synthesis of PVAMnFe<inf $>2</$ inf $>0<$ inf $>4</$ inf $>$ nanocomposite: Its magnetic investigation. Materials Research Bulletin, 48, 4066-4071.

SHANMUGAVEL, T., RAJ, S. G., KUMAR, G. R. \& RAJARAJAN, G. Synthesis and structural analysis of nanocrystalline $\mathrm{MnFe}<\mathrm{inf}>2</ \mathrm{inf}>0<\mathrm{inf}>4</$ inf $>$. Physics Procedia, 2014. 159-163.

SHARMA, R. K., DUTTA, S., SHARMA, S., ZBORIL, R., VARMA, R. S. \& GAWANDE, M. B. 2016. Fe $<$ inf $>3</$ inf $>0<$ inf $>4</$ inf $>$ (iron oxide)-supported nanocatalysts: Synthesis, characterization and applications in coupling reactions. Green Chemistry, 18, 3184-3209.

SHUAI DONG, JUN-MING LIU, SANG-WOOK CHEONG \& REN, Z. 2016. Multiferroic Materials and Magnetoelectric Physics: Symmetry, Entanglement, Excitation, and Topology. Advances in Physics, 64, 1-34.

SILVA, M., REIS, S., LEHMANN, C., MARTINS, P., LANCEROS-MÉNDEZ, S., LASHERAS, A., GUTIERREZ, J. \& BARANDIARAN, J. 2013. Optimization of the Magnetoelectric Response of Poly(vinylidene fluoride)/Epoxy/Vitrovac Laminates. ACS applied materials \& interfaces, 5.

SKINNER, S. 1970. Magnetically Ordered Ferroelectric Materials. IEEE Transactions on Parts, Materials and Packaging, 6, 68-90.

SLAUGHTER, J., SUMMERS, E. \& SNODGRASS, J. Comparison of transduction behavior of polycrystalline gallium-iron alloys and Terfenol-D. Proceedings of SPIE - The International Society for Optical Engineering, 2004. 460-467.

SMOLENSKY, G. \& IOFFE. Communication No. 71. Colloque International du Magnétisme, 1958 Grenoble. 
SMOLENSKY, G. A. \& CHUPI, I. E. 1982. Ferroelectromagnetism. Soviet Physics Uspekhi, $25,475-493$.

SNODGRASS, J. D., CALKINS, F. T., DAPINO, M. J. \& FLATAU, A. B. 1997. Improved giant magnetostrictive materials: New and improved Terfenol-D. The Journal of the Acoustical Society of America, 101, 3094-3094.

SNODGRASS, J. D. \& MCMASTERS, O. D. 1997. Optimized TERFENOL-D manufacturing processes. Journal of Alloys and Compounds, 258, 24-29.

SON, S., TAHERI, M., CARPENTER, E., HARRIS, V. G. \& MCHENRY, M. E. 2002. Synthesis of ferrite and nickel ferrite nanoparticles using radio-frequency thermal plasma torch. Journal of Applied Physics, 91, 7589-7591.

SONG, S.-H. 2007. Magnetic and magnetoelastic properties of Msubstituted cobalt ferrites ( $M=M n, C r, G a, G e)$. PhD, lowa State University.

SOSNOWSKA, I., NEUMAIER, T. P. \& STEICHELE, E. 1982. Spiral magnetic ordering in bismuth ferrite. Journal of Physics C: Solid State Physics, 15, 4835-4846.

SPALDIN, N. A. 2017. Multiferroics: Past, present, and future. MRS Bulletin, 42, 385-390. SRINIVASAN, G., PRIYA, S. \& SUN, N. 2015. Composite Magnetoelectrics: Materials, Structures, and Applications, Woodhead Publishing.

STOIA, M., MUNTEAN, C. \& MILITARU, B. 2015. Fine MnFe<inf $>2</$ inf $>0<$ inf $>4</$ inf $>$ nanoparticles for potential environmental applications: Synthesis and characterization. Journal of Thermal Analysis and Calorimetry, 121, 1003-1010.

SUCHTELEN, J. V. J. P. R. R. 1972. Product properties: a new application of composite materials. 27. 
TABARES-MUÑOZ , C. 1986. Synthèse et Caractérisation de Monocristaux de la Perovskite Ferroélectrique/Ferroélastique/Antiferromagnétique BiFeO 3 ,. Doctoral, University of Geneva,.

THAKUR, A., KUMAR, P., THAKUR, P., RANA, K., CHEVAlier, A., MATTEI, J. L. \& QUEFFÉLEC, P. 2016. Enhancement of magnetic properties of Ni0.5Zn0.5Fe2O4 nanoparticles prepared by the co-precipitation method. Ceramics International, $42,10664-10670$.

VAZQUEZ, M. \& HERNANDO, A. 1995. Nanostructured And Non-crystalline Materials Proceedings Of The Fourth International Workshop On Non-crystalline Solids, World Scientific Publishing Company.

VELEV, J., JASWAL, S. \& TSYMBAL, E. 2011. Multi-ferroic and magnetoelectric materials and interfaces. Philosophical transactions. Series A, Mathematical, physical, and engineering sciences, 369, 3069-97.

WANG, J., NEATON, J. B., ZHENG, H., NAGARAJAN, V., OGALE, S. B., LIU, B., VIEHLAND, D., VAITHYANATHAN, V., SCHLOM, D. G., WAGHMARE, U. V., SPALDIN, N. A., RABE, K. M., WUTTIG, M. \& RAMESH, R. 2003. Epitaxial BiFeO3 multiferroic thin film heterostructures. Science, 299, 1719-22.

WANG, K. F., LIU, J. M. \& REN, Z. F. 2009. Multiferroicity: The coupling between magnetic and polarization orders. Advances in Physics, 58, 321-448.

WEISHEIT, M., FÄHLER, S., MARTY, A., SOUCHE, Y., POINSIGNON, C. \& GIVORD, D. 2007. Electric Field-Induced Modification of Magnetism in Thin-Film Ferromagnets. Science, 315, 349. 
WEISSMÜLLER, J., VISWANATH, R. N., KRAMER, D., ZIMMER, P., WÜRSCHUM, R. \& GLEITER, H. 2003. Charge-induced reversible strain in a metal. Science. United States.

WENT, J. J., RATHENAU, G. W., GORTER, E. W. \& VAN OOSTERHOUT, G. W. 1952. Hexagonal Iron-Oxide Compounds as Permanent-Magnet Materials. Physical Review, 86, 424-425.

WU, K. H., HUANG, W. C., YANG, C. C. \& HSU, J. S. 2005. Sol-gel auto-combustion synthesis of Ni0.5Zn0.5Fe2O4/(SiO2)x ( $\mathrm{x}=10,20,30 \mathrm{wt} . \%)$ nanocomposites and their characterizations. Materials Research Bulletin, 40, 239-248.

WU, R. 2002. Origin of large magnetostriction in FeGa alloys. Journal of Applied Physics, $91,7358-7360$.

YANG, F. J., YAO, J., MIN, J. J., LI, J. H. \& CHEN, X. Q. 2016. Synthesis of high saturation magnetization FeCo nanoparticles by polyol reduction method. Chemical Physics Letters, 648, 143-146.

YANG, P., PENG, S., WU, X. B., WAN, J. G. \& ZHU, J. S. 2008. Magnetoelectric study in Terfenol-D/PFNT laminate composite. Integrated Ferroelectrics, 99, 86-92.

YATSUI, K. I. Y. K. T. S. H. S. W. J. K. 2002. Synthesis of Nickel Ferrite Nanosize Powders by Pulsed Wire Discharge. Surface Engineering. Surface Engineering.

ZAHI, S., HASHIM, M. \& DAUD, A. R. 2007. Synthesis, magnetic properties and microstructure of $\mathrm{Ni}-\mathrm{Zn}$ ferrite by sol-gel technique. Journal of Magnetism and Magnetic Materials, 308, 177-182.

ZAVALICHE, F., ZHENG, H., MOHADDES-ARDABILI, L., YANG, S. Y., ZHAN, Q., SHAFER, P., REILLY, E., CHOPDEKAR, R., JIA, Y., WRIGHT, P., SCHLOM, D. G., SUZUKI, Y. \& 
RAMESH, R. 2005. Electric field-induced magnetization switching in epitaxial columnar nanostructures. Nano Lett, 5, 1793-6.

ZHANG, M., ZI, Z., LIU, Q., ZHANG, P., TANG, X., YANG, J., ZHU, X., SUN, Y. \& DAI, J. 2013. Size effects on magnetic properties of ni0.5zn0.5fe2o 4 prepared by sol-gel method. Advances in Materials Science and Engineering, 2013.

ZHANG, S. T., LU, M. H., WU, D., CHEN, Y. F. \& MING, N. B. 2005. Larger polarization and weak ferromagnetism in quenched $\mathrm{BiFeO3}$ ceramics with a distorted rhombohedral crystal structure. Applied Physics Letters, 87, 262907.

ZHAO, C., PAN, L., LI, X., MA, L., LIU, Q. \& WANG, J. 2018. Optimization of magnetoimpedance effect in Co-based ribbon by laser patterning for sensor arrays application. Journal of Physics D: Applied Physics, 51.

ZHAO, H., KIMURA, H., CHENG, Z., OSADA, M., WANG, J., WANG, X., DOU, S., LIU, Y., YU, J., MATSUMOTO, T., TOHEI, T., SHIBATA, N. \& IKUHARA, Y. 2014. Large magnetoelectric coupling in magnetically short-range ordered Bi5Ti3FeO15 film. Scientific Reports, 4, 5255.

ZHAO, S., LIU, H., HAN, X., MENG, X., QU, J., LI, Y. \& LI, S. 2006. Study on the sintering method of Terfenol-D. Journal of Applied Physics, 99.

ZHAOMING, F. \& MENG, L. 2018. The possible magnetoelectric coupling induced by adsorption in SnTe films. 89-93.

ZHENG, H., WANG, J., LOFLAND, S. E., MA, Z., MOHADDES-ARDABILI, L., ZHAO, T., SALAMANCA-RIBA, L., SHINDE, S. R., OGALE, S. B., BAI, F., VIEHLAND, D., JIA, Y., SCHLOM, D. G., WUTTIG, M., ROYTBURD, A. \& RAMESH, R. 2004. Multiferroic BaTiO3-CoFe2O4 Nanostructures. Science, 303, 661-3. 
ZHONG, X., YANG, J., CHEN, Y., QIU, X. \& ZHANG, Y. 2015. Synthesis of magnetically separable $\mathrm{MnFe}<\mathrm{inf}>2</ \mathrm{inf}>0<\mathrm{inf}>4</$ inf $>$ nanocrystals via salt-assisted solution combustion method and their utilization as dye adsorbent. Journal of the Ceramic Society of Japan, 123, 394-398.

ZHOU, J., SKOMSKI, R., CHEN, C., HADJIPANAYIS, G. C. \& SELLMYER, D. J. 2000. Sm-CoCu-Ti high-temperature permanent magnets. Applied Physics Letters, 77, 15141516.

ZHOU, Y., YE, Y. X., ZHOU, S. H., FENG, Z. J., YU, S. J., CHEN, M. G. \& ZHANG, J. C. 2011. Frequency and field dependence of magnetoelectric coupling in multiferroic particulate composites. EPJ Applied Physics, 56.

ZYGMUNT SUROWIAK \& BOCHENEK, D. 2008. MULTIFERROIC MATERIALS

FOR SENSORS, TRANSDUCERS AND MEMORY DEVICES. ARCHIVES OF ACOUSTICS, 33. 